\title{
Temperature-Dependent Selenium Sorption to Mine Drainage Solids: Implication for Diel Cycling
}

Rebecca K. McGrail

Follow this and additional works at: https://researchrepository.wvu.edu/etd

\section{Recommended Citation}

McGrail, Rebecca K., "Temperature-Dependent Selenium Sorption to Mine Drainage Solids: Implication for Diel Cycling" (2017). Graduate Theses, Dissertations, and Problem Reports. 6197.

https://researchrepository.wvu.edu/etd/6197

This Thesis is protected by copyright and/or related rights. It has been brought to you by the The Research Repository @ WVU with permission from the rights-holder(s). You are free to use this Thesis in any way that is permitted by the copyright and related rights legislation that applies to your use. For other uses you must obtain permission from the rights-holder(s) directly, unless additional rights are indicated by a Creative Commons license in the record and/ or on the work itself. This Thesis has been accepted for inclusion in WVU Graduate Theses, Dissertations, and Problem Reports collection by an authorized administrator of The Research Repository @ WVU. For more information, please contact researchrepository@mail.wvu.edu. 


\title{
TEMPERATURE-DEPENDENT SELENIUM SORPTION TO MINE DRAINAGE SOLIDS: IMPLICATION FOR DIEL CYCLING
}

\section{Rebecca K. McGrail}

\author{
Thesis submitted to the \\ Davis College of Agriculture, Natural Resources, and Design \\ West Virginia University \\ in partial fulfillment of the requirements for the degree
}

Masters of Science

in

Agronomy

Louis M. McDonald, Ph.D., Chair

Dorothy J. Vesper, Ph.D.

Jeffrey G. Skousen, Ph.D.

Eugenia M. Pena-Yewtukhiw, Ph.D.

Division of Plant and Soil Science

\author{
West Virginia University \\ Morgantown, WV
}

2017

Keywords: Selenium, Diel Cycles, Sorption, Hydride Generation Atomic Fluorescence

Spectroscopy

Copyright 2017 Rebecca Kay McGrail 


\section{ABSTRACT \\ TEMPERATURE-DEPENDENT SELENIUM SORPTION TO MINE DRAINAGE SOLIDS: IMPLICATION FOR DIEL CYCLING}

\section{Rebecca K. McGrail}

Aqueous diel cycles have been observed for a variety of elements and have recently been observed for selenium (Se). Elevated concentrations of Se have been linked to adverse biological impacts on a variety of species from fish to humans. The objective of this work was to determine the role of temperature on selenite (Se(IV)) sorption, a possible mechanism for Se diel cycles. Four solids were selected as sorbents: gray and brown overburden material from the southern West Virginia coal fields and active and passive mine drainage treatment solids. Sorption isotherms were conducted at $20^{\circ} \mathrm{C}$ for all solids and at $30{ }^{\circ} \mathrm{C}$ for overburden materials. Supernatants were analyzed for Se(IV) concentration by hydride generation atomic fluorescence spectroscopy. Results indicate decreased temperature was correlated with increased Se(IV) sorption for brown sandstone while the reverse was true for gray sandstone. $\mathrm{K}_{\mathrm{D}}$ decreased for

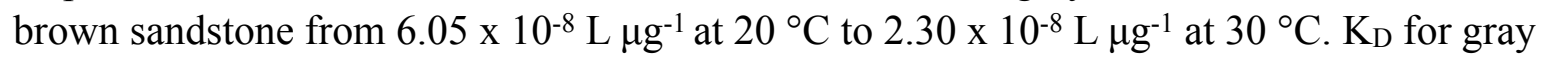

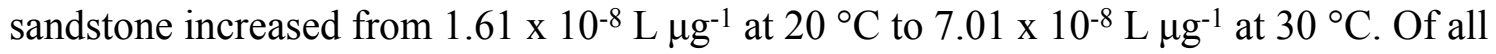
materials, the passive treatment solid exhibited the greatest distribution coefficient with a $\mathrm{K}_{\mathrm{D}}$ of

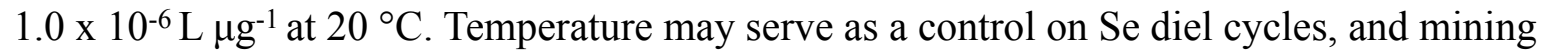
solids can serve as sorbents for $\mathrm{Se}(\mathrm{IV})$. 
This thesis is dedicated to the memories of Ella Paulman and Laura Wilkinson.

"I had discovered that learning something, no matter how complex, wasn't hard when I had a reason to want to know it.” Homer Hickam, Rocket Boys 


\section{ACKNOWLEDGEMENTS}

First and foremost I would like to acknowledge my family for their unconditional love and support. Thank you to my parents, James and Deborah McGrail, for their sacrifices so that I may pursue my education at West Virginia University. I would like to thank my sister, Amanda, for her motivational speeches and support.

I would like to thank my committee chairperson and advisor, Dr. Louis M. McDonald, for his support on this project and for providing me with the opportunity to earn my Master's degree at West Virginia University. It was an opportunity worth waiting for.

I would like to express my gratitude to the members of my committee - Dr. Dorothy Vesper, Dr. Jeffrey Skousen, and Dr. Eugenia Pena — for their unique insight on this project and for their words of encouragement.

I would like to thank lab managers Joan Wright and Lanjun Deng for their assistance both in the lab and with the ICP.

I would like to acknowledge graduate students both past and present for their camaraderie and support: Justin Brackenrich, Bethani Chambers, Kara Dallaire, Lili Lei, Kelly Morgano, Adrienne Nottingham, Matthew Pietro, Yadav Sapkota, Steffany Scagline, and Katie Stutler. Thank you for your friendship and kind words along the way.

Lastly, I would like to acknowledge my previous advisors and mentors whom have inspired me: Mrs. Sandy Morelli, Mrs. Stephanie Duck, Mrs. Irene Moore and the staff at Jefferson County Soil and Water Conservation District, Dr. Lynn Elfner, Mrs. Stephanie Vance, Dr. Caryl Fish, Dr. Bettie Davis, Dr. Matthew Fisher, Dr. Stephen Gravelle, and Mrs. Laura Wilkinson. 


\section{TABLE OF CONTENTS}

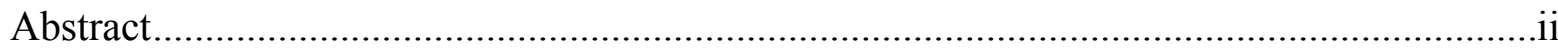

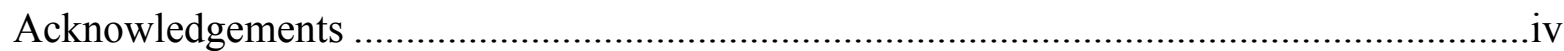

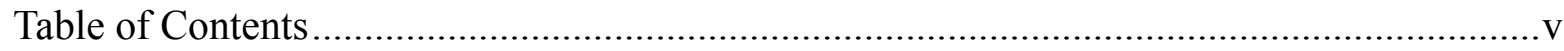

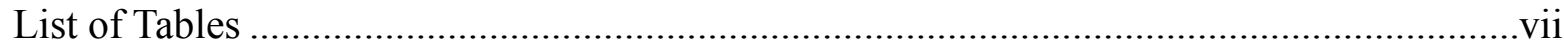

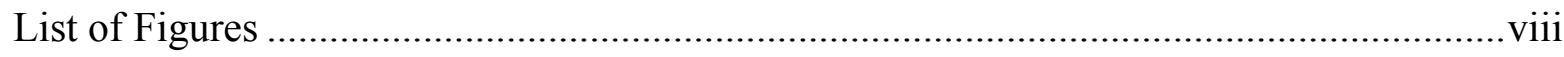

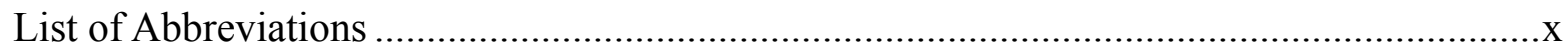

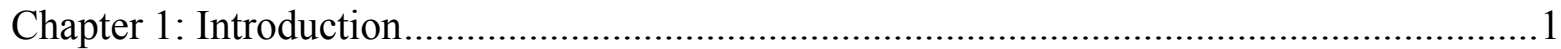

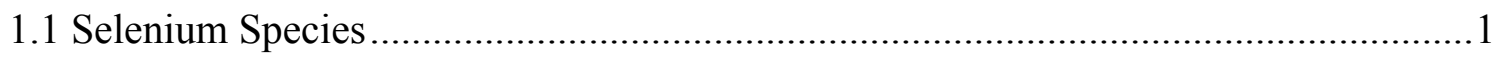

1.2 Selenium in the Environment ………..................................................................

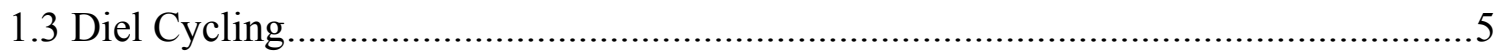

1.4 Hypothesized Primary Controls on Diel Cycling ......................................................

1.5 Hypothesized Secondary Controls on Diel Cycling ...................................................12

1.6 Research Objective ........................................................................................... 14

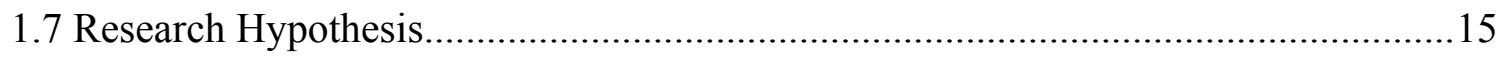

Chapter 2: Method Development and Quality Assurance …….............................................27

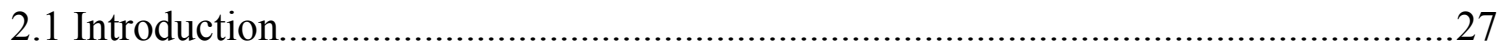

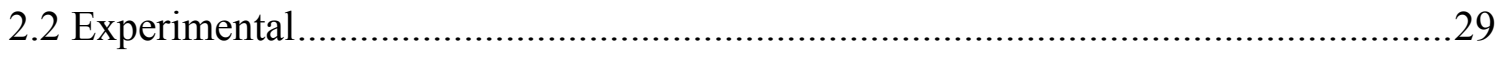

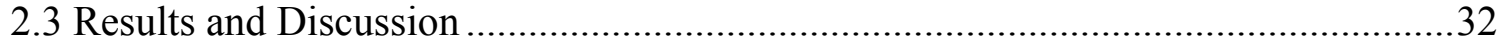

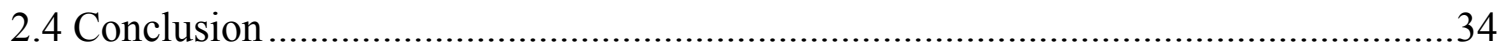

Chapter 3: Labware Evaluation for Selenium Sorption Experiments .....................................41

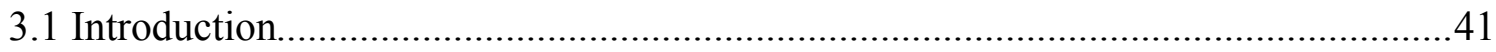

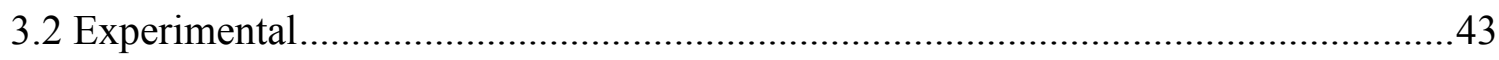

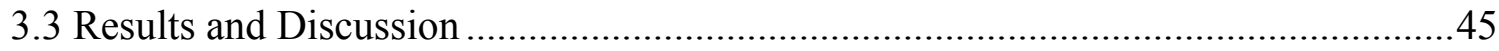

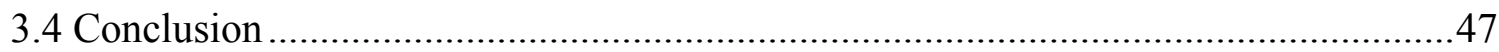

Chapter 4: Temperature Dependent Sorption of Selenium to Mining Solids ..........................52

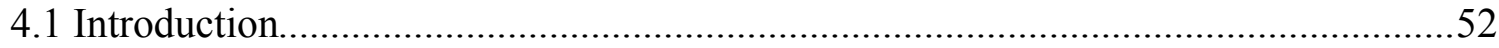

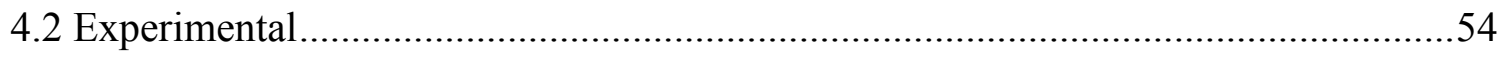

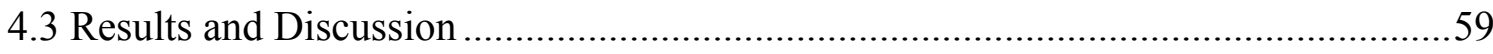

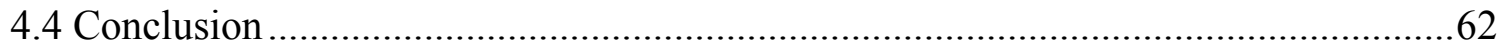


Chapter 5: Summary and Conclusions

Appendix A: Operating Conditions and method development for PSA 10.055 Millennium

Excalibur Hydride Generation-Atomic Fluorescence Spectrometry.... 


\section{LIST OF TABLES}

Table 1-1 Acid dissociation constants for selenium species at $25^{\circ} \mathrm{C}$ (Lange's Handbook of Chemistry, 1985).................................... 19

Table 1-2 Influence of temperature on selected selenium compound solubilities (Lange's Handbook of Chemistry, 2005).............................. 20

Table 2-1 Instrumental operating conditions used for Se determination by method.... 36

Table 2-2 Detection limits determined for developed methods.................... 37

Table 2-3 Effect of interfering ion(s) on Se(IV) recovery using HG-AFS............ 38

Table 3-1 Results of ANCOVA analyses for labware evaluation by nominal

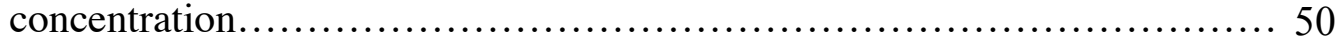

Table 3-2 ANCOVA least squares means and standard error for labware evaluation by nominal concentration ............................................ 51

Table 4-1 Description of solids assessed as sorbents for Se(IV) sorption............ 65

Table 4-2 Physical parameters of solids used in experiments...................... 66

Table 4-3a Elemental composition of solids used in experiments................... 67

Table 4-3b Elemental composition of solids used in experiments................... 67

Table 4-3c Elemental composition of solids used in experiments..................... 67

Table 4-4a Average change in $\mathrm{pH}$ and ions of interest in solution at $20^{\circ} \mathrm{C} \ldots \ldots \ldots \ldots .68$

Table 4-4b Average change in $\mathrm{pH}$ and ions of interest in solution at $30^{\circ} \mathrm{C} \ldots \ldots \ldots \ldots .68$

Table 4-5 $\quad \mathrm{K}_{\mathrm{D}}$ for each material by temperature................................ 69

Table 4-6 Se(IV) sorption capacity for varying sorbents....................... 70

Table A-1 Instrumental settings based on concentration of samples (PS Analytical

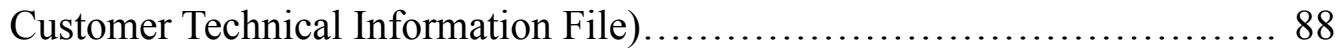

Table A-2 Operating conditions for developed methods........................... 88 


\section{LIST OF FIGURES}

Figure 1-1 pE-pH speciation of Se at $298 \mathrm{~K}$ (Santos et al., 2015). The vertical dashed

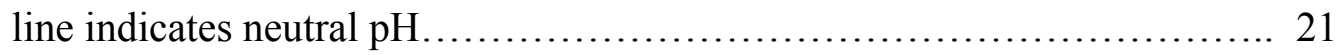

Figure 1-2 Species fraction plot of Se(IV) (top) and Se(VI) (bottom) as a function of $\mathrm{pH}$ calculated using $\mathrm{pKa}$ constants at $25{ }^{\circ} \mathrm{C}$ from Lange's Handbook of

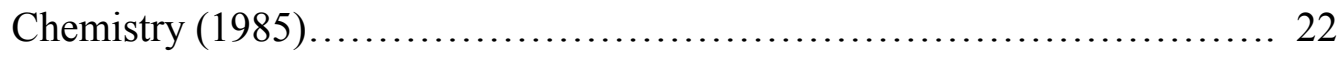

Figure 1-3 Elements identified in coal by abundance (Schweinfurth, 2009)........... 23

Figure 1-4 Diurnal cycles of flow (closed squares), manganese concentration (closed triangles), zinc concentration (open circles), arsenic concentration (open downward-facing triangles), temperature (closed circles), and $\mathrm{pH}$ (open upward-facing triangles) in Prickly Pear Creek, Montana (Nimick et al., 2011). Shaded hours indicate nighttime

Figure 1-5 Observed trends for the sorption of cations (a) and anions (b) to ferrihydrite $\left(10^{-3} M\right.$ TOTFe) as a function of solution $\mathrm{pH}$ (Benjamin, 2015). Selenite, while not shown, would be presumed to exhibit a curve between selenate and sulfate.

Figure 1-6 Sorption of anions with changes in $\mathrm{pH}$ and sorption edges denoted by $\mathrm{pKa}$ (Evangelou, 1998). 26

Figure 2-1 Schematic of flow pathways for HG-AFS (PS Analytical, 2013). Solutions are pumped from the liquid manifold on the left of the diagram to the sample valve from one of two peristaltic pumps. The sample valve butt mixes the reductant solution and blank or sample for injection to the gas/ liquid separator based on analysis time.

Figure 2-2 Effect of time on stability of samples on autosampler. Error bars indicate standard deviation.................................................. 40

Figure 4-1 Linear sorption isotherm for $\mathrm{O}-1$ at $20{ }^{\circ} \mathrm{C}$ (blue) and $30{ }^{\circ} \mathrm{C}$ (red)......... 71

Figure 4-2 Linear sorption isotherm for O-2 at $20{ }^{\circ} \mathrm{C}$ (blue) and $30{ }^{\circ} \mathrm{C}$ (red).......... 72

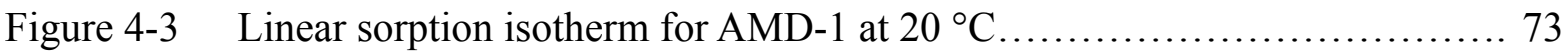

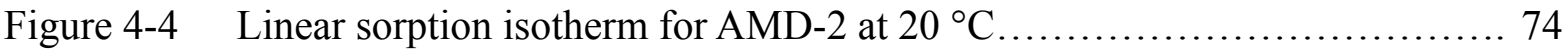

Figure A-1 Schematic diagram of HG-AFS (PSA Customer Technical Information

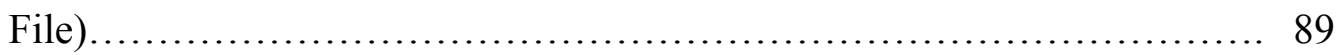

Figure A-2 Schematic diagram of liquid reagent flows (PSA Customer Technical

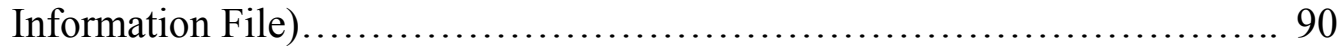

Figure A-3 Schematic diagram of the sample valve for standby and energized mode (PSA Customer Technical Information File).......................... 91

Figure A-4 Schematic diagram of reagent and gas flow from the sample valve to the gas/liquid separator and dryer drawer (PSA Customer Technical Information File) 
Figure A-5 Optical diagram of the Millennium Excalibur (PSA Customer Technical

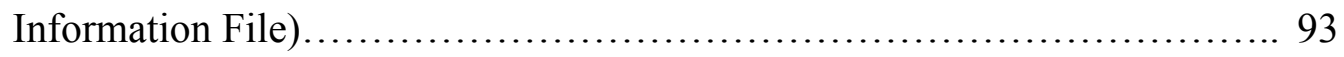

Figure A-6 Example of signal generated. Signal height was converted to concentration based on the calibration curve ...................................... 94

Figure A-7 Schematic diagram of boosted discharge hollow cathode lamp (PSA Customer Technical Information File). Curved lines indicate the flow of electrons. The first discharge of energy occurs between the anode and cathode. Most electrons are excited at the cathode. Any remaining electrons are excited by the auxiliary boost discharge at the electron emitter. 


\section{LIST OF ABBREVIATIONS}

attenuated total reflectance Fourier transform-infrared spectroscopy

ATR FT-IR

dissolved oxygen

DO

electrical conductivity

EC

Great Salt Lake

GSL

hydride generation

HG

hydride generation-atomic absorbance spectroscopy

HG-AAS

hydride generation-atomic fluorescence spectroscopy

HG-AFS

hydride generation inductively coupled plasma-mass spectrometry

HG ICP-MS

inductively coupled plasma-optical emission spectroscopy

ICP-OES

instrument detection limit

IDL

lower limit of quantitation

LLOQ

method detection limit

MDL

organic matter

$\mathrm{OM}$

PS Analytical

PSA

quality assurance/quality control

QA/QC

selenate

$\mathrm{Se}(\mathrm{VI})$

selenite

$\mathrm{Se}(\mathrm{IV})$

selenium

$\mathrm{Se}$

United States Environmental Protection Agency

USEPA

World Health Organization

WHO 


\section{CHAPTER 1: INTRODUCTION}

\subsection{Selenium Species}

Selenium (Se) was discovered in 1817 by Jon Jakob Berzelius in a sulfuric acid works

(McNeal and Balistrieri, 1989). Selenium has an atomic number of 34 and an electron configuration of $[\mathrm{Ar}] 3 \mathrm{~d}^{10} 4 \mathrm{~s}^{2} 4 \mathrm{p}^{4}$. Selenium belongs to Group VIa along with oxygen, sulfur, polonium, and tellurium. It shares similar properties with both sulfur and tellurium but behaves more similarly to sulfur, allowing for isomorphic substitution. Selenium can exist in a variety of forms due to its four naturally occurring oxidation states: $-2,0,+4$, and +6 .

Speciation of Se is governed by many parameters such as $\mathrm{pH}$, redox conditions, and solubility. The relationship between $\mathrm{pH}$ and $\mathrm{pE}$ on Se speciation is shown in Figure 1-1. Elemental $\mathrm{Se}\left(\mathrm{Se}^{0}\right)$ is chemically stable in weakly oxidizing conditions (Figure 1-2). It appears in three allotropes: dark red crystals, red amorphous powder, and black vitreous sheets (Barceloux, 1999). Elemental Se is not soluble in water. However, some species of bacteria have been found to oxidize elemental Se into Se(IV) and Se(VI) which are soluble in water (Sarathchandra and Watkinson, 1981).

Selenide $\left(\mathrm{Se}^{-2}\right)$ is chemically similar to sulfide $\left(\mathrm{S}^{-2}\right)$. As a result, many metal selenides are formed by isomorphic substitution of Se for sulfur in metal ores. Under reducing conditions, selenide is generally present as either hydrogen selenide $\left(\mathrm{H}_{2} \mathrm{Se}\right)$ or as metal selenides (Barceloux, 1999). Hydrogen selenide is a weak acid when dissolved in water with a $\mathrm{pK}_{\mathrm{a} 1}$ of 3.89 and $\mathrm{pK}_{\mathrm{a} 2}$ of 11.0 (Lange's Handbook of Chemistry, 1985; Table 1-1). Most metal selenides have low 
solubilities (Elrashidi et al., 1987). Aqueous $\mathrm{H}_{2} \mathrm{Se}$ can be oxidized to $\mathrm{Se}^{0}$, which will precipitate from solution (Elrashidi et al., 1987).

Selenite $\left(\mathrm{SeO}_{3}{ }^{-2}\right)$ is present under mildly oxidizing environments (Figure 1-1). Selenious acid $\left(\mathrm{H}_{2} \mathrm{SeO}_{3}\right)$, the fully protonated form of selenite, is existent at highly acidic $\mathrm{pH}(0.0-2.0)$.

Selenious acid is a weak acid with $\mathrm{pK}_{\mathrm{a}}$ values of 2.64 and 8.27 (Lange's Handbook of Chemistry, 1985) (Table 1-1). As a result of its $\mathrm{pK}_{\mathrm{a}}$ values, the singly protonated form $\left(\mathrm{HSeO}_{3}{ }^{-}\right)$is predominant at a $\mathrm{pH}$ between 2.0 and 8.0 and the non-protonated form $\left(\mathrm{SeO}_{3}{ }^{-2}\right)$ is present in alkaline conditions (Figure 1-2). In moderately reducing conditions, selenite is the predominate species (Santos et al., 2015). Generally, selenite salts have low solubilities compared to selenate salts (Barceloux, 1999) (Table 1-2).

Selenate $\left(\mathrm{SeO}_{4}^{-2}\right)$ is present in highly oxidizing environments (Figure 1-1). The singly

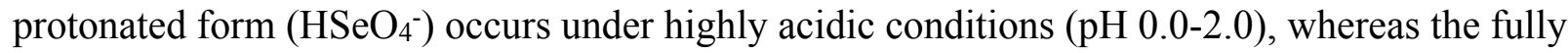
protonated form, selenic acid $\left(\mathrm{H}_{2} \mathrm{SeO}_{4}\right)$, is present across a wide range of $\mathrm{pH}$ vales (2.0-14.0) because of its acid dissociation values (Table 1-1). Selenic acid is a strong acid with $\mathrm{pK}_{\mathrm{a}}$ values of -3 and 1.66 (Lange's Handbook of Chemistry, 1985; Figure 1-2). Generally, the more oxidized Se species are more soluble than reduced species, such as selenite or metal selenides (Zawislanski et al., 2003; Table 1-2).

\subsection{Selenium in the Environment}

Selenium is a natural component of Earth's crust and is widespread across Earth's spheres: atmosphere, lithosphere, and hydrosphere (Santos et al., 2015). Selenium is present in the environment through both natural and anthropogenic sources. Naturally occurring sources of Se 
include both volcanic activity and weathering of Se-containing rocks and soils. Anthropogenic sources of Se are widespread due to the numerous applications of Se in industry, such as the manufacture of ceramics, glass, photoelectric cells, semiconductors, and steel (Barceloux, 1999). Selenium is additionally utilized in photography, the vulcanization of rubber, and production of pharmaceuticals (Barceloux, 1999). Both natural and anthropogenic sources introduce Se into different areas of the environment with varying impacts.

The single natural input of Se into the atmosphere is volcanic activity. During volcanic degassing events, Se within magma and magmatic materials is transformed into gases that are released into the atmosphere (Floor and Román-Ross, 2012). The amount of Se off-gased into the atmosphere is directly proportional to the Se content of magmatic materials and the temperature reached within the magma chamber. Volcanic off-gassing releases significant levels of Se into the atmosphere. For example, the 1980 eruption of Mount Saint Helens released 1.3 Gg of Se (Vossler et al., 1981).

The atmospheric concentration of Se ranges between 0.01 and $1 \mathrm{mg} \mathrm{m}^{-3}$ in non-volcanic regions. However, Se concentration in the atmosphere is also impacted by industrial activity in a given region, such as coal-fired power plants (Fordyce, 2013). Selenium is one of the most volatile elements in coal and is released as $\mathrm{SeO}_{2}$ and $\mathrm{SeO}$ gases during combustion (Yan et al., 2001). Because these gases are similar to sulfur dioxide, $\mathrm{SeO}_{2}$ and $\mathrm{SeO}$ are removed from flue gas through desulfurization systems. Selenium gases partition into cooling wastewater which must then be properly disposed. Wastewater from flue gas desulfurization systems contains 1-10 $\mathrm{mg} \mathrm{L}{ }^{-1}$ of Se on average (Santos et al., 2012). 
Selenium concentration in soil varies across the globe based on soil parent material. Most soils contain between 0.01 and $2 \mathrm{mg} \mathrm{kg}^{-1}$ of Se (Fernández-Martínez and Charlet, 2009). Elemental Se is immobile under anaerobic conditions and is typically found only in association with humic acids as colloidal particles (Barceloux, 1999). The primary forms of Se in soil are salts of selenic and selenious acids located within pore water (Barceloux, 1999) or bound to soil particle surfaces such as iron oxides, amorphous iron hydroxides, and aluminum sesquioxides (Merrill et al., 1986). Metal selenides and Se sulfides are predominately found in acidic soils with large amounts of organic material. These forms of Se are immobile. Selenide compounds are found in well-drained soils with neutral $\mathrm{pH}$. Aluminum and iron oxides will bind $\mathrm{Se}(\mathrm{IV})$ species under acidic to neutral $\mathrm{pH}$, and, consequently, most $\mathrm{Se}(\mathrm{IV})$ compounds are immobile (Barceloux, 1999). Selenate compounds are more mobile compared to Se(IV). Selenate compounds dominate other Se species under alkaline $\mathrm{pH}$ conditions.

Selenium is not found in mineable deposits. Rather, Se is found primarily in rock formations, such as coal. Coal — predominately composed of carbon, hydrogen, nitrogen, oxygen, and sulfur — may contain as many as 76 of the 90 naturally occurring elements of the Periodic Table (Figure 1-3). Selenium was first identified in coal from Belgium in 1896 (Yudovich and Ketris, 2006). In 1935, Goldschmidt and Strock observed that coals with the greatest Se enrichment corresponded to those with abundant pyrite $\left(\mathrm{FeS}_{2}\right)$ formations along the coal seam (Yudovich and Ketris, 2006). Generally, coals with high sulfur content are Se-bearing coals (Coleman et al., 1993). Increased Se content is commonly observed in both lignites and bituminous coals, which typically have increased sulfur content compared to anthracite (Yudovich and Ketris, 2006). 
The worldwide average concentration of Se in freshwater is $0.02 \mu \mathrm{g} \mathrm{L}^{-1}$ (Fernández-Martínez and Charlet, 2009) and $0.08 \mu \mathrm{g} \mathrm{L}-1$ in saltwater (Mitchell et al., 2012). Generally, groundwater has an elevated Se concentration compared to surface water due to contact with Se-bearing soils and rocks. Mining wastewaters and agricultural drainage can also contain increased levels of Se. Selenium concentrations in mining discharges range between $3 \mu \mathrm{L} \mathrm{L}^{-1}$ and $12 \mu \mathrm{g} \mathrm{L}-1$ (Wasewar et al., 2009). Agricultural discharges can contain increased Se levels due to irrigation. Numerous studies conducted in California's San Joaquin Valley have detected increased Se loads, including a study that established a typical total Se concentration of $350 \mu \mathrm{g} \mathrm{L}-1$ (Santos et al., 2012).

Increased Se levels within wastewaters associated with mining and agriculture are of concern. The United States Environmental Protection Agency has established $5 \mu \mathrm{g} \mathrm{L} \mathrm{L}^{-1}$ as a chronic aquatic life criterion - an estimate of the highest concentration of Se to which an aquatic community can be exposed indefinitely without any adverse effect (USEPA, 2014). This criterion was established in 1999 and is currently undergoing evaluation as a result of increased research. The World Health Organization set a Se guideline in drinking water at $40 \mu \mathrm{g} \mathrm{L}-1$ (WHO, 2011), but countries have established their own drinking water standard based upon the WHO guideline. The United Sates has established a maximum contamination level of $50 \mu \mathrm{g} \mathrm{L}{ }^{-1}$ in drinking water (USEPA, 2009).

\subsection{Diel Cycling}

A twenty-four hour cycle, termed diel cycle, occurs for a variety of environmental parameters, including $\mathrm{pH}$, dissolved oxygen (DO), and water temperature in all aquatic systems (Brick and Moore, 1996; Nimick et al., 2003, 2005) (Figure 1-4). These cycles arise from daily 
changes in the sun's position relative to Earth's surface, in temperature, and in the cycle of photosynthesis and respiration by aquatic plants. Elemental diurnal cycles have been reported for streams, especially those impacted by mine drainage (Gammons et al., 2007) and natural geochemical anomalies (Drahota el al., 2011, 2013).

Diel data was previously limited to few elements: iron, manganese, copper, mercury, aluminum, cadmium, nickel, arsenic, and zinc (Nimick et al., 2011). Two studies conducted in 2011 at fringe wetlands along the Great Salt Lake (GSL) have reported Se diel cycles. In the first study, two locations were sampled within a single perimeter wetland along the GSL in both August and September. Se concentrations varied within a single day by $13 \%$ at the first site and 20-26\% at the second site in August (Carling et al., 2011). Minimum and maximum Se concentrations at both locations occurred at 0800 and at 1400 hours respectively. At a second sampling date in September, no significant fluctuation in Se concentration was detected at either location.

In a second study, a single location within the same fringe wetland was sampled in May, August, and September. At the August sampling event, a significant Se diel cycle was observed with aqueous Se concentration reaching a minimum at 0600, two hours earlier than observed in the first study (Dicataldo et al., 2011). This difference in time may be attributed to a difference in water temperature between the two studies. Water temperatures ranged from $19.9-25.8^{\circ} \mathrm{C}$ in Carling's study and from $19-30{ }^{\circ} \mathrm{C}$ in Dicataldo's study. The $6.8^{\circ} \mathrm{C}$ difference in water temperature in the morning hours of Dicataldo's study may explain the earlier minimum concentration. Dicataldo noted that the increase in aqueous Se concentration occurred in conjunction with both increases in $\mathrm{DO}$ and $\mathrm{pH}$. Because Se concentration increased directly with 
changes in $\mathrm{pH}$ and $\mathrm{DO}$, the diel cycle was more strongly correlated to $\mathrm{pH}(\mathrm{r}=0.74)$ and to $\mathrm{DO}$ $(\mathrm{r}=0.75)$ than water temperature $(\mathrm{r}=0.55)$ at the August sampling date (Dicataldo et al., 2011). It was concluded that while water temperature is an important factor, temperature may not be as important as $\mathrm{pH}$ and DO in controlling Se diel cycles. Both studies concluded that while temperature, $\mathrm{pH}$, and DO appeared to be primary controls in Se cycling, there must also be seasonal factors that resulted in diel cycle observations in August only (Carling et al., 2011; Dicataldo et al., 2011).

The mechanism that generates Se diel events is not well understood. It is currently hypothesized that diel cycles are associated with temperature changes, photochemical processes, and photosynthesis-induced changes in $\mathrm{pH}$ and $\mathrm{DO}$, which ultimately cause mass transfer of the species itself. Proposed primary mass transfer processes are (1) sorption and desorption from sediment or particulate matter within the water column, (2) precipitation and dissolution, (3) biological uptake, (4) sedimentation and resuspension, and (5) volatilization at the wateratmosphere interface (Nimick et al., 2003). Two secondary mass transfer processes - upstream elemental loading and daily flow changes - have also been proposed but likely contribute minimally compared to mass transfer associated with primary processes. Previous studies have shown that divalent cations, such as zinc and cadmium, reach maximum concentration during the night, whereas oxyanions, such as $\mathrm{Se}(\mathrm{VI})$ and $\mathrm{Se}(\mathrm{IV})$, reach maximum concentration during the day (Barring et al., 2008; Brick and Moore, 1996; Nimick et al., 2003, 2005). These simultaneous opposing cycles suggest that a single mechanism, such as sorption, results in the diurnal cycling of all dissolved ions. 


\subsection{Hypothesized Primary Controls on Diel Cycling}

Diel cycles are hypothesized to be the result of temperature and $\mathrm{pH}$ dependent sorption reactions. Sorption - the accumulation of molecules at the interface between two phases plays a critical role in the transport, bioavailability, and fate of contaminants in aquatic systems (Benjamin, 2015). Sorption reactions can also affect the properties and behaviors of the sorbent, including surface charge, hydrophobicity, and tendency to collide with other particles to produce larger aggregates (Benjamin, 2015). Unlike the other proposed mechanisms for diel cycles, sorption is the only mechanism that explains the opposing cycles exhibited simultaneously in time between anions and cations (Nimick et al., 2003). For both cations and anions, the solute shifts from being almost completely bound to the solid sorbent to almost completely in solution over a $\mathrm{pH}$ change of one or two units, termed the $\mathrm{pH}$-sorption edge (Benjamin, 2015).

\subsubsection{Influence of $\mathrm{pH}$ on Sorption}

One of the main physiochemical properties that impacts the sorption of dissolved ions is $\mathrm{pH}$ (Guibaud et al., 2012). For sorption modeling, the surface complexation model, which considers the sorbent surface to be a collection of ligands, is generally used (Benjamin, 2015). Each surface ligand corresponds to a specific site. Therefore, this model is often referred to as a sitebinding model because it is assumed that each sorbate molecule is bonded to a single ligand or site. Dissolved species become complexed to the surface ligand resulting in sorption.

The surfaces of metal oxides can become charged when in contact with aqueous solutions because of water's ability to dissociate at the metal surface and form hydroxyl groups to satisfy bond valence (Machesky et al., 2008; Wesolowski et al., 2008). When the $\mathrm{pH}$ of the bulk solution 
decreases, hydrogen ions become the dominating species on the surface of metal oxides. In order to create a charge balance, anionic species form the majority of the electrical double layer (Wesolowski et al., 2008). As pH increases, more hydroxyl groups are present on the sorbent surface, and cations compose the majority of the double layer in order to balance charge. Therefore, the sorption of cations increases with increasing $\mathrm{pH}$ whereas sorption of anions decreases with increasing $\mathrm{pH}$ (Figure 1-5).

Sorption of compounds to a surface exhibiting variable charge is, generally, predicted by the hydrolysis constant — the equilibrium constant for the dissolution of the sorbate (Evangelou, 1998). Because a Lewis acid is defined by the ability of a species to donate electrons to solution, cations are acidic species whereas anions are basic species with the ability to accept electrons. The hydrolysis constant and sorption edge are inversely proportional — the greater the hydrolysis constant the lower the sorption edge $\mathrm{pH}$. (Figure 1-6). For oxyanions, the sorption edge $\mathrm{pH}$ is approximately equal to the $\mathrm{pK}_{\mathrm{a}}$ of the acid. Further, the length of the plateau, where sorption is maximized, is proportional to the number of $\mathrm{pK}_{\mathrm{a}}$ values for that oxyanion.

In a study conducted by Martinez et al. (2006), the effect of $\mathrm{pH}$ on the sorption of $\mathrm{Se}(\mathrm{VI})$ and $\mathrm{Se}(\mathrm{IV})$ onto magnetite, a common iron oxide, was investigated. Sorption was studied across a $\mathrm{pH}$ range of 2 to 12 . As predicted through models, Se behaved similarly to other anionic species with decreased sorption in conjunction with increasing $\mathrm{pH}$, which may explain the lack of observed anionic diel events in alkaline water systems. Selenite and selenate sorption decreased as percentage of $\mathrm{HSeO}_{4}{ }^{-}$and $\mathrm{HSeO}_{3}{ }^{-}$increased in conjunction with increasing $\mathrm{pH}$. Similar studies conducted on goethite and hematite showed similar results (Duc et al., 2003; Rovira et al., 2008). Sorption of Se species followed standard anionic sorption patterns. In the case of sorption onto 
goethite and hematite, Se(IV) ions were sorbed more easily than Se(VI) ions (Duc et al., 2003; Rovira et al., 2008).

\subsubsection{Influence of Temperature on Sorption}

Temperature is an important variable when conducting sorption experiments, as a fluctuation of $3{ }^{\circ} \mathrm{C}$ in solution temperature can result in different isotherms (Roy et al., 1991). Most sorption experiments are conducted at room temperature, which is generally around $25^{\circ} \mathrm{C}$. Work by Hasan and Ranjan (2010) investigated the sorption of Se anions on wheat, rice, and corn brans at three temperatures: $20^{\circ} \mathrm{C}, 30^{\circ} \mathrm{C}$, and $40{ }^{\circ} \mathrm{C}$. The sorption of both Se(IV) and $\mathrm{Se}(\mathrm{VI})$ decreased with increasing temperature. The decreased sorption of Se(IV) and Se (VI) with increasing temperature indicates that the rate of desorption is more significant than the rate of sorption, implying the reaction is exothermic (Hasan and Ranjan, 2010). At high temperatures, the sorbatesorbent complex becomes unstable as a result of increased energy. Sorbate ions then have enough energy to overcome the attractive forces of the sorbent and are released back into the bulk solution. It was further hypothesized that at increasing temperatures, damage to the sorption sites may occur in conjunction with the instability of the complex (Hasan and Ranjan, 2010). This could also explain the decreased sorption at higher temperatures as fewer sites would be suitable for sorption.

A second study on $\mathrm{Se}(\mathrm{VI})$ sorption corroborates the results and conclusions of Hasan and Ranjan through the use of attenuated total reflectance Fourier transform-infrared spectroscopy (ATR FT-IR) to study the structure of the complex. Through the use of ATR FT-IR, it was determined that $\mathrm{Se}(\mathrm{VI})$ forms an outer-sphere complex with the anatase surface, which has a 
slightly skewed symmetry at all temperatures (Jordan et al., 2015). This asymmetry may indicate some chemical contribution, such as a smaller hydration shell, to the electrostatic attraction between $\mathrm{Se}(\mathrm{VI})$ and anatase, which results in decreased entropy. At increased temperatures, the impact of the asymmetry increases as a result of an increased hydration shell (Jordan et al., 2015). The increased hydration shell decreases the electrostatic attraction between Se(VI) and anatase, allowing for $\mathrm{Se}(\mathrm{VI})$ to release back into the bulk solution. It was also concluded that the exothermic nature of this reaction results in decreased sorption with increased temperature.

Other studies on the influence of temperature on Se sorption support decreasing sorption with increasing temperature ( Balistrieri and Chao,1986; Kersten and Vlasova, 2013; Machesky, 2008). A study that investigated Se(VI) sorption to goethite calculated negative enthalpy values for both outer-sphere surface complexation and inner-sphere bidentate complexation, indicating an exothermic reaction (Kersten and Vlasova, 2013). These values were obtained using the 1-pK basic Stern model of surface protonation of goethite (Kersten and Vlasova, 2013). The bidentate inner-sphere complex exhibited greater sensitivity to increasing temperature with an enthalpy value of $-70 \mathrm{~kJ} \mathrm{~mol}^{-1}$ than the outer-sphere complex $\left(-36 \mathrm{~kJ} \mathrm{~mol}^{-1}\right)$. Balistrieri and Chao (1986) determined hydrogen selenite $\left(\mathrm{HSeO}_{3}{ }^{-}\right)$sorption to goethite has an enthalpy of -29 and $-22 \mathrm{~kJ}$ $\mathrm{mol}^{-1}$ based on the fractional area of the surface covered. Overall, enthalpies of Se(IV) sorption are near $-20 \mathrm{~kJ} \mathrm{~mol}^{-1}$ (Balistrieri and Chao, 1986). With the exception of the bidentate innersphere complex observed by Kersten and Vlasova (2013), the low enthalpy values support the hypothesis that Se sorption occurs through physisorption rather than chemisorption.

Enthalpy values, the thermodynamic quantity equal to the internal energy of the system in addition to pressure and volume, indicate that Se sorption reactions to metal oxides are 
exothermic in nature and generally occur as physisorption. The enthalpy of physisorption is lower than the enthalpy of chemisorption, generally around $-20 \mathrm{~kJ} \mathrm{~mol}^{-1}$. In physiosorption, there is a van der Waals attraction between the sorbent and sorbate. Molecular vibrations of the sorbate are accepted by the lattice of the sorbent, and the excess vibrational energy is transmitted to the surroundings as heat (Atkins et al., 2009). Because van der Waals forces are weak, physisorption is reversible. Low enthalpy values such as those found in Se sorption studies and the exothermic nature of Se sorption reactions indicate that physisorption may be occurring. The exothermic nature of Se sorption is consistent with temperature change in relation to Se diel cycles. Because physiosorption enthalpy is low, the sorbate is not changed during the sorption process and retains its chemical identity.

The impact of temperature on sorption may also be related to the structure of water. The density of water changes with temperature due to changes in hydrogen bonding between water molecules. Water is densest at $4{ }^{\circ} \mathrm{C}$ due to increased entropy (Marcus, 2009). Ice crystals begin to form at this temperature resulting in an increased ordering of the structure of water. The increasing order of water molecules at decreasing temperatures may provide the structural order that results in preferential sorption of anions over cations.

\subsection{Hypothesized Secondary Controls on Diel Cycling}

While elemental diel cycles are currently hypothesized to be driven by daily changes in temperature and $\mathrm{pH}$, the observance of significant Se diel cycles in only August has resulted in the hypothesis that there may be secondary controls on diel cycles, such as seasonal flow changes, microbial activity, and presence of particulate metals. Nimick et al. (2005) monitored 
diel cycles of As, $\mathrm{Mn}$, and $\mathrm{Zn}$ on all dates regardless of high flow or low flow conditions (Nimick et al., 2005). The simultaneous occurrence of maximum As concentration with minimum $\mathrm{Mn}$ and $\mathrm{Zn}$ suggests that hydrological processes, such as increased water flow due to snowmelt, simply cannot explain simultaneous opposing cycles of the ions. Nimick et al. (2005), therefore, concluded that under neutral to alkaline $\mathrm{pH}$, the geochemical processes driving diel cycles should result in a cycle regardless of seasonal flow conditions.

Seasonal fluctuations in biofilm abundance and activity may explain the seasonality of Se diel cycles detected by Carling et al. (2011) and Dicataldo et al. (2011) in the wetlands surrounding the GSL but not the seasonality of As, Mn, and Zn diel cycles observed in Prickly Pear Creek (Nimick et al., 2005). Water transparencies within the GSL reach 2-4 meters during the summer months, which is deep enough for photosynthesis to occur at depths between 4-8 meters (Wurtsbaugh et al., 2011). The deep photosynthetic zone allows for increased biofilm activity during summer months, which corresponds to the time of observed Se diel cycles. In the winter, proliferation of phytoplankton reduces water transparency and the photosynthetic zone. The decrease in photosynthetic activity limits the growth of biofilm and its ability to remove Se from the water. Analysis of periphyton, which grows on biostromes in the GSL, determined that Se contributes $124 \mathrm{ng} \mathrm{g}^{-1}$ of the periphyton dry weight (Wurtsbaugh et al., 2011). The difference in biofilm productivity with season may account for the seasonal Se diel trends observed by Carling et al. (2011) and Dicataldo et al. (2011).

In addition to fluctuations of ionic species in the presence of biofilms, two studies have concluded that ion concentrations can vary in the presence of particulate metals, such as crusts of hydrous Mn-Zn oxide (Gammons et al., 2007) and Fe solids (Waychunas et al., 2005). The 
observation of elemental diel cycles in waterways impacted by AMD is most likely generated by sorption to mining solids. Iron oxides (hematite, magnetite), oxyhydroxides (goethite, akaganeite, lepidocrocite, feroxyhyte), and hydrous oxides (ferrihydrite, hydrohematite, maghemite) have high sorption capacities for metals and anionic contaminants, such as As and Se. Contaminant entrapment is mainly accomplished through surface sequestration, whereas aggregation of particulates may result in the encapsulation of sorbed contaminants preventing their release.

\subsection{Research Objective}

The overall objective of this research was to determine the role of temperature in $\mathrm{Se}$ (IV) sorption to materials common in aquatic systems impacted by mine drainage. In order to achieve the overall goal, iron precipitates were collected from one passive AMD treatment system in Latrobe, Pennsylvania, and one active AMD treatment system in Upshur County, West Virginia. Overburden samples from the southern West Virginia coalfields, comprised predominately by brown and gray sandstones, were used to represent minerals in contact with alkaline mine drainage. The research included the following objectives:

Objective 1: Refine methodology used to quantify inorganic Se in the form of Se(IV) via hydride-generation atomic fluorescence spectroscopy (HG-AFS).

Objective 2: Determine sorption parameters for $\mathrm{Se}(\mathrm{IV})$ to iron oxides formed during mine drainage treatment and to other minerals commonly found in acid and alkaline drainage impacted waters as a function of temperature. 


\subsection{Research Hypothesis}

Based on the studies conducted by Carling et al. (2011) and Dicataldo et al. (2011), it was

hypothesized that decreased temperature corresponds to increased Se sorption and vice versa.

\section{References}

Atkins, P., de Paula, J., \& Friedman, R. (2009). The first law of thermodynamics Quanta, Matter, and Change: A molecular approach to physical chemistry (pp. 442-478). New York, NY: W.H. Freeman and Company.

Balistrieri, L. S., \& Chao, T. T. (1987). Selenium Adsorption by Goethite. Soil Science Society of America Journal, 51(5), 1145-1151.

Barceloux, D. G. (1999). Selenium. Clinical Toxicology, 37, 145-172.

Barringer, J. L., Wilson, T. P., Szabo, Z., Bonin, J. L., Fischer, J. M., \& Smith, N. P. (2008). Diurnal variations in, and influences on, concentrations of particulate and dissolved arsenic and metals in the mildly alkaline Wallkill River, New Jersey, USA. Environmental Geology, 53, 1183-1199.

Benjamin, M. M. (2015). Adsorption Reactions Water Chemistry (Second ed., pp. 769-845). Long Grove, Illinois: Waveland Press, Inc.

Brick, C. M., \& Moore, J. N. (1996). Diel variation of trace metals in Upper Clark Fork River, Montana. Environmental Science \& Technology, 30(6), 1953-1960.

Carling, G. T., Fernandez, D. P., Rudd, A., Pazmino, E., \& Johnson, W. P. (2011). Trace element diel variation and particulate pulses in perimeter freshwater wetlands of Great Salt Lake, Utah. Chemical Geology, 283, 87-98.

Dicataldo, G., Johnson, W. P., Naftz, D. L., Hayes, D. F., Moeller, W. O., \& Miller, T. (2011). Diel variation of selenium and arsenic in a wetland of the Great Salt Lake, Utah. Applied Geochemistry, 26, 28-36..

Drahota, P., Novakova, B., Matousek, T., Mihajevic, M., Rohovec, J., \& Filippi, M. (2013). Diel variation of arsenic, molybdenum, and antimony in a stream draining natural As geochemical anomaly. Applied Geochemistry, 31, 84-93.

Drahota, P., Mihajevic, M., Grygar, T., Rohovec, J., \& Pertold, Z. (2011). Seasonal variation of $\mathrm{Zn}, \mathrm{Cu}, \mathrm{As}$, and Mo in arsenic-rich stream at the Mokrsko Gold Deposit, Czech Republic. Environmental Earth Science, 62, 429-441.

Duc, M., Lefevre, G., Fedoroff, M., Jeanjean, J., Rouchaud, J. C., Moneil-Rivera, F., . . Milonjic, S. (2003). Sorption of selenium anionic species on apatites and iron oxides from aqueous solutions. Journal of Environmental Radioactivity, 70, 61-72.

Elrashidi, M. A., Adriano, D. C., Workman, S. M., \& Lindsay, W. L. (1987). Chemical Equilibria Of Selenium In Soils: A Theoretical Development. Soil Science, 144(2), 141-152.

Evangelou, V. P. (1998). Environmental Soil and Water Chemistry: Principles and Applications. New York, New York: John Wiley and Sons, Inc. 
Floor, G. H., \& Román-Ross, G. (2012). Selenium in volcanic environments: a review. Applied Geochemistry, 27, 517-531.

Fordyce, F. M. (2013). Selenium Deficiency and Toxicity in the Environment. In O. Selinus (Ed.), Essentials of Medical Geology: Revised Edition (pp. 375-416). Dordrecht: Springer Netherlands.

Gammons, C. H., Milogragovich, L., \& Belanger-Woods, J. (2007). Occurrence of diurnal cycles on metal concentrations and loads in streams draining abandoned mine lands: an example from High Ore Creek, Montana. Environmental Geology, 53, 611-622.

Guibaud, G., Bhatia, D., d'Abzac, P., Bourven, I., Bordas, F., van Hullebusch, E. D., \& Lens, P. N. L. (2012). Cd(II) and $\mathrm{Pb}(\mathrm{II})$ sorption by extracellular polymeric substances (EPS) extracted from anaerobic granular biofilms: Evidence of a $\mathrm{pH}$-sorption edge. Journal of the Taiwan Institute of Chemical Engineers, 43, 444-449.

Hasan, S. H., \& Ranjan, D. (2010). Agro-industrial waste: a low-cost option for the biosorptive remediation of selenium anions. Industrial \& Engineering Chemistry Research, 49, 8927-8934.

Jordan, N., Muller, K., Franzen, C., \& Brendler, V. (2013). Temperature impact on the sorption of selenium(VI) onto anatase. Journal of Colloid and Interface Science, 390, 170-175.

Kersten, M., \& Vlasova, N. N. (2009). Arsenite adsorption on goethite at elevated temperatures. Applied Geochemistry, 24, 32-43.

Lange's Handbook of Chemistry. (2005). (J. A. Dean Ed. Fifteenth ed.). New York: McGraw-Hill Book Company.

Lange's Handbook of Chemistry. (1985). (J. A. Dean Ed. Thirteenth ed.). New York: McGrawHill Book Company.

Machesky, M. L., Wesolowski, D. J., Ridley, M. K., Palmer, D. A., Rosenqvist, J., Lvov, S., . . Vlcek, L. (2008). The Protonation Behavior of Metal Oxide Surfaces to Hydrothermal Conditions. ECS Transactions, 11(27), 151-166.

Marcus, Y. (2009). Effect of Ions on the Structure of Water: Structure Making and Breaking. Chemical Reviews, 109(3), 1346-1370.

Martínez, M., Giménez, J., de Pablo, J., Rovira, M., \& Duro, L. (2006). Sorption of selenium(IV) and selenium(VI) onto magnetite. Applied Surface Science, 252, 3767-3773.

McNeal, J. M., \& Balistrieri, L. S. (1989). Geochemistry and occurrence of Selenium: an overview. Paper presented at the Selenium in Agriculture and the Environment: Proceedings of a Symposium.

Merrill, D. T., Manzione, M. A., Parker, D. S., Peterson, J. J., Chow, W., \& Hobbs, A. O. (1987). Field evaluation of arsenic and selenium removal by iron coprecipitation. Environmental Progress, 6, 82-89.

Mitchell, K., Mason, P. R. D., Van Cappellen, P., Johnson, T. M., Gill, B. C., Owens, J. D., \& al., (2012). Selenium as a paleo-oceanographic proxy: a first assessment. Geochimica et Cosmochimica Acta, 89, 302-317. 
Nimick, D. A., Gammons, C. H., \& Parker, S. R. (2011). Diel biogeochemical processes and their effect on the aqueous chemistry of streams: a review. Chemical Geology, 283, 3-17.

Nimick, D. A., Cleasby, T. E., \& McClesky, R. B. (2005). Seasonality of diel cycles of dissolved trace-metal concentrations in a Rocky Mountain Stream. Environmental Geology, 47, 603-614.

Nimick, D. A., Gammons, C. H., Cleasby, T. E., Madison, J. P., Skarr, D., \& Brick, C. M. (2003). Diel cycles in dissolved metal concentrations in streams: occurrence and possible causes. Water Resources Research, 39, 1247-1263.

Rovira, M., Gimenez, J., Martinez, M., Martinez-Llado, X., de Pablo, J., Marti, V., \& Duro, L. (2008). Sorption of selenium(IV) and selenium(VI) onto natural iron oxides: goethite and hematite. Journal of Hazardous Materials, 150, 279-284.

Roy, W. R., Krapac, I. G., Chous, S. F. J., \& Griffin, R. A. (1991). Batch-Type Procedures for Estimating Soil Adsorption of Chemicals. USEPA Technical Resource Document EPA/ 530-SW-87-006-F.

Santos, S., Ungureanu, G., Boaventura, R., \& Botelho, C. (2015). Selenium contaminated waters: an overview of analytical methods, treatment options and recent advances in sorption methods. Science of the Total Environment, 521-522, 246-260.

Sarathchandra, S. U., \& Watkinson, J. H. (1981). Oxidation of elemental selenium to selenite by Bacillus megatherium. Science, 21, 600-601.

Schweinfurth, S. P. (2009). Chapter C: An Introduction to Coal Quality. In B. S. Pierce \& K. O. Dennen (Eds.), The National Coal Resource Assessment Overview. Reston, Virginia: U.S. Geological Survey.

USEPA. (2014). External Peer-Review Draft - Aquatic Life Ambient Water Quality Criterion for Selenium - Freshwater 2014 (EPA 820-F-09-005 2014).

USEPA. (2009). National Preliminary Drinking Water Regulations, List of Contaminants and their MCLs (EPA 816-F-09-0004).

Vossler, T., Anderson, D. L., Aras, N. K., Phelan, J. M., \& Zoller, W. H. (1981). Trace element composition of the Mount St. Helens plume: stratospheric samples from the 18 May eruption. Science of the Total Environment, 211, 827-830. .

Wasewar, K. L., Prasad, B., \& Gulipalli, S. (2009). Adsorption of selenium using bagasse fly ash. Clean Soil Air Water, 37, 534-543.

Waychunas, G. A., Kim, C. S., \& Banfield, J. F. (2005). Nanoparticulate iron oxide minerals in soils and sediments: unique properties and contaminant scavenging mechanisms. Journal of Nanoparticle Research, 7, 409-433.

Wesolowski, D. J., Machesky, M. L., Ridley, M. K., Palmer, D. A., Zhang, Z., \& Fenter, P. (2008). Ion adsorption on metal oxide surfaces to hydrothermal conditions. ECS Transactions, 11(27), 167-189.

WHO. (2011). Guidelines for Drinking-water Quality. 
Wurtsbaugh, W. A., Gardberg, J., \& Izdepski, C. (2011). Biostome communities and mercury and selenium bioaccumulation in the Great Salt Lake (Utah, USA). Science of the Total Environment, 409, 4425-4434.

Yan, R., Gauthier, D., Flamant, G., \& Peraudeau, G. (2001). Fate of selenium in coal combustion: volatilization and speciation in the flue gas. Environmental Science \& Technology, 35, 1406-1410.

Yudovich, Y. E., \& Ketris, M. P. (2006). Selenium in coal: a review. International Journal of Coal Geology, 67, 112-126.

Zawislanski, P. T., Benson, S. M., Terberg, R., \& Borglin, S. E. (2003). Selenium speciation, solubility, and mobility in land-disposed dredged sediments. Environmental Science \& Technology, 37, 2415-2420. 
Table 1-1. Acid dissociation constants for selenium species at $25^{\circ} \mathrm{C}$ (Lange's Handbook of Chemistry, 1985).

\begin{tabular}{lc}
\hline \multicolumn{1}{c}{ Acid-Base Reaction } & $\mathrm{pK}_{\mathrm{a}}$ \\
\hline $\mathrm{Se}(-\mathbf{I I})$ & 3.89 \\
$\mathrm{H}_{2} \mathrm{Se}+\mathrm{H}_{2} \mathrm{O} \rightleftharpoons \mathrm{HSe}^{-}+\mathrm{H}_{3} \mathrm{O}^{+}$ & 11.0 \\
$\mathrm{HSe}^{-}+\mathrm{H}_{2} \mathrm{O} \rightleftharpoons \mathrm{Se}^{-2}+\mathrm{H}_{3} \mathrm{O}^{+}$ & \\
$\mathrm{Se}(\mathbf{I V})$ & 2.64 \\
$\mathrm{H}_{2} \mathrm{SeO}_{3}+\mathrm{H}_{2} \mathrm{O} \rightleftharpoons \mathrm{HSeO}_{3}-\mathrm{H}_{3} \mathrm{O}^{+}$ & 8.27 \\
$\mathrm{HSeO}_{3}^{-}+\mathrm{H}_{2} \mathrm{O} \rightleftharpoons \mathrm{SeO}_{3}^{-2}+\mathrm{H}_{3} \mathrm{O}^{+}$ & \\
$\mathbf{S e}(\mathbf{V I})$ & -3.00 \\
$\mathrm{H}_{2} \mathrm{SeO}_{4}+\mathrm{H}_{2} \mathrm{O} \rightleftharpoons \mathrm{HSeO}_{4}^{-}+\mathrm{H}_{3} \mathrm{O}^{+}$ & 1.66 \\
$\mathrm{HSeO}_{4}^{-}+\mathrm{H}_{2} \mathrm{O} \rightleftharpoons \mathrm{SeO}_{4}^{-2}+\mathrm{H}_{3} \mathrm{O}^{+}$ & \\
\hline
\end{tabular}


Table 1-2. Influence of temperature on selected selenium compound solubilities (Lange's Handbook of Chemistry, 2005).

\begin{tabular}{|c|c|c|c|c|c|}
\hline & \multirow{2}{*}{ Formula } & \multicolumn{4}{|c|}{ Temperature $\left({ }^{\circ} \mathrm{C}\right)$} \\
\hline & & 0 & 10 & 20 & 30 \\
\hline & & \multicolumn{4}{|c|}{ 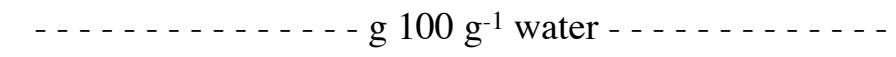 } \\
\hline Calcium Selenate & $\mathrm{CaSeO}_{4}$ & 9.73 & 9.77 & 9.22 & 8.79 \\
\hline Copper (II) Selenate & $\mathrm{CuSeO}_{4}$ & 12.04 & 14.53 & 17.51 & 21.04 \\
\hline Magnesium Selenite & $\mathrm{MgSeO}_{3}$ & 20.0 & 30.4 & 38.3 & 44.3 \\
\hline Potassium Selenate & $\mathrm{K}_{2} \mathrm{SeO}_{4}$ & 107 & 109 & 111 & 113 \\
\hline Potassium Selenite & $\mathrm{K}_{2} \mathrm{SeO}_{3}$ & 169 & 186 & 203 & 217 \\
\hline Sodium Selenate & $\mathrm{Na}_{2} \mathrm{SeO}_{4}$ & 13.3 & 25.2 & 26.9 & 77.0 \\
\hline Sodium Selenite & $\mathrm{Na}_{2} \mathrm{SeO}_{3}$ & 78.6 & 81.2 & 86.2 & 94.2 \\
\hline Selenic Acid & $\mathrm{H}_{2} \mathrm{SeO}_{4}$ & 426 & -- & 567 & 1328 \\
\hline Selenious Acid & $\mathrm{H}_{2} \mathrm{SeO}_{3}$ & 90.1 & 122.2 & 166.7 & 235.6 \\
\hline
\end{tabular}




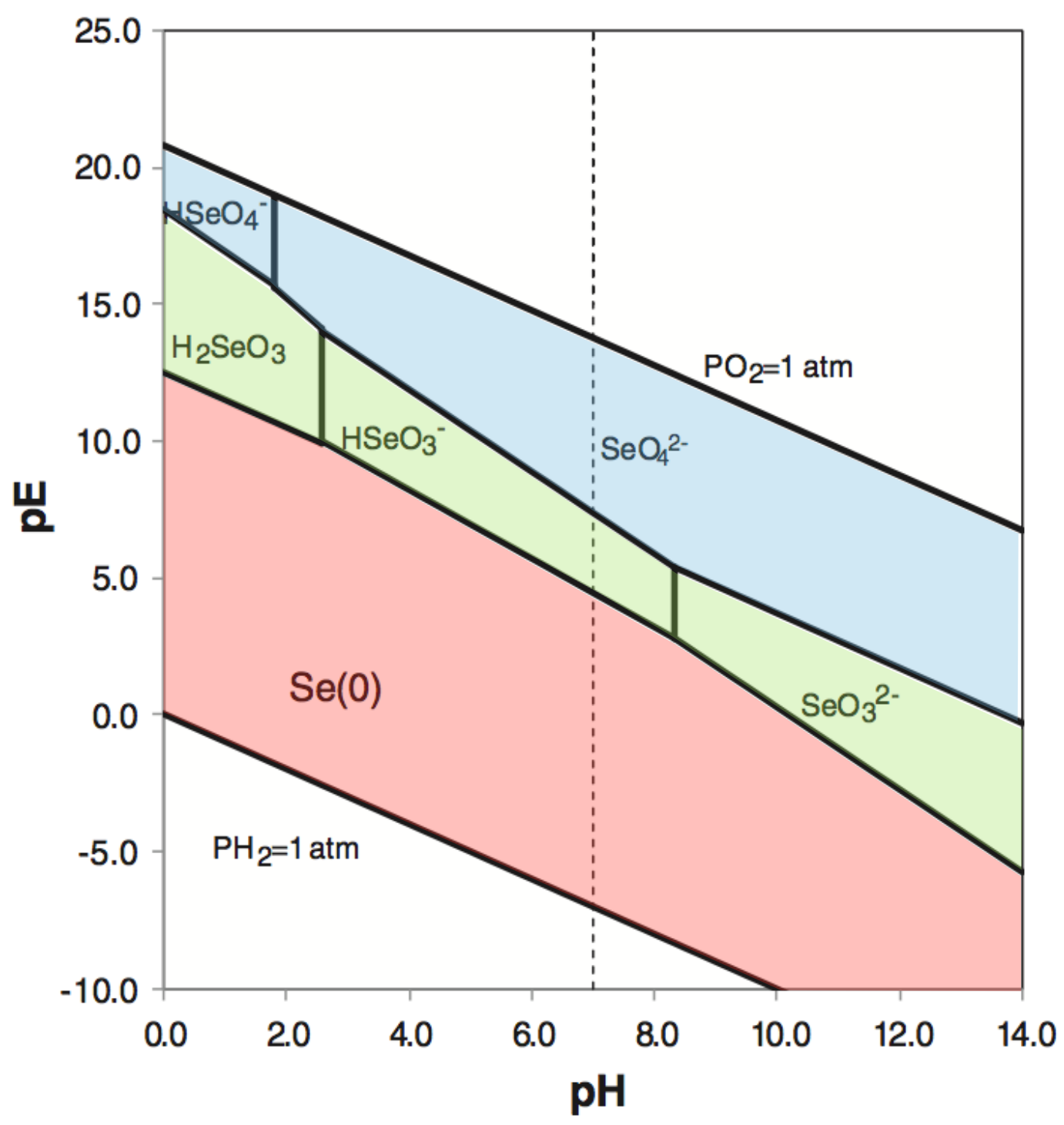

Figure 1-1. pE-pH speciation of Se at $298 \mathrm{~K}$ (Santos et al., 2015). The vertical dashed line indicates neutral $\mathrm{pH}$. 

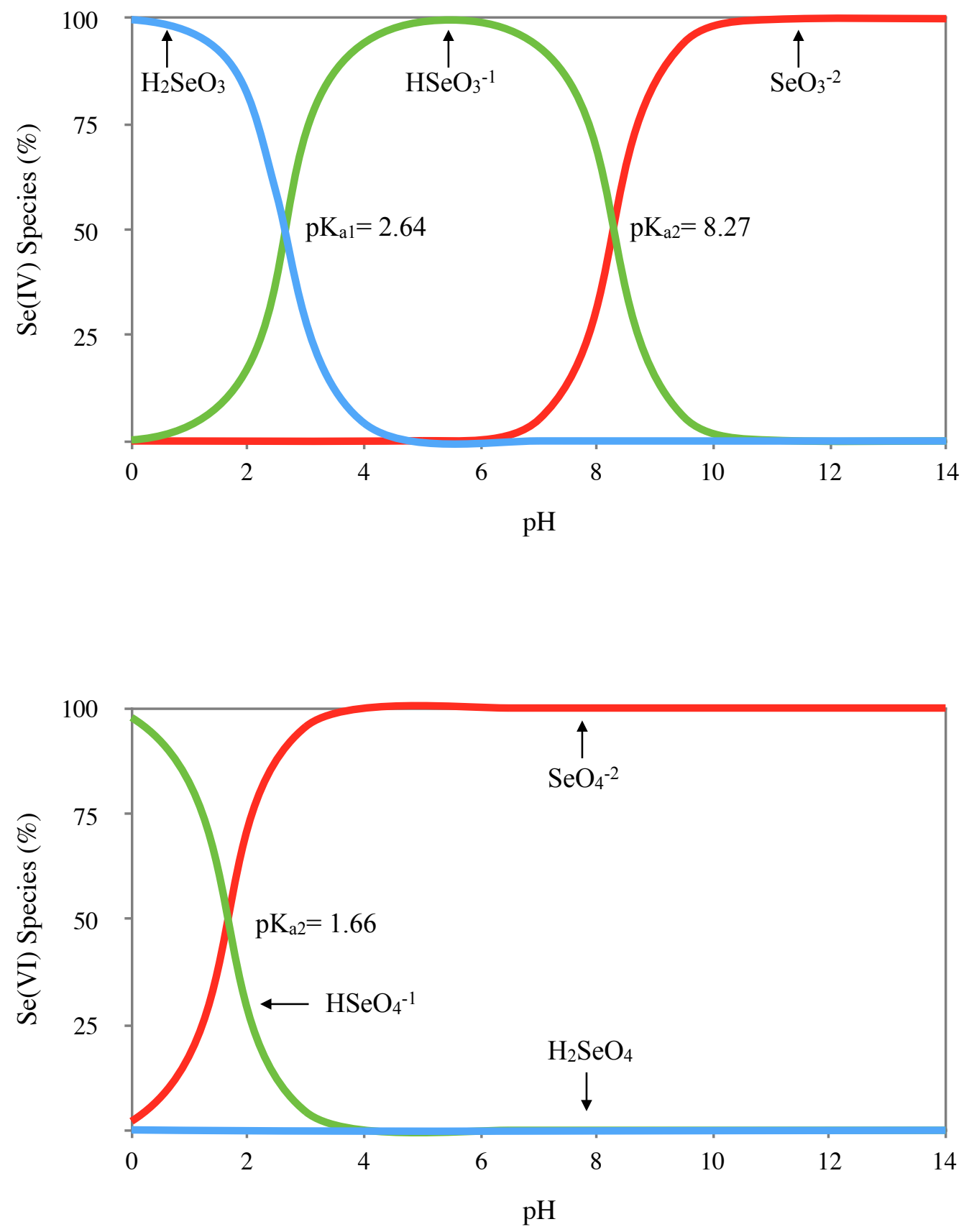

Figure 1-2. Species fraction plot of $\mathrm{Se}(\mathrm{IV})$ (top) and $\mathrm{Se}(\mathrm{VI})$ (bottom) as a function of $\mathrm{pH}$ calculated using $\mathrm{pK}_{\mathrm{a}}$ constants at $25^{\circ} \mathrm{C}$ from Lange's Handbook of Chemistry (1985). 


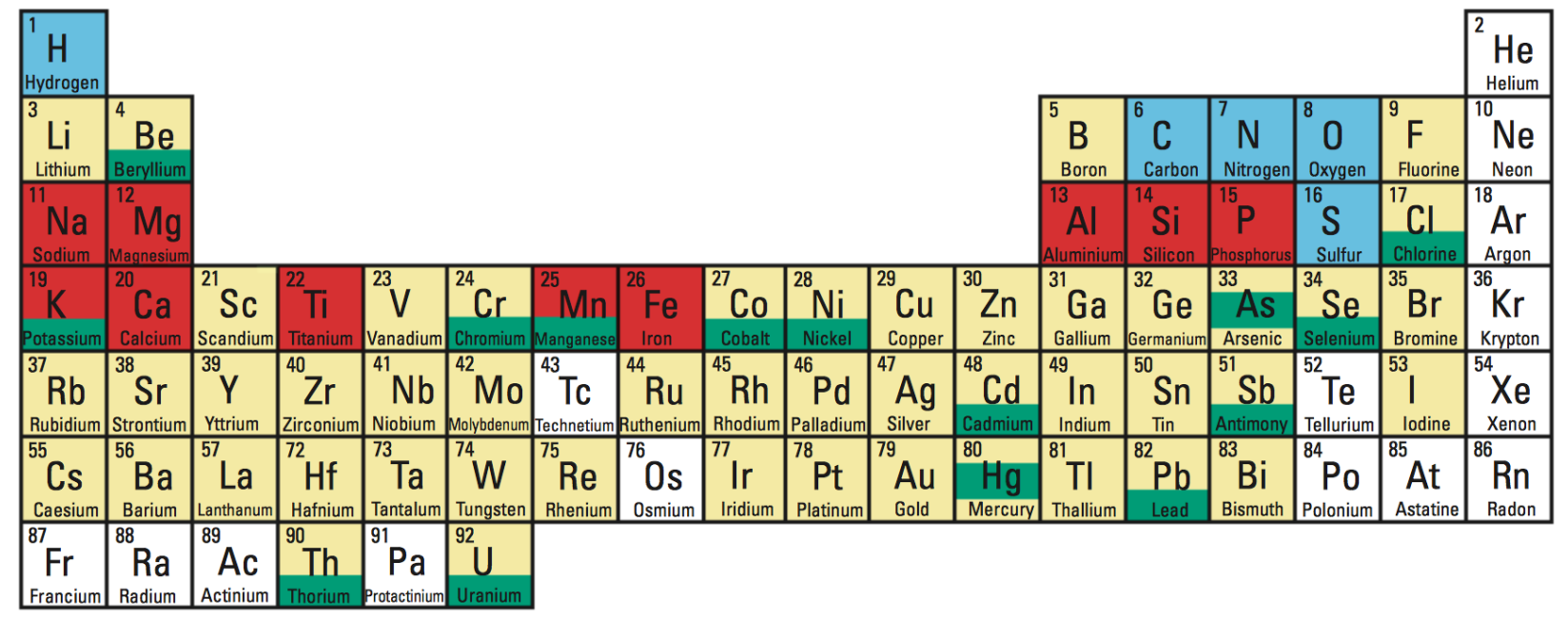

RARE - EARTH

ELEMENTS

\begin{tabular}{|c|c|c|c|c|c|c|c|c|c|c|c|c|c|}
\hline${ }^{58} \mathrm{Ce}$ & ${ }^{59} \mathrm{Pr}$ & ${ }^{60} \mathrm{Nd}$ & $\mathrm{Pm}$ & ${ }_{\mathrm{Sm}}^{62}$ & ${ }^{63} \mathrm{Eu}$ & ${ }^{64} \mathrm{Gd}$ & ${ }^{65} \mathrm{~Tb}$ & ${ }^{66} \mathrm{Dy}$ & ${ }^{67} \mathrm{Ho}$ & ${ }^{68} \mathrm{Er}$ & Tm & ${ }^{70} \mathrm{Yb}$ & ${ }^{71}$ Lu \\
\hline
\end{tabular}

major element $(>1 \%$ in abundance)

minor element $(>0.01 \%$ in abundance $)$

trace element $(<0.001 \%)$

- trace element dismissed as hazards pursuant to Clean Air Act of 1990

- trace element under investigation pursuant to Clean Air Act of 1990

Figure 1-3. Elements identified in coal by abundance (Schweinfurth, 2009). 

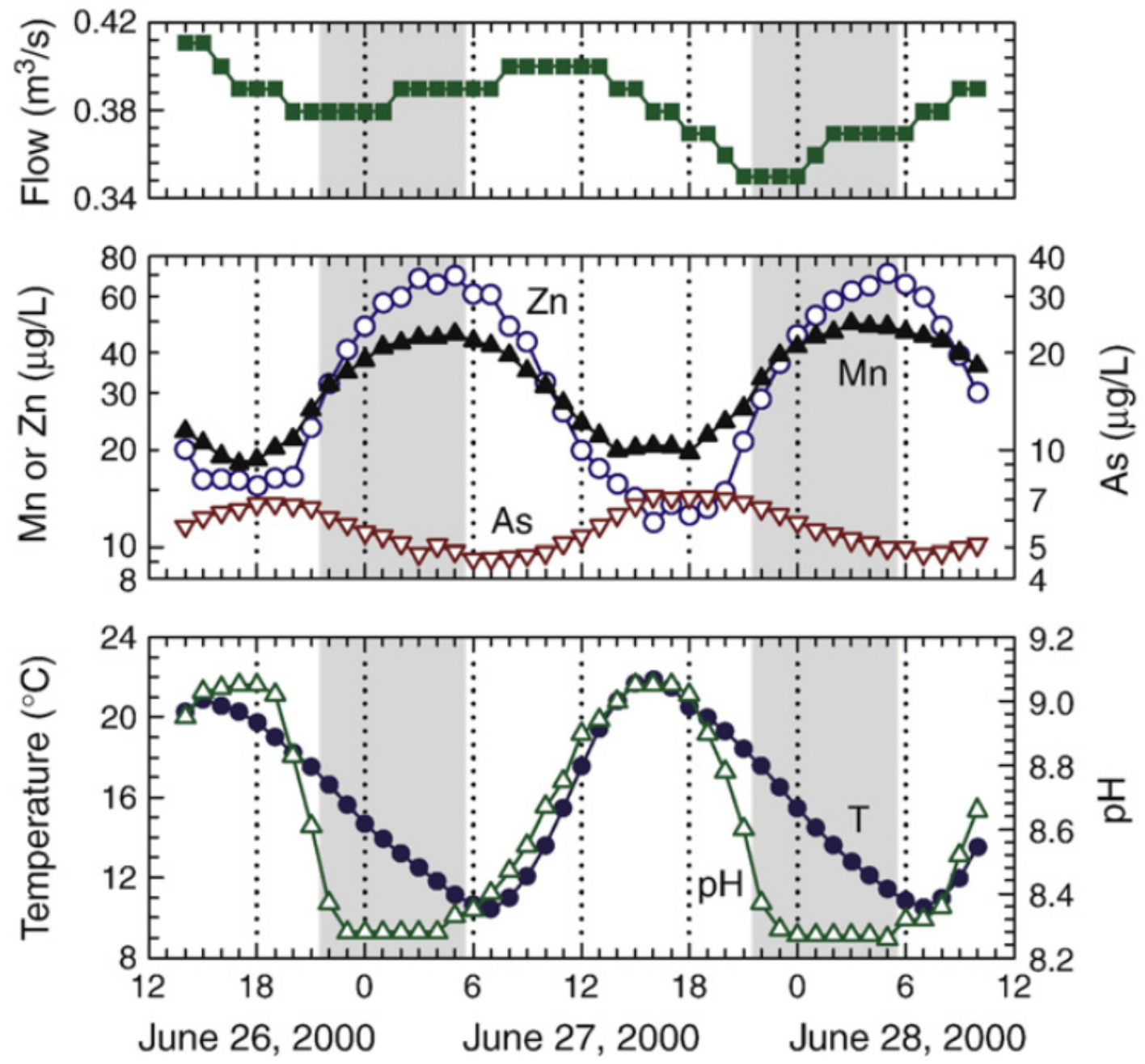

Figure 1-4. Diurnal cycles of flow (closed squares), manganese concentration (closed triangles), zinc concentration (open circles), arsenic concentration (open downward-facing triangles), temperature (closed circles), and pH (open upward-facing triangles) in Prickly Pear Creek, Montana (Nimick et al., 2011). Shaded hours indicate nighttime. 
(a)

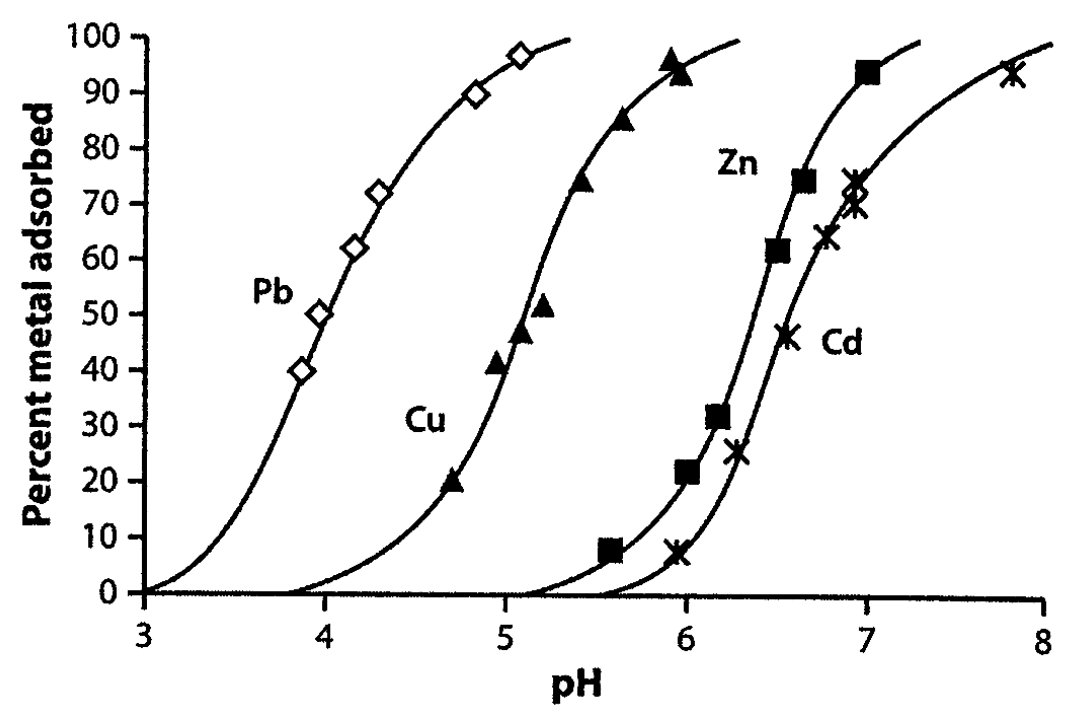

(b)

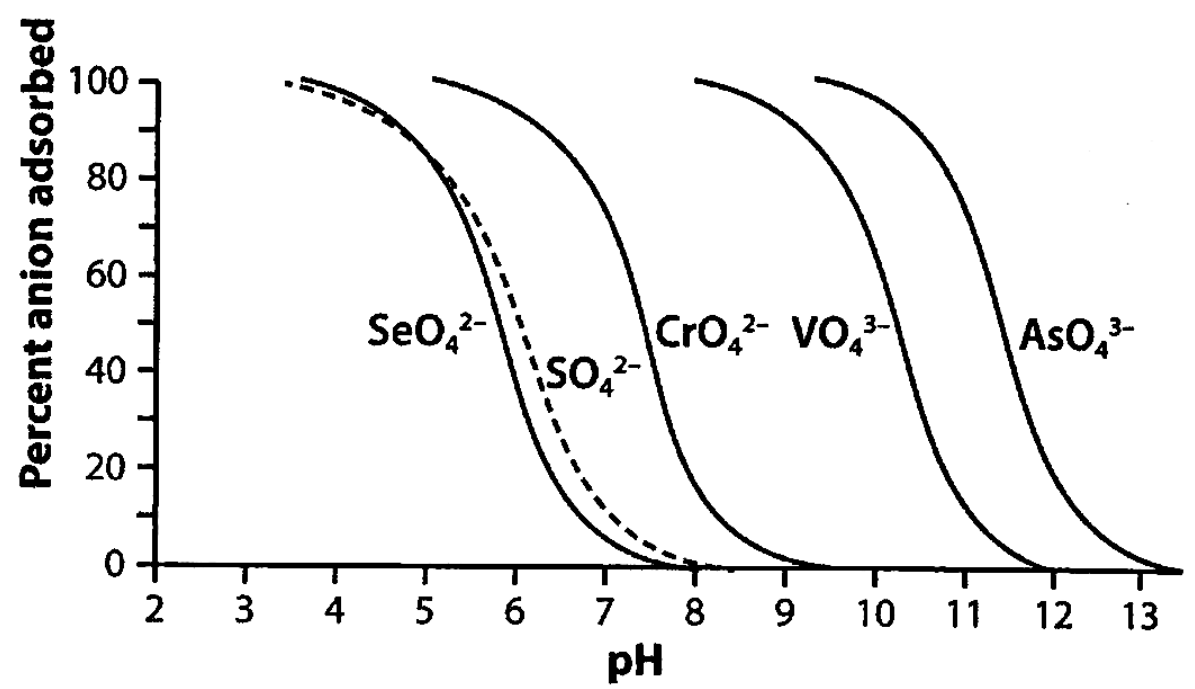

Figure 1-5. Observed trends for the sorption of cations (a) and anions (b) to ferrihydrite $\left(10^{-3} \mathrm{MTOTFe}\right)$ as a function of solution $\mathrm{pH}$ (Benjamin, 2015). Selenite, while not shown, would be presumed to exhibit a curve between selenate and sulfate. 


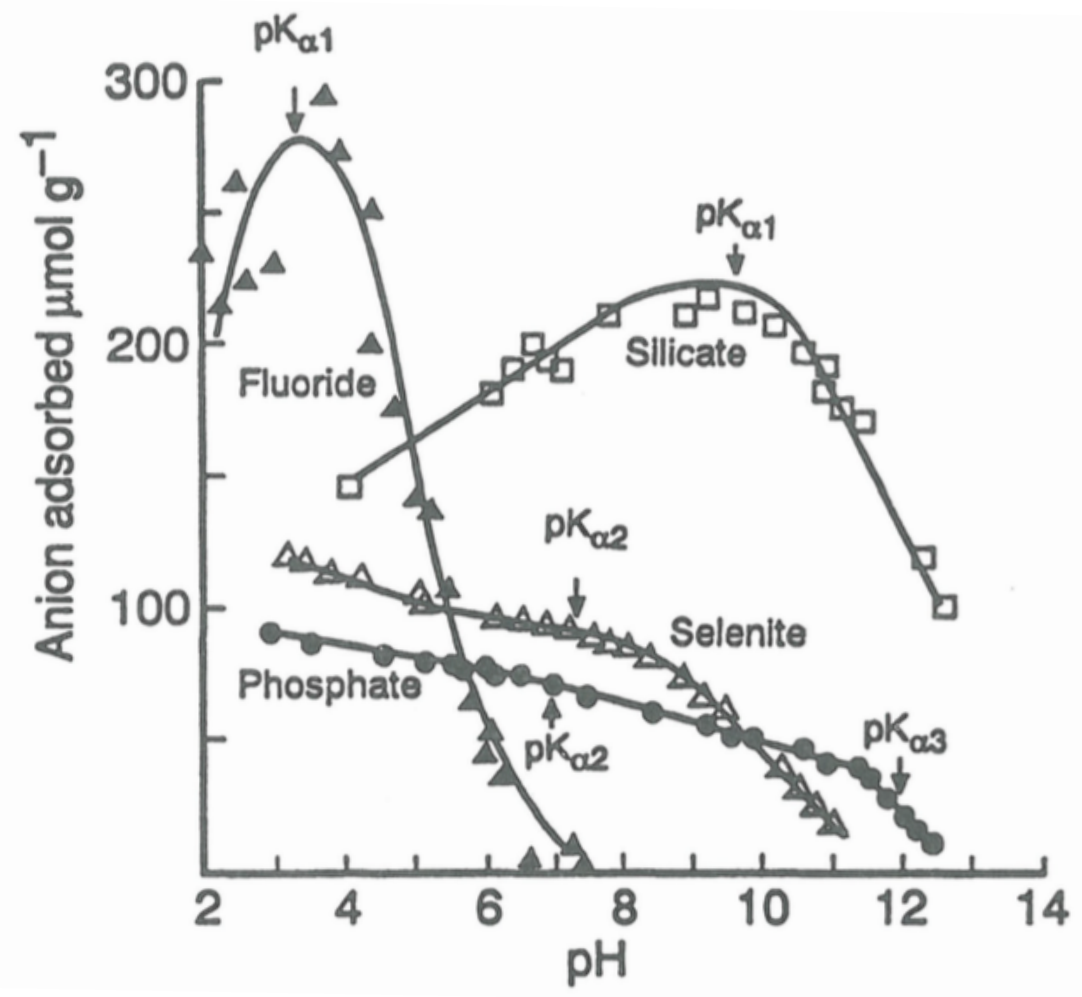

Figure 1-6. Sorption of anions with changes in $\mathrm{pH}$ and sorption edges denoted by $\mathrm{pK}_{\mathrm{a}}$ (Evangelou, 1998). 


\section{CHAPTER 2: METHOD DEVELOPMENT AND QUALITY ASSURANCE}

\subsection{Introduction}

Atomic absorption spectrometry (AAS) and inductively coupled plasma mass spectrometry (ICP-MS) were popular techniques for the quantification of trace metals from 1960 to the 1990s (Wei et al., 1998). However, chemical and spectral interferences from the sample matrix can reduce accuracy and recovery of volatile elements (Wei et al., 1998); as a result, hydride generation was coupled with these techniques (HG-AAS, HG ICP-MS) for the quantification of gaseous hydride forming elements, especially arsenic, mercury, and selenium (Cai, 2000; Stockwell and Corns, 1993). HG-AAS and HG ICP-MS techniques require either an on-line or off-line concentration step, which can introduce error and can result in decreased sensitivity (Cai, 2000). HG ICP-MS is less sensitive than other techniques because the high ionization potential of Se $(9.8 \mathrm{eV})$ inhibits complete ionization of Se, typically by $30 \%$. HG-AFS has been shown to exhibit increased sensitivity over other instrumentation, including HG-AAS and HG ICP-MS (Cai, 2000).

HG-AFS is a sensitive and selective technique for the determination of the gaseous hydride forming elements — arsenic, selenium, antimony, tellurium, mercury, and bismuth (Cai, 2000). Detection limits of 0.10 and $0.05 \mu \mathrm{g} \mathrm{L}^{-1}(3 \sigma)$ have been reported for As and Se (Corns et al., 1993). For Se determination, specifically, only Se(IV) is capable of producing a hydride - a binary compound of a species with hydrogen. Before analysis, $\mathrm{Se}(\mathrm{VI})$ must be converted to $\mathrm{Se}(\mathrm{IV})$. This is accomplished by an offline pre-digestion in which samples are heated at $100{ }^{\circ} \mathrm{C}$

for twenty minutes in a hydrochloric acid medium (PS Analytical, 2013). The combination of 
heat and acidic medium create conditions necessary for the conversion of $\mathrm{Se}(\mathrm{VI})$ to $\mathrm{Se}(\mathrm{IV})$. The addition of hydrochloric acid to the sample is also necessary for the generation of a hydride.

Once the hydride has been generated, an inert gas, such as argon, is used as a carrier gas to move the hydride to the atomizer. At the atomizer, a hollow cathode lamp is used as a fluorescence source to excite Se atoms in the sample at $196.0 \mathrm{~nm}$. Both the wavelength of excitation and the wavelength of fluorescence are characteristic of each element capable of forming a gaseous hydride. HG-AFS quantification is superior to HG-AAS or HG ICP-MS because HG-AFS can only be used for the six gaseous hydride-forming elements and the wavelength of fluorescence is characteristic of each element (Cai, 2000).

Despite increased sensitivity and selectivity, Se determination using HG-AFS is susceptible to some interferences. Using hydride generation techniques, the presences of transition metals, including nickel, cobalt, and copper, can cause signal suppression (Pierce and Brown, 1977; Ding and Sturgeon, 1997). The magnitude of signal suppression as a result of the presence of these metals is dependent on both the instrument used and the environmental conditions. Huang (2010) investigated the possible interference of manganese, ferrous iron, and ferric iron on Se(IV) recovery using MSIS ICP-OES. There was no significant effect of the concentration at which the interfering ion was present on Se recovery. The presence or absence of the interfering ion on Se recovery was statistically significant. Ferric iron and manganese resulted in a slight positive bias whereas ferrous iron and sulfate resulted in a negative bias. While the result was statistically significant, these biases resulted in $\leq 4 \%$ change in recovered Se concentration and are, therefore, analytically insignificant (Huang, 2010). 


\subsection{Experimental}

\subsubsection{Apparatus}

All samples were analyzed with a PS Analytical (PSA) 10.055 Millennium Excalibur HG-AFS (Orpington, Kent, United Kingdom) operating with a Se boosted discharge hollow cathode lamp and operating conditions summarized in Table 2-1 and detailed in Appendix A. A PSA 20.400 autosampler was used in all analyses with reagent flows according to Figure 2-1. Homologous polytetrafluoroethylene tubes provided by PSA (Environmental Express; SC, USA) were used to hold all samples on the autosampler.

Glassware was cleaned according to laboratory standards before cleaning in a two stage acid bath. Glassware was first soaked in 7.0 $\mathrm{M}$ nitric acid for a minimum of twenty-four hours. Glassware was rinsed with distilled deionized water before soaking in 1.0 $\mathrm{M}$ hydrochloric acid bath for a minimum of twenty-four hours. Glass was rinsed with distilled deionized water and air-dried prior to use.

\subsubsection{Reagents}

All reagents used were of analytical grade. Trace metal grade hydrochloric acid (11.65 $M)$ for sample acidification and instrumental blank and autosampler wash solutions was purchased from Fisher Scientific (CO, USA). Sodium hydroxide pellets and sodium borohydride powder (99\% pure, nitrogen flushed) were purchased from Acros Organic (NJ, USA). A 0.7\% m/v sodium borohydride solution was prepared daily by dissolving sodium borohydride powder in distilled deionized water and was stabilized with $0.1 \mathrm{M}$ sodium hydroxide prepared with sodium hydroxide pellets. All samples were prepared in $0.1 \mathrm{M}$ sodium nitrate from Fisher Scientific (CO, 
USA). Anhydrous sodium sulfate was purchased from Fisher Scientific (CO, USA). A 1000 mg

$\mathrm{L}^{-1}$ Se standard was purchased from AccuStandard (CN, USA). A $1000 \mathrm{mg} \mathrm{L}^{-1} \mathrm{Fe}^{+3}$ standard was purchased from Fisher Scientific (CO, USA).

\subsubsection{Procedure}

$\underline{\text { Stability of Samples on Autosampler with Time }}$

The autosampler is capable of holding 63 samples at a given time. As each sample requires slightly over a minute per draw, the last sample would have been on the autosampler for three hours before analysis. To determine if sample concentrations decreased with time on the autosampler, a stability test was performed. Calibration standards of $0,12.5,25.0,37.5$, and 50.0 $\mu \mathrm{g} \mathrm{L}^{-1}$ were prepared using Se standard in $0.1 \mathrm{M}$ sodium nitrate to adjust for ionic strength and $0.2 \mathrm{v} / \mathrm{v}$ hydrochloric acid. After calibration, standards were analyzed every twenty minutes until the point at which remaining volume prevented further analysis.

\section{Determination of Detection Limits}

The detection limit is defined as the smallest quantity of analyte that is statistically different from the blank. The procedure utilized produces a detection limit with $99 \%$ chance of being greater than the blank or a $1 \%$ chance of a false positive. The instrument detection limit (IDL) was determined by analyzing a single sample seven times. The method detection limit (MDL), which is greater than the instrument detection limit, was determined by analyzing seven samples one time each. The lower limit of quantitation (LLOQ) is the smallest concentration that can be 
measured with reasonable accuracy and is defined as the signal that is ten times greater than the background noise. The LLOQ was determined by analyzing seven samples one time each.

Samples were prepared with Se standard in $0.1 \mathrm{M}$ sodium nitrate and $0.2 \mathrm{v} / \mathrm{v}$ hydrochloric acid. Following calibration, a prepared sample of 0.20 for the low range method $\left(0-10 \mu \mathrm{g} \mathrm{L}^{-1}\right)$ and a prepared sample of $2.0 \mu \mathrm{g} \mathrm{L}^{-1}$ for the high range method $\left(0-50 \mu \mathrm{g} \mathrm{L}^{-1}\right)$ were analyzed seven times for IDL determination for each method. Seven samples of $0.2 \mu \mathrm{g} \mathrm{L}^{-1}\left(0-10 \mu \mathrm{g} \mathrm{L}^{-1}\right.$ method) and $2.0 \mu \mathrm{g} \mathrm{L}^{-1}\left(0-50 \mu \mathrm{g} \mathrm{L}^{-1}\right)$ Se standard were analyzed once each to compute LLOQs and MDLs for the two developed methods.

The IDL was determined by analyzing one sample seven times. The instrument detection was computed according to equation 1 (Harris, 2010a):

$$
\mathrm{IDL}=\frac{3 \mathrm{~s}}{\mathrm{~m}}
$$

where s was the standard deviation of the seven measurements on one sample and $\mathrm{m}$ was the slope of the calibration equation. The MDL, which is greater than the IDL, was determined by analyzing seven samples one time each. The MDL was then calculated according to equation 2 (Harris, 2010a):

$$
\mathrm{MDL}=\frac{3 \mathrm{~s}}{\mathrm{~m}}
$$

where $\mathrm{s}$ was the standard deviation of the seven samples and $\mathrm{m}$ was the slope of the calibration equation. The LLOQ was determined by analyzing seven samples one time each. The LLOQ was calculated according to equation 3 (Harris, 2010a):

$$
\mathrm{LLOQ}=\frac{10 \mathrm{~s}}{\mathrm{~m}}
$$


where s was the standard deviation of the seven samples and $\mathrm{m}$ was the slope of the calibration equation.

\section{Influence of Competing Ions}

Samples were prepared with Se standard in $0.1 \mathrm{M}$ sodium nitrate and $0.2 \mathrm{v} / \mathrm{v}$ hydrochloric acid to a concentration of $25 \mu \mathrm{g} \mathrm{L^{-1 }}$ with and without common ions present in mine drainage solids: ferric iron and sulfate. Ferric iron was added to samples at a level of $0,2.5$, and $5.0 \mu \mathrm{g} \mathrm{L}^{-1}$ using a $1000 \mathrm{mg} \mathrm{L}^{-1} \mathrm{Fe}(\mathrm{III})$ standard. Sulfate was added to samples at a level of 0, 125, and 250 $\mu \mathrm{g} \mathrm{L}^{-1} \mathrm{using}$ a prepared standard made from sodium sulfate. All samples were prepared in silanized glass vials and were wrapped in aluminum foil. Samples were placed on a rotary shaker at room temperature $\left(20^{\circ} \mathrm{C}\right)$ for twenty-four hours. After the twenty-four hour hold period, samples were analyzed for total Se by HG-AFS using the $0-50 \mu \mathrm{g} \mathrm{L}^{-1}$ (high range) method. Error was calculated according to equation 4 (Huang, 2010):

$$
\mathrm{e}=\frac{\mathrm{C}-\mu}{\mu}
$$

where e was the error, $\mathrm{C}$ was the reading of the sample with the interfering ion, and $\mu$ was the reading of the control sample with no interfering ions.

\subsection{Results and Discussion}

\section{$\underline{\text { Stability of Samples on Autosampler with Time }}$}

The average loss was $0.025 \mu \mathrm{g} \mathrm{L}^{-1} \mathrm{~min}^{-1}$ or $0.2 \%$ hour-1, which suggests that for a minimum acceptable precision rate of $5 \%$ at most 25 samples can be analyzed in a single instrumental run. 
For analyses in which there are more than 25 samples, samples will placed on the autosampler at different times to minimize loss.

\section{Determination of Detection Limits}

The two developed methods have differing instrument detection limits (Table 2-2) because of differing calibration equation slopes and instrumental settings, most notably the gain setting and filter value. For the low range method, the gain was set to 10 whereas the gain setting was 1 for the high range method. The gain setting establishes the amplification of the detector. The higher the gain setting, the greater the sensitivity of the method (PSA, 2010). The gain ranges are determined based on the concentration range of samples being analyzed. The filter value for the low range method was 32 and 16 for the high range method. The filter value smoothes the signal using Box Car integration to DAMP the displayed signal (PSA, 2010). The filter value set was the number of points averaged to plot as a single point along the signal curve. The larger the filter value, the greater the amount of smoothing that was applied to the curve. The filter value was determined by the concentration of samples analyzed. While the methods are capable of detecting $0.001 \mu \mathrm{g} \mathrm{L}^{-1}$ and $0.02 \mu \mathrm{g} \mathrm{L}^{-1}$ respectively, sample concentrations reported below the LLOQ will be reported as $0 \mu \mathrm{g} \mathrm{L}^{-1}$.

\section{Influence of Competing Ions}

The presence of ferric iron and sulfate resulted in a depression of Se(IV) recovery. The average error of all samples with only one interfering ion was less than 0.1 (Table 2-3). Hence, the presence of these ions at trace levels was not of analytical concern. Samples with more than 
one interfering ion had an error of between 0.2 and 0.3 and may be of concern analytically. Iron when in the presence of hydrochloric acid is a source of isobaric error in other methods including HG-ICP-MS (Harris, 2010b). Because HG-AFS does not calculate concentration based on the mass of ions produced, isobaric error is not a source of error in this method. It is possible that $\mathrm{Fe}^{+3}$ may form a complex with $\mathrm{Se}(\mathrm{IV})$ that does not excite at the wavelength of excitation used in this method or that does not fluoresce at the characteristic wavelength of Se(IV), which would result in a suppression of Se recovery.

\subsection{Conclusion}

HG-AFS is a sensitive and selective technique for Se determination. The instrument and method used is selective in that only six elements form a gaseous hydride and each of these elements has a characteristic wavelength of excitation and fluorescence. The detection limits determined for the developed high range method are comparable to limits reported by Corns et al. (1993). Detection limits determined for the low range methods are comparable to limits reported by Weir et al. (1998). Sample stability on the autosampler should be considered in future developed methods as there was a $5 \%$ loss in precision per hour. The presence of iron or sulfate alone resulted in a slight negative bias that was not of analytical concern $(\leq 0.1)$. The presence of iron and sulfate together resulted in a negative bias, between 0.2 and 0.3 . The developed methodology was sensitive for $\mathrm{Se}(\mathrm{IV})$ quantitation. Precautions such as placing no more than 25 samples on the autosampler at a time, analyzing other ions in solution, and keeping samples in the dark until acidified will further add to the sensitivity of the developed methods. 


\section{References}

Cai, Y. (2000). Speciation and analysis of mercury, arsenic, and selenium by atomic fluorescence spectrometry. TrAC Trends in Analytical Chemistry, 19(1), 62-66.

Corns, W. T., Stockwell, P. B., Ebdon, L., \& Hill, S. J. (1993). Development of an atomic fluorescence spectrometer for the hydride-forming elements. Journal of Analytical Atomic Spectrometry, 8, 71-77.

Ding, W. W., \& Sturgeon, R. E. (1997). Minimization of transition-metal interferences with hydride-generation techniques. Journal of Analytical Chemistry, 69(3), 527-531.

Harris D.C. (2010a). Quality assurance and calibration equations Quantitative Chemical Analysis (Eighth ed., pp. 117-141). New York: W.H. Freeman and Company.

Harris D.C. (2010b) Atomic spectroscopy Quantitative Chemical Analysis (Eighth ed., pp. 479-501). New York: W.H. Freeman and Company.

Huang, D. (2010). Mechanism for Heterogenous Reduction of Selenite by Zero Valent Iron-Steel Wool. (Ph.D. in Soil Science Dissertation), West Virginia University, Morgantown, WV.

Kikuchi E. \& Sakamoto H. (2000). Kinetics of the reduction reaction of selenate ions by $\mathrm{TiO}_{2}$ photocatalyst. Journal of the Electrochemical Society 147(12),4589-4593.

PS Analytical. (2007). Millennium Excalibur Methods for Selenium in Drinking, Surface, Ground, Saline, and Industrial \& Domestic Waste Waters PSA Customer Technical Information File.

PS Analytical. (2010). Millennium Software User Manual. PSA Millennium Excalibur User Manual.

Pierce, F. D., \& Brown, H. R. (1977). Comparison of inorganic interferences in atomic absorption spectrometric determination of arsenic and selenium. Analytical Chemistry, 49(9), 1417-1422.

Stockwell, P. B., \& Corns, W. T. (1993). The role of atomic fluorescence spectrometry in the automatic environmental monitoring of trace element analysis. Journal of Automatic Chemistry, 15(3), 79-84.

Wei, L., Gupta, P., Hernandez, R., \& Farhat, F. (1999). Determination of Ultratrace Selenium and Arsenic at Parts-per-Trillion Levels in Environmental and Biological Samples by Atomic Fluorescence Spectrometry with Flow Injection Hydride Generation Technique. Microchemical Journal, 62(1), 83-98. 
Table 2-1. Instrumental operating conditions used for Se determination by method.

\begin{tabular}{|c|c|c|}
\hline Parameter & Low Range Method & High Range Method \\
\hline Gain & 10 & 1 \\
\hline Filter & 32 & 16 \\
\hline Wavelength & $196.0 \mathrm{~nm}$ & $196.0 \mathrm{~nm}$ \\
\hline Primary Current & $20.0 \pm 0.5 \mathrm{~mA}$ & $20.0 \pm 0.5 \mathrm{~mA}$ \\
\hline Boost Current & $25.0 \pm 0.5 \mathrm{~mA}$ & $25.0 \pm 0.5 \mathrm{~mA}$ \\
\hline Delay Time & $10 \mathrm{sec}$ & $10 \mathrm{sec}$ \\
\hline Analysis Time & $5 \mathrm{sec}$ & $15 \mathrm{sec}$ \\
\hline Memory Time & $40 \mathrm{sec}$ & $40 \mathrm{sec}$ \\
\hline Probe Rinse Solution & $40 \% \mathrm{v} / \mathrm{v} \mathrm{HCl}$ & $40 \% \mathrm{v} / \mathrm{v} \mathrm{HCl}$ \\
\hline Probe Rinse Flow Rate & $8 \mathrm{~mL} \mathrm{~min}^{-1}$ & $8 \mathrm{~mL} \mathrm{~min}^{-1}$ \\
\hline Sample Flow Rate & $8 \mathrm{~mL} \mathrm{~min}^{-1}$ & $8 \mathrm{~mL} \mathrm{~min}^{-1}$ \\
\hline Sample Acidity & $5 \% \mathrm{v} / \mathrm{v} \mathrm{HCl}$ & $5 \% \mathrm{v} / \mathrm{v} \mathrm{HCl}$ \\
\hline Blank Solution & $20 \% \mathrm{v} / \mathrm{v} \mathrm{HCl}$ & $20 \% \mathrm{v} / \mathrm{v} \mathrm{HCl}$ \\
\hline Blank Flow Rate & $8 \mathrm{~mL} \mathrm{~min}^{-1}$ & $8 \mathrm{~mL} \mathrm{~min}^{-1}$ \\
\hline Reductant & $0.7 \% \mathrm{~m} / \mathrm{v} \mathrm{NaBH}_{4}$ in $0.1 \mathrm{MNaOH}$ & $0.7 \% \mathrm{~m} / \mathrm{v} \mathrm{NaBH} \mathrm{N}_{4}$ in $0.1 M \mathrm{NaOH}$ \\
\hline Reductant Flow Rate & $4.5 \mathrm{~mL} \mathrm{~min}^{-1}$ & $4.5 \mathrm{~mL} \mathrm{~min}^{-1}$ \\
\hline Carrier Gas & Argon & Argon \\
\hline Carrier Gas Flow Rate & $0.60 \mathrm{~L} \mathrm{~min}^{-1}$ & $0.60 \mathrm{~L} \mathrm{~min}^{-1}$ \\
\hline Drier Gas & Argon & Argon \\
\hline Drier Gas Flow Rate & $2.5 \mathrm{~L} \mathrm{~min}^{-1}$ & $2.5 \mathrm{~L} \mathrm{~min}^{-1}$ \\
\hline
\end{tabular}


Table 2-2. Detection limits determined for developed methods.

\begin{tabular}{cccc}
\hline & IDL & MDL & LLOQ \\
\hline Low Range Method & 0.0008 & 0.0001 & 0.0005 \\
High Range Method & 0.02 & 0.02 & 0.05 \\
\hline
\end{tabular}


Table 2-3. Effect of interfering ion(s) on Se(IV) recovery using HG-AFS.

\begin{tabular}{cccc}
\hline Ion $(\mathrm{s})$ & Delivered Concentration & Average Error & St Dev \\
\hline $\mathrm{Fe}^{+3}$ & $-\ldots-\mathrm{g} \mathrm{L}^{-1} \ldots \ldots$ & \\
$\mathrm{Fe}^{+3}$ & 5.0 & -0.07 & 0.06 \\
$\mathrm{SO}_{4}^{-2}$ & 125 & -0.11 & 0.05 \\
$\mathrm{SO}_{4}^{-2}$ & 250 & -0.075 & 0.002 \\
$\mathrm{Fe}^{+3}, \mathrm{SO}_{4}^{-2}$ & $2.5,125$ & -0.12 & 0.05 \\
$\mathrm{Fe}^{+3}, \mathrm{SO}_{4}^{-2}$ & $2.5,250$ & -0.12 & 0.02 \\
$\mathrm{Fe}^{+3}, \mathrm{SO}_{4}^{-2}$ & $5.0,125$ & -0.24 & 0.03 \\
$\mathrm{Fe}^{+3}, \mathrm{SO}_{4}^{-2}$ & $5.0,250$ & -0.26 & 0.03 \\
\hline
\end{tabular}




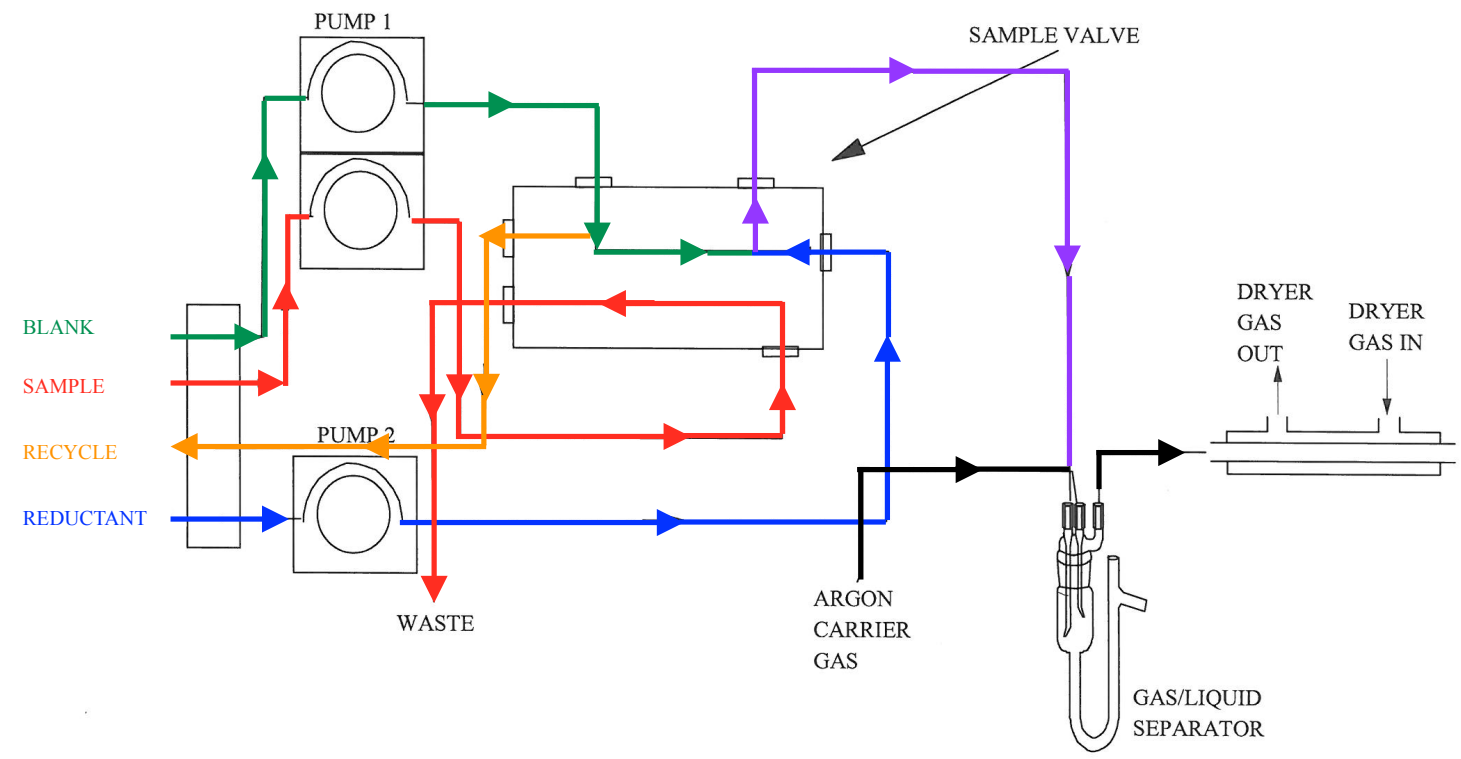

Figure 2-1. Schematic of flow pathways for HG-AFS (PS Analytical, 2013). Solutions are pumped from the liquid manifold on the left of the diagram to the sample valve from one of two peristaltic pumps. The sample valve butt mixes the reductant solution and blank or sample for injection to the gas/liquid separator based on the analysis time. 


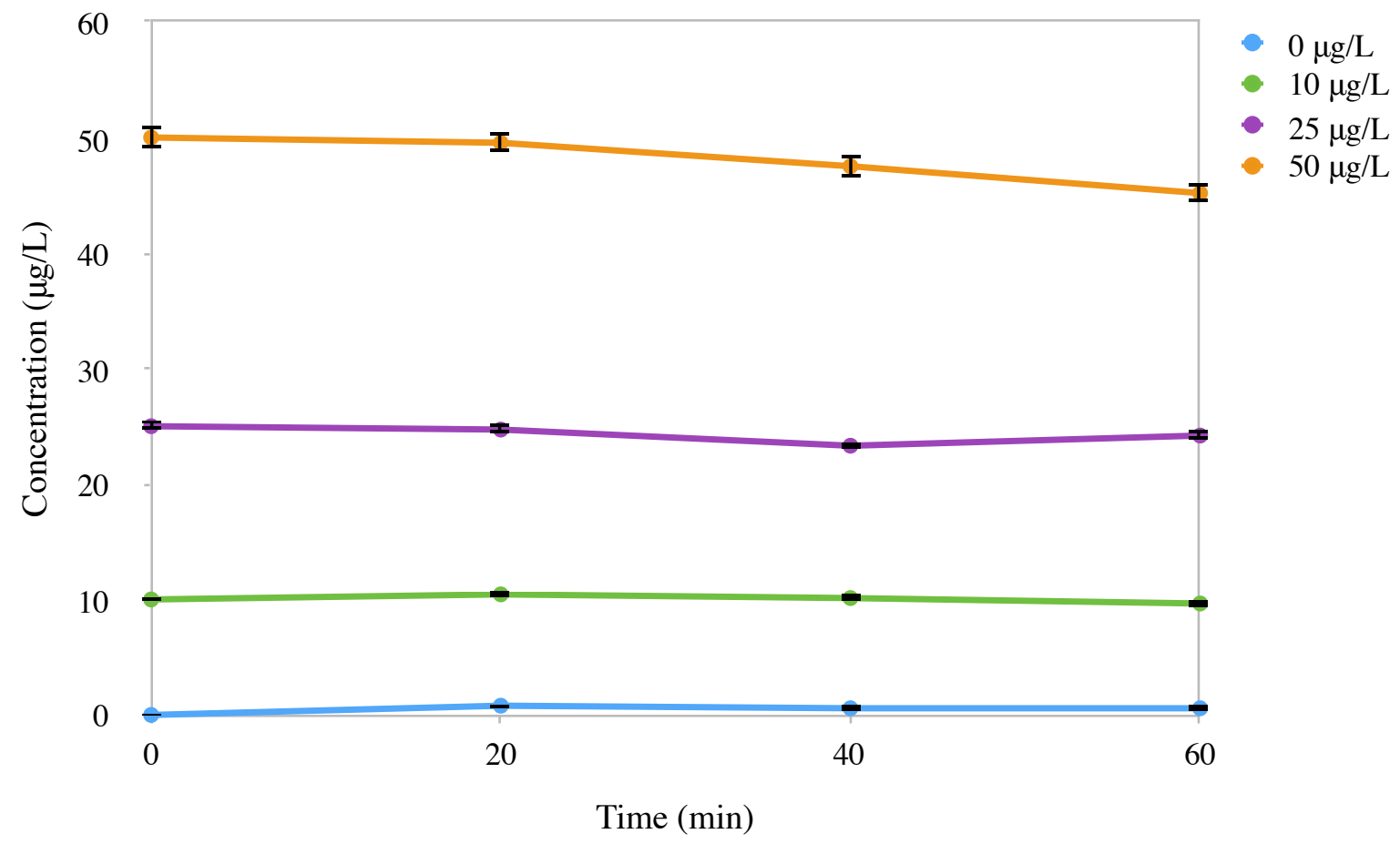

Figure 2-2. Effect of time on stability of samples on autosampler. Error bars indicate standard deviation. 


\section{CHAPTER 3: LABWARE EVALUATION FOR SELENIUM SORPTION EXPERIMENTS}

\subsection{Introduction}

The type of labware used in any experiment must be carefully selected so as not to affect the sample itself. The composition of a sample may change over time as a result of chemical changes, interaction with air, or interaction with the container. The loss of target compounds from solution to container surfaces has been recognized as an issue in trace metal analysis, especially in speciation analyses (Zief, 1976; Batley, 1989; Kosta, 1982). Adsorptive losses to glassware can be significant particularly near pH of 6 (Pinheiro and Bosker, 2004). Glass, while very practical for cleanliness needed in experiments, is a notorious ion exchanger. Glass contains silicate and silanol groups which can act as ion-exchange centers, thereby altering the concentration of trace ions in solution (Seed, 2000). Pepe and Byrne (1980) noted significant losses of a hexachlorinated biphenyl congener to glass, serving as a possible source of error in PCB quantitation.

In order to minimize the loss of dissolved ionic species through sorption to ion-exchange centers on the surface of glass, silanizing, also called siliconizing, can be performed on labware. A silanizing agent contains either short polymers of dimethylsiloxane or caps of trimethylsilixane (Seed, 2000). These compounds react with silanol groups to produce a siloxane linkage on the surface of the material as well as trace amounts of $\mathrm{HCl}$. The siloxane linkage forms a water repellant layer on the surface of the glass and effectively seals ion exchange centers. Thereby, silanizing can minimize the loss of ionic species to labware. Silanization of glass and some plastics is common in microbiological techniques (Seed, 2000) but can be especially useful when 
working with small volumes of samples (Farrell, 2014). Muldew et al. (1982) determined silanization of glassware can slow the loss of a hexachlorinated biphenyl congener to glassware a problem identified by Pepe and Byrne (1980).

Other materials can be used to store solutions in order to minimize loss. Target compound loss to labware can be minimized by storing samples in Teflon ${ }^{\circledR}$ at low temperatures (Pinheiro and Bosker, 2004.) Polytetrafluoroethylene (PTFE), known under the name Teflon ${ }^{\circledR}$, is a fluorinated polymer with a non-polar surface area. The non-polar surface area minimizes sorption of polar ions and, thereby reduces loss (Knapp and Schramel, 2003). However, PTFE has a porous structure due to the process used to synthesize PTFE polymers, which can allow for losses of analyte at the trace level. A $2 \mathrm{M} \mathrm{Ag}^{+2}$ solution stored in a Teflon ${ }^{\circledR}$ bottle lost $2 \%$ of concentration in a single day and $28 \%$ in a month (Versieck, 1983).

Polypropylene (PP) is widely used in laboratory materials ranging from pipette tips to centrifuge tubes. PP plastic is a hydrophobic non-polar material, which limits attraction of ions to the material surface (Gaillard and Strauss, 1998). PP plastic is a non-homologous thermoplastic. Three tacticities of the propylene polymer unit are possible: syntactic, isotactic, and atactic. The tacticities of the polymer can create areas of small charge imbalances that may promote attraction of analyte. For example, atactic PP promoted clustering of solvent molecules over isotactic PP (Ochiai et al., 1971). The process used to make PP polymers results in a porous surface which allows for sorption of compounds to the PP surface. Numerous studies have found that PP plastics are capable of sorbing organic pollutants: polychlorinated biphenyls, DDT, DDD, polyaromatic hydrocarbons, and nonylphenols (Mato, 2001; Rochman et al., 2014; Teuten et al., 2007; Teuten et al., 2009). PP plastics are additionally capable of sorbing both major and trace 
metals. Studies have found significant amounts of $\mathrm{Fe}, \mathrm{Al} \mathrm{Cu}, \mathrm{Zn}, \mathrm{Pb}, \mathrm{Ag}, \mathrm{Cd}, \mathrm{Co}, \mathrm{Cr}, \mathrm{Mo}, \mathrm{Sb}, \mathrm{Sn}$, and U sorbed to PP plastics in aquatic settings (Ashton et al., 2014). A 1977 study found that PP was not a suitable material for the sampling and storage of natural water samples to be processed for metal analyses (Bately and Gardner, 1977).

Overall, labware selected for use in any analysis must be carefully selected to minimize interferences. Labware should be evaluated before use in sorption studies specifically. Loss of analyte to the sample container rather than the sorbent can result in an overestimation of the sorptive properties of the sorbent. Standard methods for sorption work do not include any preliminary work to select appropriate labware for use (Roy et al., 1991; McDonald and Evangelou, 1991), and sorption studies often do not indicate if any preliminary work was conducted to determine labware material for use. One notable exception is a study by Figueroa et al. (2004) which found PP plastic was suitable for sorption experiments with tetracycline. Therefore, determination of appropriate labware for Se work must be determined.

\subsection{Experimental}

\subsubsection{Apparatus}

All samples were analyzed with a PSA 10.055 Millennium Excalibur HG-AFS (Orpington, Kent, United Kingdom) operating with a Se boosted discharge hollow cathode lamp with primary and secondary discharges of 20.0 and $25.5 \mathrm{~mA}$ respectively. A PSA 20.400 autosampler was used in all analyses. Homologous polytetrafluoroethylene tubes (Environmental Express; SC, USA) were used to hold all samples on the autosampler. These tubes are recommended for 
use by the manufacturer. Losses to these containers are not of analytical concern because the samples are acidified and because the containers are homologous.

Glassware was cleaned according to laboratory standards before cleaning in a two stage acid bath. Glassware was first soaked in 7.0 $M$ nitric acid for a minimum of twenty-four hours. Glassware was rinsed with distilled deionized water before soaking in $1.0 \mathrm{M}$ hydrochloric acid bath for a minimum of twenty-four hours. Glass was rinsed with distilled deionized water and air-dried prior to use.

Glassware was silanized by filling each vial with Sigmacote ${ }^{\circledR}$ once the vial was completely dry. After ten seconds, the vial was emptied by pouring all Sigmacote ${ }^{\circledR}$ back into its original container. Vials were allowed to air dry for twenty-four hours before use. Nalgene 3114 Oak Ridge Teflon centrifuge tubes tubes were purchased from Spectrum Chemical (NJ, USA). Falcon-brand PP tubes were purchased from Fisher Scientific (CO, USA).

\subsubsection{Reagents}

All reagents used were of analytical grade. Trace metal grade hydrochloric acid (37\%) for sample acidification and instrumental blank and wash solutions was purchased from Fisher Scientific (CO, USA). Sodium hydroxide pellets and sodium borohydride powder (99\% pure, nitrogen flushed) were purchased from Acros Organic (NJ, USA). A $0.7 \% \mathrm{~m} / \mathrm{v}$ sodium borohydride solution was prepared daily by dissolving sodium borohydride powder in distilled deionized water and was stabilized with $0.1 M$ sodium hydroxide prepared from sodium hydroxide pellets. All samples were prepared in $0.1 M$ sodium chloride from Fisher Scientific 
(CO, USA). A $1000 \mathrm{mg} \mathrm{L}^{-1}$ Se standard was purchased from AccuStandard (CN, USA).

Sigmacote ${ }^{\circledR}$ was purchased from Sigma-Aldrich (MO, USA).

\subsubsection{Procedure}

To determine the material most suitable for Se sorption experiments, four types of materials were assessed: glass, silanized glass, polytetrafluoroethylene (PTFE), and polypropylene (PP). Varying Se stock solutions $\left(0,10,25\right.$, and $\left.50 \mu \mathrm{g} \mathrm{L}^{-1}\right)$ were prepared in $0.1 \mathrm{M} \mathrm{NaCl}$ in triplicate. Each sample was $40 \mathrm{~mL}$ in volume. Samples were placed on a rotary shaker (Glas-Col; IN, USA) at 30 revolutions per minute for $6,12,24$, or 48 hours to evaluate the ability of the material to suitably hold samples for sorption studies. Samples were prepared for each individual time point. After equilibration time, samples were transferred to homologous polypropylene tubes (Environmental Express; SC, USA ) for determination of total Se by HG-AFS. Samples were prepared in triplicate in a completely randomized design $(\mathrm{n}=180)$.

\subsection{Results and Discussion}

Analysis of covariance (ANCOVA) was used for statistical analysis with a response variable of normalized concentration and an interval variable of time. Normalized concentration was used for analysis because the trace metal grade hydrochloric acid used for acidification contains trace levels of Se ( $\leq 1 \mu \mathrm{g} \mathrm{L}^{-1}$ per manufacturer specification). The variable of time was referred to as the covariate and reflects conditions under which the experiment was carried out, in this case time points at which samples were allowed to equilibrate. The time for which the samples 
equilibrated was assumed not to be impacted by the factor levels of the experiment, in this case the normalized concentration.

Time alone was not statistically significant for any concentration analyzed with all p-values greater than 0.05 (Table 3-1). The interaction of treatment (labware used) and time was statistically significant for both the 25 and $50 \mu \mathrm{g} \mathrm{L}-1$ model, whereas treatment was statistically significant for the $25 \mu \mathrm{g} \mathrm{L} \mathrm{L}^{-1}$ model (p-value $<0.005$ ). As treatment was only statistically significant for the $25 \mu \mathrm{g} \mathrm{L} \mathrm{L}^{-1}$, this model was used to determine which labware was most suitable for Se sorption experiments. In this model, silanized glass was statistically different from all other labware tested. Silanized glass, overall, demonstrated a greater ability to maintain concentration over time at all levels analyzed and corresponded to the greatest least squares means and smallest standard error in each model (Table 3-2).

Interestingly, measured concentration increased over time for samples contained in silanized glass and polypropylene plastic. This increases was less than 5\% and was, therefore, not of concern analytically. The increase in concentration over time in these samples could be due to differences in dilution through the addition of hydrochloric acid for analyses $(0.2 \mathrm{v} / \mathrm{v})$. If silanization resulted in a patchy seal, ion-exchange sites on the glass were not sealed and sorption of Se to these sites could occur, causing a decreased concentration in these samples. With time and movement of solution across the container surface through use of the rotary shaker, Se could release back into solution as other ions replace Se on the exchange sites on the container itself or the caps. 


\subsection{Conclusion}

Silanized glass was most suitable for labwork concerning Se. Samples contained in silanized glass had the greatest measured concentration across all time points. Silanized glass corresponded with the greatest least squares means as well as the smallest error. The ability of silanized glass to successfully maintain concentration across time with minimal loss was correlated with the sealing of ion-exchange centers on the glass surface with polysiloxane chains. Each container tested corresponded with some loss, which may be to the cap. Any residual moisture on the glass surface could result in an improper seal of silanized containers, allowing for loss to ion exchange sites on the glass itself.

Silanization of glass creates a hydrophobic barrier that was resistant to most chemicals. The possibility of this barrier scratching in the presence of solids for sorption experiments was a concern. A non-silanized glass vial, a freshly silanized glass vial, and a used silanized glass vial were filled with Gentian violet indicator for twenty-four hours. After this period, the vials were visually assessed for purple staining indicating that dye had sorbed to ion-exchange centers on the glass surface. The non-silanized vial was stained, whereas neither silanized vials were stained. Therefore, the silanized layer does not scratch or degrade during sorption experiments with solid sorbents. 


\section{References}

Ashton, K., Holmes, L., \& Turner, A. (2010). Association of metals with plastic production pellets in the marine environment. Marine Pollution Bulletin, 60(11), 2050-2055.

Batley, G. E. (1989). Collection, preparation, and storage of samples for speciation analysis Trace Element Speciation: Analytical methods and problems. Boa Raton: CRC Press.

Batley G.E. \& Gardner D. (1977). Sampling and storage of natural waters for trace metal analysis. Water Research 11,745-756.

Farrell, J. R. E. (2014). Appendix H: Silanizing Centrifuge Tubes and GlasswareRNA Methodologies (3rd ed). Burlington, US: Academic Press. Retrieved from http:// www.ebrary.com.

Figueroa R.A., Leonard A., \& Mackay A.A. (2004). Modeling tetracycline antibiotic sorption to clays. Environmental Science and Technology, 38, 476-483

Gaillard C. \& Strauss F. (1998). Avoiding adsorption of DNA to polypropylene tubes and denaturation of short DNA fragments. Technical Tips Online 3, 63-65.

Knapp, G., \& Schramel, P. (2003). Sources of analyte contamination and loss during the analytical process. In Z. Mester \& R. Sturgeon (Eds.), Sample Preparation for Trace Element Analysis (Vol. 41, pp. 23-45). Amsterdam: Elsevier.

Kosta, L. (1982). Contamination as a limiting parameter in trace analysis. Talanta, 29(11), 985-992.

Mato, Y., Isobe, T., Takada, H., Kanehiro, H., Ohtake, C., \& Kaminuma, T. (2001). Plastic Resin Pellets as a Transport Medium for Toxic Chemicals in the Marine Environment. Environmental Science \& Technology, 35(2), 318-324.

McDonald Jr., L. M., \& Evangelou, V. P. (1997). Optimal solid-to-solution ratios for organic chemical sorption experiments. Soil Science Society of America Journal, 61, 1655-1659.

Muldrew, D. H., Worobey, B. L., \& Webster, G. R. B. (1982). Sorption of $\left[{ }^{14} C\right]$ 2,4,5,2 ',2 ',5 'hexachlorobiphenyl to glass and plastic surfaces. Paper presented at the 16th Annual Workshop on Pesticide Residue Analysis, Western Canada.

Ochiai, H., Gekko, K., \& Yamamura, H. (1971). Sorption properties of polypropylene. Journal of Polymer Science Part A-2: Polymer Physics, 9(9), 1629-1640.

Pepe M.G., \& Byrne J.J.(1980). Adhesion-binding of 2,2',4,4',5,5'-hexachlorobiphenyl to glass and plastic: a possible source of error for PCB analysis. Bulletin of Environmental Contamination and Toxicology 25, 936-940.

Pinheiro, J. P., \& Bosker, W. (2004). Polystyrene film-coated glassware: a new means of reducing metal losses in trace metal speciation. Analytical and Bioanalytical Chemistry, 380(7), 964-968.

Rochman, C. M., Hentschel, B. T., \& Teh, S. J. (2014). Long-Term Sorption of Metals Is Similar among Plastic Types: Implications for Plastic Debris in Aquatic Environments. PLOS ONE, 9(1), e85433. 
Roy, W. R., Krapac, I. G., Chous, S. F. J., \& Griffin, R. A. (1991). Batch-Type Procedures for Estimating Soil Adsorption of Chemicals. USEPA Technical Resource Document EPA/ 530-SW-87-006-F.

Seed, B. (2001). Silanizing Glassware Current Protocols in Cell Biology: John Wiley \& Sons, Inc.

Teuten E.L., Rowland S.J., Galloway T.S., \& Thompson R.C. (2007). Potential for plastics to transport hydrophobic contaminants. Environmental Science and Technology 41, 7759-7764.

Teuten, E. L., Saquing, J. M., Knappe, D. R. U., Barlaz, M. A., Jonsson, S., Björn, A., . . Takada, H. (2009). Transport and release of chemicals from plastics to the environment and to wildlife. Philosophical Transactions of the Royal Society B: Biological Sciences, 364(1526), 2027-2045.

Versieck J. (1983). Biological sample collection and preparation for trace elemental analysis. Trends in Analytical Chemistry 2, 110-113.

Zief M., and Mitchell, J.W. (1976) Contamination control in trace element analysis. Wiley, New York. 
Table 3-1. Results of ANCOVA analyses for labware evaluation by nominal concentration.

\begin{tabular}{ccccc}
\hline & & \multicolumn{3}{c}{$\mathrm{p}$-values } \\
Nominal Concentration & $\operatorname{Pr}>\mathrm{F}$ & Time & Treatment & Treatment $\times$ Time \\
\hline $10 \mu \mathrm{g} \mathrm{L} \mathrm{C}^{-1}$ & 0.17 & 0.34 & 0.07 & 0.45 \\
$25 \mu \mathrm{g} \mathrm{L}{ }^{-1}$ & $*<0.0001$ & 0.06 & $* 0.005$ & $*<0.0001$ \\
$50 \mu \mathrm{g} \mathrm{L}-1$ & $* 0.02$ & 0.51 & 0.20 & $* 0.001$ \\
\hline
\end{tabular}

A p-value $\leq 0.05$ was statistically significant. Significant values are indicated by *. 
Table 3-2. ANCOVA least squares means and standard error for labware evaluation by nominal concentration.

\begin{tabular}{|c|c|c|c|c|c|c|c|c|}
\hline \multirow[b]{2}{*}{$\begin{array}{c}\text { Nominal } \\
\text { Concentration }\end{array}$} & \multicolumn{2}{|c|}{ Glass } & \multicolumn{2}{|c|}{$\mathrm{PP}$} & \multicolumn{2}{|c|}{ PTFE } & \multicolumn{2}{|c|}{ Silanized Glass } \\
\hline & LSM & St Error & LSM & St Error & LSM & St Error & LSM & St Error \\
\hline & -- & & & -- & $\mathrm{L}^{-1}$ & 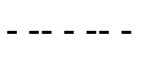 & --- & -- \\
\hline $10 \mu \mathrm{g} \mathrm{L}^{-1}$ & 6.57 & -0.02 & 6.41 & 0.01 & 6.41 & -0.02 & 6.99 & 0.00 \\
\hline $25 \mu \mathrm{g} \mathrm{L}^{-1}$ & 20.67 & -0.20 & 17.56 & 0.03 & 17.23 & 0.03 & 19.42 & 0.02 \\
\hline $50 \mu \mathrm{g} \mathrm{L}^{-1}$ & 37.32 & -0.18 & 32.52 & 0.08 & 34.78 & -0.03 & 35.63 & 0.05 \\
\hline
\end{tabular}




\section{CHAPTER 4: TEMPERATURE DEPENDENT SORPTION OF SELENIUM TO MINING SOLIDS}

\subsection{Introduction}

Elemental diel cycles are hypothesized to be the result of temperature dependent sorption reactions. Adsorption — the accumulation of molecules at the interface between two phases plays a critical role in the transport, bioavailability, and fate of contaminants in aquatic systems (Benjamin, 2015). Unlike the other proposed mechanisms for diel cycles, sorption is the only mechanism that explains the opposing cycles exhibited simultaneously in time between anions and cations (Nimick et al., 2003).Temperature is an important variable when conducting sorption experiments, as a fluctuation of $3{ }^{\circ} \mathrm{C}$ in solution temperature can lead to different isotherms (Roy et al., 1991). Most sorption experiments are conducted at room temperature, which is generally around $25^{\circ} \mathrm{C}$. Few papers have been published on the impact of temperature on the sorption of dissolved species.

Hasan and Ranjan (2010) investigated the sorption of Se anions on wheat, rice, and corn brans at three temperatures: $20^{\circ} \mathrm{C}, 30^{\circ} \mathrm{C}$, and $40{ }^{\circ} \mathrm{C}$. The uptake of both $\mathrm{Se}(\mathrm{IV})$ and $\mathrm{Se}(\mathrm{VI})$ decreased with increasing temperature, indicating that the rate of desorption is more significant than the rate of sorption. Decreased uptake with increasing temperature also implies that the reaction is exothermic (Hasan and Ranjan, 2010). The sorbate-sorbent complex becomes unstable as a result of increased energy at high temperatures. Ions held by the sorbent have enough energy to overcome the attractive forces of the sorbent and release back into the bulk solution. It was further hypothesized that at increasing temperatures, damage to the sorption sites may occur in conjunction with the instability of the complex (Hasan and Ranjan, 2010). This 
could also explain the decreased sorption at higher temperatures as fewer sites would be suitable for sorption.

Attenuated total reflectance Fourier transform-infrared spectroscopy utilized in a study of Se sorption to anatase suggests that the exothermic nature of such reactions may be the result of the size of the hydration shell (Jordan et al., 2015). Selenate forms an outer-sphere complex with the anatase surface, which has a slightly skewed symmetry at all temperatures (Jordan et al., 2015). This asymmetry may indicate some chemical contribution to the electrostatic attraction, such as a reduced hydration shell, between $\mathrm{Se}(\mathrm{VI})$ and anatase, which results in decreased entropy. At increased temperatures, the effect of the asymmetry increases in conjunction with an increased hydration shell (Jordan et al., 2015). The increased hydration shell decreases the electrostatic attraction between $\mathrm{Se}(\mathrm{VI})$ and anatase to such a point that $\mathrm{Se}(\mathrm{VI})$ releases back into the bulk solution.

Studies on the influence of temperature on Se sorption support decreasing sorption with increasing temperature. An investigation of $\mathrm{Se}(\mathrm{VI})$ sorption to goethite calculated negative enthalpy values for both outer-sphere surface complexation and inner-sphere bidentate complexation, indicative of an exothermic reaction (Kersten and Vlasova, 2013). These values were obtained using the 1-pK basic Stern model of surface protonation of goethite (Kersten and Vlasova, 2013). The bidentate inner-sphere complex exhibited greater sensitivity to increasing temperature with an enthalpy value of $-70 \mathrm{~kJ} \mathrm{~mol}^{-1}$ than the outer-sphere complex $\left(-36 \mathrm{~kJ} \mathrm{~mol}^{-1}\right)$. Balistrieri and Chao (1986) determined hydrogen selenite $\left(\mathrm{HSeO}_{3}{ }^{-}\right)$sorption to goethite has an enthalpy of -29 and $-22 \mathrm{~kJ} \mathrm{~mol}^{-1}$ based on the fractional area of the surface covered. Overall, enthalpies of Se(IV) sorption are near $-20 \mathrm{~kJ} \mathrm{~mol}^{-1}$ (Balistrieri and Chao). With the exception of 
the bidentate inner-sphere complex observed by Kersten and Vlasova, the low enthalpy values support the hypothesis that Se sorption occurs through physisorption. Low enthalpy values, such as those found in Se sorption studies, and the exothermic nature of Se sorption reactions indicate that physisorption may be occurring thereby explaining diel cycles of Se in conjunction with daily changes in temperature.

The impact of temperature on sorption could also be related to the structure of water. The density of water changes with temperature through changes in hydrogen bonding between water molecules. Water is densest at $4{ }^{\circ} \mathrm{C}$ due to increased entropy (Marcus, 2009). Ice crystals begin to form at this temperature causing an increased ordering of the structure of water. The increasing order of water molecules at decreasing temperatures may provide the structural order that results in preferential sorption or anions over cations seen in diel cycling.

\subsection{Experimental}

\subsubsection{Apparatus}

Solution $\mathrm{pH}$ was determined using a Mettler Toledo SevenEasy $\mathrm{pH}$ meter calibrated using three points. (Mettler Toledo International, Inc. Schwarzenbach, Switzerland). Solution electrical conductivity (EC) was analyzed using a Mettler Toledo SevenCompact conductivity meter calibrated using four points (Mettler Toledo International, Inc. Schwarzenbach, Switzerland). A MARS 5 Microwave (CEM Corporation Mathews, NC) was used for the digestion of samples necessary for elemental determination. Digested samples were analyzed for aluminum, iron, manganese, magnesium, calcium, and sodium by ICP-OES (Perkin-Elmer Optima DV2100, Perkin-Elmer Corp. Norwalk, CT) and for total Se by HG-AFS (PSA 10.055 Millennium 
Excalibur, PSA, Orpington, Kent, United Kingdom). Solids were also analyzed for carbon, hydrogen, and sulfur using a Vario MAX cube (Elementar, Langenselbold, Germany).

All samples were analyzed with a PSA 10.055 Millennium Excalibur HG-AFS (Orpington, Kent, United Kingdom) operating with a Se boosted discharge hollow cathode lamp with primary and secondary discharges of 20.0 and $25.5 \mathrm{~mA}$ respectively. A PSA 20.400 autosampler was used in all analyses. Homologous polytetrafluoroethylene tubes provided by PSA were used to hold all samples on the autosampler. Supernatants were additionally analyzed for iron, aluminum, sulfur, and calcium by ICP-OES (Perkin-Elmer Optima DV2100, Perkin-Elmer Corp. Norwalk, CT) and pH (Mettler Toledo International, Inc. Schwarzenbach, Switzerland).

Glassware was cleaned according to laboratory standards before cleaning in a two stage acid bath. Glassware was first soaked in 7.0 $M$ nitric acid for a minimum of twenty-four hours. Glassware was rinsed with distilled deionized water before soaking in $1.0 \mathrm{M}$ hydrochloric acid bath for a minimum of twenty-four hours. Glass was rinsed with distilled deionized water and air-dried prior to use.

Glassware was silanized by filling each vial with Sigmacote ${ }^{\circledR}$ once the vial was completely dry. After ten seconds, the vial was emptied by pouring all Sigmacote ${ }^{\circledR}$ back into its original container. Vials were allowed to air dry before use for a minimum of twenty-four hours.

\subsubsection{Reagents}

All reagents used were of analytical grade. Trace metal grade hydrochloric acid (11.65 M) for sample acidification and instrumental blank and wash solutions was purchased from Fisher Scientific (CO, USA). Sodium hydroxide pellets and sodium borohydride powder (99\% pure, 
nitrogen flushed) were purchased from Acros Organic (NJ, USA). A 0.7\% m/v sodium borohydride solution was prepared daily by dissolving sodium borohydride powder in distilled deionized water and was stabilized with $0.1 M$ sodium hydroxide prepared with sodium hydroxide pellets. All samples were prepared in $0.1 \mathrm{M}$ sodium chloride from Fisher Scientific (CO, USA). A $1000 \mathrm{mg} \mathrm{L}^{-1}$ Se standard was purchased from AccuStandard (CN, USA). Sigmacote ${ }^{\circledR}$ was purchased from Sigma-Aldrich (MO, USA).

\subsubsection{Procedure}

\section{$\underline{\text { Characterization of Solids }}$}

Four sorbents were selected for use: gray and brown overburden material from the southern West Virginia coal fields and passive and active mine drainage solids (Table 4-1). Adsorbents were characterized for a variety of physical properties (Table 4-2) that may impact sorption: $\mathrm{pH}$, EC, moisture content, organic matter content. Elemental composition for all solids was also determined (Table 4-3). The $\mathrm{pH}$ for all solids was determined using 1:1 mass:volume suspension $\mathrm{pH}$. After measuring $\mathrm{pH}$, a volume of $5.0 \mathrm{~mL}$ of distilled deionized water was added to the soufflé cup processed for $\mathrm{pH}$, and samples equilibrated by standing for one hour. Moisture content was determined by heating sorbents for twenty-four hours at $105{ }^{\circ} \mathrm{C}$ to remove water. OM content was determined via loss upon ignition after drying to remove water. Elemental composition of adsorbents was determined following microwave assisted digestion described by EPA Method 3051A. 


\section{Determination of Solid:Solution Ratios}

Before completing the final sorption experiment at varying temperatures, the appropriate solid:solution ratios and equilibrium time must be determined. Following the procedure described in Roy (1991), five solid:solution ratios were tested: 0.2, 0.4, 0.6, 0.8, and 1.0 grams of sorbent per one liter of $0.1 \mathrm{M} \mathrm{NaCl}$ solution. While the solids were suspended in solution, $40 \mathrm{~mL}$ of solution was transferred to silanized glass vials. The initial Se concentration of solution was prepared to $50 \mu \mathrm{g} \mathrm{L}^{-1}$ using a secondary standard prepared from sodium selenite. Replicate samples were wrapped in aluminum foil and were placed on a rotary shaker for twenty-four hours. Samples were analyzed for total selenium by HG-AFS using the high-range method. The percent Se sorbed was calculated according to Equation 1 were $\mathrm{C}_{\mathrm{i}}$ was initial concentration and $\mathrm{C}_{\mathrm{e}}$ was the measured equilibrium concentration.

$$
\% \text { Sorbed }=\frac{\left(C_{i}-C_{e}\right)}{C_{i}} \times 100
$$

\section{Determination of Equilibration Time}

Replicate samples containing the proper mass of solid as determined through the solid:solution ratio were prepared to $50 \mu \mathrm{g} \mathrm{L}^{-1}$ Se using a secondary standard prepared from sodium selenite in $0.1 \mathrm{M} \mathrm{NaCl}$. Samples were wrapped in aluminum foil and were placed on a rotary shaker for a 1, 24, 48, and 72 hours. Samples were analyzed by HG-AFS after each equilibration time for total Se using the high-range method. The rate of change was calculated 
according to Equation 2 where $C_{t}$ was the equilibrium concentration at the measured time point and $\mathrm{C}_{\mathrm{t}-1}$ was the equilibrium concentration at the previous time point.

$$
\% \text { Change }=\frac{\left(\mathrm{C}_{\mathrm{t}}-\mathrm{C}_{\mathrm{t}-1}\right)}{\mathrm{C}_{\mathrm{t}}} \times 100
$$

$\underline{\text { Isotherm Determination }}$

A $0.1 M \mathrm{NaCl}$ solution was prepared, and the appropriate amount of sorbent as determined by the solid:solution ratio was added. The solution was agitated with a stir bar, and while the solids were suspended in solution, $40 \mathrm{~mL}$ of solution was transferred to silanized glass vials. Varying initial Se concentrations $\left(0,10,20,30,40\right.$ and $\left.50 \mu \mathrm{g} \mathrm{L}^{-1}\right)$ were established in each vial using a secondary standard prepared from sodium selenite in triplicate. Each sample was $40 \mathrm{~mL}$ in volume. All vials were wrapped in aluminum foil and were placed on a rotary shaker (Glas-Col; IN, USA) at 30 revolutions per minute for 48 hours. Samples for the $20{ }^{\circ} \mathrm{C}$ isotherm were kept on the laboratory counter with the room temperature at $20{ }^{\circ} \mathrm{C} \pm 1{ }^{\circ} \mathrm{C}$ Samples for the $30{ }^{\circ} \mathrm{C}$ isotherm underwent equilibrium in an oven kept at $30{ }^{\circ} \mathrm{C} \pm 1{ }^{\circ} \mathrm{C}$. After equilibration time, samples were transferred to homologous polypropylene tubes (Environmental Express; SC, USA ) and acidified for determination of total Se by HG-AFS. An aliquot was transferred to a polypropylene centrifuge tube and was refrigerated until analysis by ICP-OES for iron, aluminum, sulfur, and calcium content (Table 4-4). The $\mathrm{pH}$ of all samples was determined before and after equilibrium (Table 4-4). 
Solid blank vials underwent the same equilibration and processing for determination using HG-AFS. The measured concentration of these vials was used as the initial concentration. The measured concentration of all samples was the equilibrium concentration. Sorbed concentration was determined according to Equation 3:

$$
\mathrm{C}_{\mathrm{S}}=\frac{\mathrm{C}_{\mathrm{I}}-\mathrm{C}_{\mathrm{E}}}{\mathrm{m}} \times \mathrm{V}
$$

where $\mathrm{C}_{\mathrm{S}}$ was the concentration sorbed $(\mu \mathrm{g} \mathrm{L}-1), \mathrm{C}_{\mathrm{I}}$ was the initial concentration determined from the blanks ( $\left.\mu \mathrm{g} \mathrm{L}^{-1}\right), \mathrm{C}_{\mathrm{E}}$ was the equilibrium concentration $\left(\mu \mathrm{g} \mathrm{L}^{-1}\right), \mathrm{m}$ was the mass of sorbent $(\mu \mathrm{g})$, and $\mathrm{V}$ was the volume of solution (L). Regression analysis was conducted with equilibrium concentration as the $\mathrm{x}$-variable and sorbed concentration as the $\mathrm{y}$-variable (Equation 4).

$$
\mathrm{y}=\mathrm{K}_{\mathrm{D}} \mathrm{x}+\mathrm{b}
$$

\subsection{Results and Discussion}

\section{Determination of Solid:Solution Ratios}

A solid:solution ratio that resulted in $45-55 \%$ sorption was used for all sorption work based on the work conducted by McDonald and Evangelou (1997). Based on this criteria, a mass of 1.0 $\mathrm{g}$ was selected for O-2 and $0.4 \mathrm{~g}$ for AMD-2. A mass of $0.4 \mathrm{~g}$ was selected for AMD-2 while a ratio of $0.6 \mathrm{~g}$ also resulted in $50 \%$ sorption because $0.4 \mathrm{~g}$ was the smallest mass that exhibited $50 \%$ sorption. A greater solid mass was not selected to prevent the possibility that more than $55 \%$ sorption would occur and prevent accurate detection of supernatant Se(IV) concentration. 
Therefore, selecting the smaller mass minimized the possibility that a greater percentage of sorption occurred and minimized error in quantification. Linear extrapolation based on the test ratios was used to determine the proper ratios for O-1 and AMD-2: $1.9 \mathrm{~g}$ and 0.05 respectively.

\section{Determination of Equilibration Time}

The equilibration time was operationally defined as the minimum amount of time needed to establish a rate of change in solute concentration less than or equal to $5 \%$ per 24 hour interval (Roy, 1991). The least reactive solids - O-1 and AMD-1 — were used to select an equilibrium time point for all solids. These solids exhibited less than a 5\% change at 48 hours. Because O-1 and AMD-1 were least reactive, a shorter equilibrium period would result in small changes in Se(IV) change that would not be detectable. Time points longer than 48 hours resulted in equilibrium concentrations that were low and could increase error in quantitation. Additionally, the 48 hour time point was selected because this was the greatest amount of time in which the labware used had been assessed for Se(IV) recovery.

\section{$\underline{\text { Isotherm Determination }}$}

Isotherms were developed for all solids at $20^{\circ} \mathrm{C}$ and for both overburden materials at $30^{\circ} \mathrm{C}$. Sorbents were not corrected for moisture content. All sorbents exhibited linear isotherms. Work by Hasan and Ranjan (2010) found that Se exhibited Langmuir isotherms for several biosorbents, yet linear isotherms were identified for Se sorption to anatase (Jordan et al., 2013) and for arsenite sorption to goethite (Kersten and Vlasova, 2009). A large enough range of initial 
concentrations may not have been analyzed in either this study or other studies to achieve the Langmuir isotherm found by Hasan and Ranjan (2010).

$\mathrm{K}_{\mathrm{D}}$ increased with increasing temperature for $\mathrm{O}-1$ and decreased with increasing temperature for O-2 (Table 4-5). O-1 was gray sandstone, which is generally unweathered, and may have minimal sorption sites available. With increasing temperature, it was possible that calcium carbonates within the sandstone dissolved and provided additional binding sites for Se. O-2 was brown sandstone, which is weathered, and should have an increased number of binding sites compared to gray sandstone. This was supported by differences in electrical conductivity. O-1 had the highest electrical conductivity of the two overburden materials $\left(229 \mu \mathrm{S} \mathrm{cm}^{-1}\right)$. The observance of decreased sorption with increased temperature, as exhibited by O-2, was consistent with other anion sorption work conducted with other sorbents, such as goethite (Balistrieri and Chao, 1987; Kersten and Vlasova, 2009), anatase (Jordan et al., 2013), and brans (Hasan and Ranjan, 2010).

Differences in the composition of the sorbents may also have contributed to the differences in sorption. AMD- 1 was $82 \%$ iron by mass, whereas AMD- 2 was only $32 \%$ iron by mass. O- 1 and O-2 have similar iron content: $46 \%$ and $43 \%$ respectively. At $20{ }^{\circ} \mathrm{C}$, the greatest amount of sorption was to AMD-1. The solids are AMD-1, AMD-2, O-1, and O-2 in order of decreasing $\mathrm{K}_{\mathrm{D}}$. The high iron content of AMD-1 most likely resulted in its high distribution coefficient. Other differences that may result in a greater distribution coefficient for Se was organic matter content. O-1 had a greater distribution coefficient than $\mathrm{O}-2$ at $20^{\circ} \mathrm{C}$ and was $3.7 \%$ organic matter. O-2 was $3.2 \%$ organic matter. 
Sorption capacities were not determined for the solids used in this experiment as a linear isotherm was exhibited. Less sorption occurred per gram of sorbent in this study than in in other studies (Table 4-6). The differences in sorption for AMD-1 and AMD-2 in comparison to other metal oxides, such as $\mathrm{Fe}(\mathrm{III}) / \mathrm{Ce}(\mathrm{III})$ hydroxides, are low. This may be due to the amorphous nature of the AMD solids used in this experiment. A crystalline, ordered solid may exhibit greater sorption potential for $\mathrm{Se}(\mathrm{IV})$ than an amorphous solid. Additionally, the ratio of $\mathrm{Fe}$ (III) to Fe(II) in the AMD solids used was not determined. A higher ratio of Fe(III) may result in a greater sorption affinity for $\mathrm{Se}(\mathrm{IV})$. The overburden materials assessed in this experiment have a much lower sorption affinity for Se(IV) than other sorbents.

Changes in solution $\mathrm{pH}$ during sorption experiments were not the related to sorption. There was no correlation between equilibrium concentration and change in $\mathrm{pH}$. The possibility of selenium species conversion cannot be ruled out at this time. Changes in $\mathrm{pH}$ may be attributed to species conversion possibly due to the presence of iron.

\subsection{Conclusion}

Increasing temperature corresponded with decreased sorption for O-1, which corroborates studies that determined Se sorption was an exothermic process. However, the reverse trend was observed for O-2. The distribution coefficient of the two overburden materials varied with temperature, suggesting that temperature may contribute to diel cycles. The exact role of temperature on Se sorption was inconclusive because opposing trends were exhibited by different materials. It may be possible the influence of temperature on Se sorption was dependent on the nature of the sorbent. 


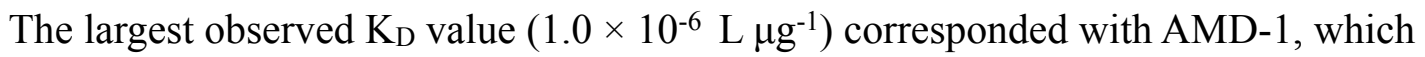
contained the most iron by mass percent of the solids tested. Iron content may be correlated with Se sorption affinity. Other studies have shown high sorption affinity for materials containing iron. Sorption exhibited by the AMD solids tested was less than that of other iron-containing materials studied. This may be due to the amorphous nature of AMD treatment solids or differences in the $\mathrm{Fe}(\mathrm{III}) / \mathrm{Fe}(\mathrm{II})$ ratio. The sorptive nature of this AMD-1 may explain the observance of diel cycles in the fringe wetlands of the Great Salt Lake, which are impacted by mine drainage (Carling et al., 2011; Dicataldo et al., 2011).

\section{References}

Atkins, P., de Paula, J., \& Friedman, R. (2009). The first law of thermodynamics Quanta, Matter, and Change: A molecular approach to physical chemistry (pp. 442-478). New York, NY: W.H. Freeman and Company.

Balistrieri, L. S., \& Chao, T. T. (1987). Selenium Adsorption by Goethite. Soil Science Society of America Journal, 51(5), 1145-1151.

Benjamin, M. M. (2015). Adsorption Reactions Water Chemistry (Second ed., pp. 769-845). Long Grove, Illinois: Waveland Press, Inc.

Carling, G. T., Fernandez, D. P., Rudd, A., Pazmino, E., \& Johnson, W. P. (2011). Trace element diel variation and particulate pulses in perimeter freshwater wetlands of Great Salt Lake, Utah. Chemical Geology, 283, 87-98.

Dicataldo, G., Johnson, W. P., Naftz, D. L., Hayes, D. F., Moeller, W. O., \& Miller, T. (2011). Diel variation of selenium and arsenic in a wetland of the Great Salt Lake, Utah. Applied Geochemistry, 26, 28-36.

Doulati, F.; Marandi, M.; Marandi, A.; Mirhabibi, A. R.; Baaki, E. (2005). Effects of pH and biomass concentrations in the removal of selenite from acid mine drainage by Aspergillus niger as biosorbent in Sarcheshmeh porphyry copper mine. International Mine Water Congress, 9th, 51-55.

El-Shafey, E. I. (2007). Removal of Se(IV) from aqueous solution using sulphuric acid-treated peanut shell. Journal of Environmental Management, 84, 620-627.

Hasan, S. H., \& Ranjan, D. (2010). Agro-industrial waste: a low-cost option for the biosorptive remediation of selenium anions. Industrial \& Engineering Chemistry Research, 49, 8927-8934. 
Jordan, N., Muller, K., Franzen, C., \& Brendler, V. (2013). Temperature impact on the sorption of selenium(VI) onto anatase. Journal of Colloid and Interface Science, 390, 170-1

Kersten, M., \& Vlasova, N. N. (2009). Arsenite adsorption on goethite at elevated temperatures. Applied Geochemistry, 24, 32-43.

Kuan, W. H.; Lo, S. L.; Wang, M. K.; Lin, C. F. (1998). Removal of Se(IV) and Se(VI) from water by aluminum-oxide-coated sand. Water Research, 32, 915-923.

Marcus, Y. (2009). Effect of Ions on the Structure of Water: Structure Making and Breaking. Chemical Reviews, 109(3), 1346-1370.

McDonald Jr., L. M., \& Evangelou, V. P. (1997). Optimal solid-to-solution ratios for organic chemical sorption experiments. Soil Science Society of America Journal, 61, 1655-1659.

McKay, G.; Otterburn, M. S.; Sweeny, A. G. (1981). Surface mass transfer process during colour removal from effluents using silica. Water Research, 15, 321-331.

Namasivayam, C.; Prathap, K. (2006). Removal of selenite using "waste" Fe(III)/Cr(III) hydroxide: Adsorption kinetics and isotherms. Toxicology and Environmental Chemistry, $88,85-98$.

Nimick, D. A., Gammons, C. H., Cleasby, T. E., Madison, J. P., Skarr, D., \& Brick, C. M. (2003). Diel cycles in dissolved metal concentrations in streams: occurrence and possible causes. Water Resources Research, 39, 1247-1263.

Odenheimer, J. L. (2013). Determining a Total Dissolved Solids Release Index from Overburden in Appalachian Coal Fields. (MS in Agronomy), West Virginia University, Morgantown, WV.

Roy, W. R., Krapac, I. G., Chous, S. F. J., \& Griffin, R. A. (1991). Batch-Type Procedures for Estimating Soil Adsorption of Chemicals. USEPA Technical Resource Document EPA/ 530-SW-87-006-F.

Zhang, N.; Lin, L. S.; Gang, D. (2008). Adsorptive selenite removal from water using ironcoated GAC adsorbents. Water Research, 42, 3809-3816. 
Table 4-1. Description of solids assessed as sorbents for Se(IV) sorption.

\begin{tabular}{cccc}
\hline Sample ID & Sample Description & Origin & Particle Size \\
\hline O-1 & Gray Sandstone & Eskdale, WV & $<-\ldots$ mm $-\ldots . .-$ \\
O-2 & Brown Sandstone & Cowen, WV & $<0.063$ \\
AMD-1 & Passive Treatment & Latrobe, PA & $0.125-0.063$ \\
& Solid & & $0.125-0.063$ \\
AMD-2 & Active Treatment & Upshur County, WV & \\
& Solid & & \\
\hline
\end{tabular}


Table 4-2. Physical parameters of solids used in experiments.

\begin{tabular}{ccccccccc}
\hline Sample ID & \multicolumn{2}{c}{$\mathrm{pH}$} & \multicolumn{2}{c}{ EC } & \multicolumn{2}{c}{ Moisture Content } & \multicolumn{2}{c}{ OM Content } \\
& Mean & St Dev & Mean & St Dev & Mean & St Dev & Mean & St Dev \\
\hline O-1 & 7.69 & 0.02 & 229 & 8 & 0.23 & 0.01 & 3.7 & 0.3 \\
O-2 & 6.99 & 0.01 & 38 & 1 & 0.23 & 0.07 & 3.1 & 0.5 \\
AMD-1 & 6.57 & 0.06 & 635 & 4 & 12.5 & 0.7 & 9.32 & 0.09 \\
AMD-2 & 8.78 & 0.01 & 2,390 & 42 & 3.64 & 0.07 & 10.83 & 0.08 \\
\hline
\end{tabular}

All characterizations were performed in duplicate. 
Table 4-3a. Elemental composition of solids used in experiments.

\begin{tabular}{|c|c|c|c|c|c|c|c|c|}
\hline \multirow[t]{2}{*}{ Sample ID } & \multicolumn{2}{|c|}{$\mathrm{Al}$} & \multicolumn{2}{|c|}{$\mathrm{Fe}$} & \multicolumn{2}{|c|}{ Mn } & \multicolumn{2}{|c|}{$\mathrm{Mg}$} \\
\hline & Mean & St Dev & Mean & St Dev & Mean & St Dev & Mean & St Dev \\
\hline & \multicolumn{8}{|c|}{ 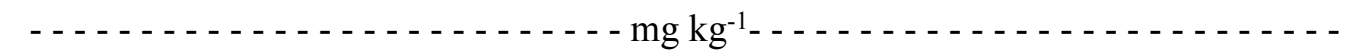 } \\
\hline O-1 & 27,000 & 4,000 & 30,000 & 8,000 & 300 & 100 & 4,300 & 800 \\
\hline $\mathrm{O}-2$ & 39,000 & 19,000 & 34,000 & 8,000 & 400 & 100 & 4,200 & 200 \\
\hline AMD-1 & 11,200 & 800 & 67,000 & 3,000 & 314 & 9 & 630 & 30 \\
\hline AMD-2 & 35,000 & 1,000 & 82,000 & 4,000 & 2,800 & 100 & 9,000 & 200 \\
\hline
\end{tabular}

Table 4-3b. Elemental composition of solids used in experiments.

\begin{tabular}{|c|c|c|c|c|c|c|}
\hline \multirow[t]{2}{*}{ Sample ID } & \multicolumn{2}{|c|}{$\mathrm{Ca}$} & \multicolumn{2}{|c|}{$\mathrm{Na}$} & \multicolumn{2}{|c|}{$\mathrm{Se}$} \\
\hline & Mean & St Dev & Mean & St Dev & Mean & St Dev \\
\hline & - - - - & 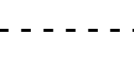 & - - - & $g^{-1}-\ldots$ & - - - - & - - - - - \\
\hline O-1 & 2,300 & 700 & 700 & 200 & 0.9 & 0.8 \\
\hline $\mathrm{O}-2$ & 1,800 & 400 & 740 & 70 & 5 & 6 \\
\hline AMD-1 & 1,900 & 300 & 260 & 60 & 0.55 & 0.5 \\
\hline AMD-2 & 128,000 & 7,000 & 290 & 90 & 0.4 & 0.2 \\
\hline
\end{tabular}

Table 4-3c. Elemental composition of solids used in experiments.

\begin{tabular}{cccc}
\hline Sample ID & $\mathrm{C}$ & $\mathrm{N}$ & $\mathrm{S}$ \\
\hline O-1 & 3.14 & b.d. & 0.08 \\
O-2 & 0.40 & b.d. & 0.06 \\
AMD-1 & 2.87 & b.d. & 0.27 \\
AMD-2 & b.d. & b.d. & 0.52 \\
\hline
\end{tabular}

b.d. indicates below detection

AMD solids were processed in sextuplicate for elements other than Se, C, N, andS. Overburden materials were AMD solids were processed in sextuplicate for elements other than Se. Overburden materials were previously characterized by Odenheimer (2013) for all elements other than Se. All sorbents were processed for Se in duplicate. Materials were processed singly for $\mathrm{C}, \mathrm{N}$, and $\mathrm{S}$ using the vario MAX cube. 
Table 4-4a. Average change in $\mathrm{pH}$ and ions of interest in solution at $20^{\circ} \mathrm{C}$.

\begin{tabular}{|c|c|c|c|c|c|c|c|c|c|c|}
\hline \multirow[t]{2}{*}{ Sample ID } & \multicolumn{2}{|c|}{$\Delta \mathrm{pH}$} & \multicolumn{2}{|c|}{$\mathrm{Fe}$} & \multicolumn{2}{|c|}{$\mathrm{Al}$} & \multicolumn{2}{|c|}{$\mathrm{Ca}$} & \multicolumn{2}{|c|}{$\mathrm{S}$} \\
\hline & Mean & St Dev & Mean & St Dev & Mean & St Dev & Mean & St Dev & Mean & St Dev \\
\hline & stand & ard unit & & & & $-\mu g \mathrm{~L}^{-1}$ & & & & \\
\hline O-Blank & -0.5 & 0.3 & n.d. & n.d. & n.d. & n.d. & n.d. & n.d. & n.d. & n.d. \\
\hline O-1 & -0.5 & 0.2 & 0.1 & 0.1 & b.d. & b.d. & 0.7 & 0.2 & b.d. & b.d. \\
\hline $\mathrm{O}-2$ & -0.5 & 0.3 & 1.0 & 0.8 & 2 & 1 & 31 & 11 & 5 & 2 \\
\hline $\begin{array}{l}\text { AMD } \\
\text { Blank }\end{array}$ & -0.14 & 0.07 & n.d. & n.d. & n.d. & n.d. & n.d. & n.d. & n.d. & n.d. \\
\hline AMD-1 & -2.0 & 0.3 & 0.1 & 0.1 & b.d. & b.d. & 2 & 2 & 0.8 & 0.7 \\
\hline AMD-2 & -1.9 & 0.2 & 0.3 & 0.4 & 0.1 & 0.2 & 2.5 & 0.3 & 0.3 & 0.1 \\
\hline
\end{tabular}

Table 4-4b. Average change in $\mathrm{pH}$ and ions of interest in solution at $30^{\circ} \mathrm{C}$.

\begin{tabular}{|c|c|c|c|c|c|c|c|c|c|c|}
\hline \multirow[t]{2}{*}{ Sample ID } & \multicolumn{2}{|c|}{ pH Change } & \multicolumn{2}{|c|}{$\mathrm{Fe}$} & \multicolumn{2}{|c|}{$\mathrm{Al}$} & \multicolumn{2}{|c|}{$\mathrm{Ca}$} & \multicolumn{2}{|c|}{$\mathrm{S}$} \\
\hline & Mean & St Dev & Mean & St Dev & Mean & St Dev & Mean & St Dev & Mean & St Dev \\
\hline & stande & rd unit & & & & $-\mu \mathrm{g} \mathrm{L}^{-1}$ & & & & \\
\hline O-Blank & -0.2 & 0.2 & n.d. & n.d. & n.d. & n.d. & n.d. & n.d. & n.d. & n.d. \\
\hline O-1 & -0.8 & 0.2 & 0.2 & 0.2 & b.d. & b.d. & 1.2 & 0.2 & 0.4 & 0.3 \\
\hline $\mathrm{O}-2$ & -0.3 & 0.3 & 0.2 & 0.2 & b.d. & b.d. & 1.2 & 0.2 & 0.4 & 0.3 \\
\hline $\begin{array}{l}\text { AMD } \\
\text { Blank }\end{array}$ & n.d. & n.d. & n.d. & n.d. & n.d. & n.d. & n.d. & n.d. & n.d. & n.d. \\
\hline AMD-1 & n.d. & n.d. & n.d. & n.d. & n.d. & n.d. & n.d. & n.d. & n.d. & n.d. \\
\hline AMD-2 & n.d. & n.d. & n.d. & n.d. & n.d. & n.d. & n.d. & n.d. & n.d. & n.d. \\
\hline
\end{tabular}

b.d. indicates below detection n.d. indicates not done 
Table $4-5 . K_{D}$ for each material by temperature.

\begin{tabular}{|c|c|c|c|c|c|c|c|c|}
\hline & \multicolumn{2}{|c|}{ O-1 } & \multicolumn{2}{|c|}{ O-2 } & \multicolumn{2}{|c|}{ AMD-1 } & \multicolumn{2}{|c|}{ AMD-2 } \\
\hline & $\mathrm{K}_{\mathrm{D}}$ & St Error & $\mathrm{K}_{\mathrm{D}}$ & St Error & $\mathrm{K}_{\mathrm{D}}$ & St Error & $\mathrm{K}_{\mathrm{D}}$ & St Error \\
\hline${ }^{\circ} \mathrm{C}$ & & & & $-10^{-8} \mathrm{~L} \mu \mathrm{g}$ & & & & - \\
\hline 20 & 6.05 & 0.06 & 1.61 & 0.03 & 100 & 12 & 8.48 & 1.7 \\
\hline 30 & 2.30 & 0.04 & 7.01 & 1.14 & $\mathrm{n} / \mathrm{a}$ & $\mathrm{n} / \mathrm{a}$ & $\mathrm{n} / \mathrm{a}$ & $\mathrm{n} / \mathrm{a}$ \\
\hline
\end{tabular}


Table 4-6. Se(IV) sorption capacity for varying sorbents.

\begin{tabular}{cccc}
\hline Source & Sorbent & Temperature & Sorption Capacity \\
\hline & & ${ }^{\circ} \mathrm{C}$ & $\mathrm{mg} \mathrm{g}^{-1}$ \\
1 & wheat bran & 20 & 0.089 \\
2 & Aspergillus niger & 20 & 111.1 \\
3 & pretreated Fe(III)/Ce(III) hydroxide & --- & 15.6 \\
3 & untreated Fe(III)/Ce(III) hydroxide & --- & 6.04 \\
4 & iron coated GAC & 25 & 2.50 \\
5 & aluminum-oxide coated sand & 25 & 1.08 \\
6 & carbonaceous sorbent from peanut shell (wet) & 45 & 42.96 \\
6 & carbonaceous sorbent from peanut shell (dry) & 45 & 32.15 \\
7 & carbonaceous sorbent from rice husk (wet) & 45 & 40.92 \\
\hline
\end{tabular}

${ }^{1}$ Hasan \& Ranjan, 2010.

2 Doulati et al., 2005.

${ }^{3}$ Namasivayam \& Prathap, 2006.

${ }^{4}$ Zhang et al., 2008.

${ }^{5}$ Kuan et al., 1998.

${ }^{6}$ El-Shafey, 2007.

${ }^{7}$ McKay et al., 1981. 


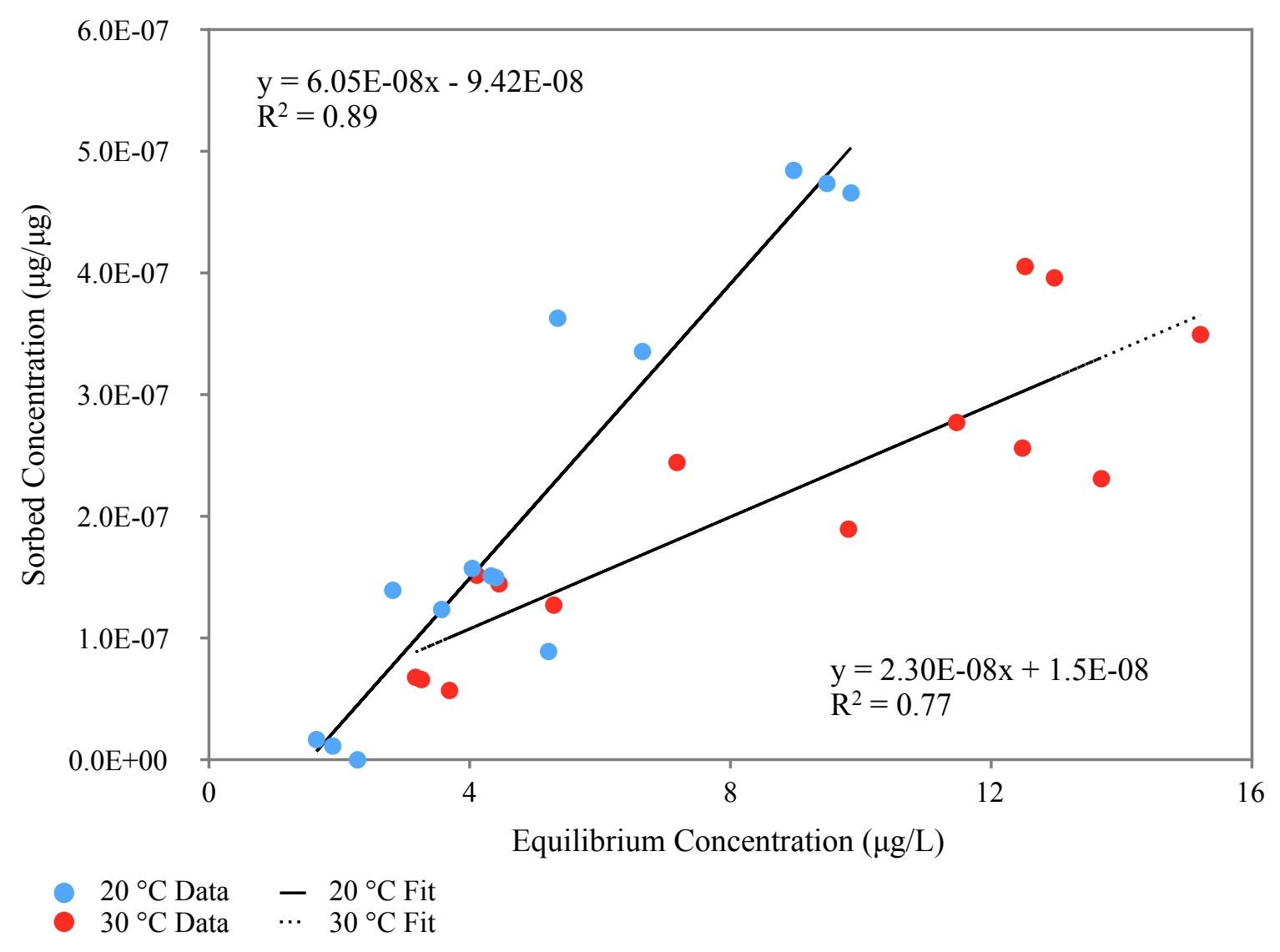

Figure 4-1. Linear sorption isotherm for $\mathrm{O}-1$ at $20^{\circ} \mathrm{C}$ (blue) and $30{ }^{\circ} \mathrm{C}$ (red). 


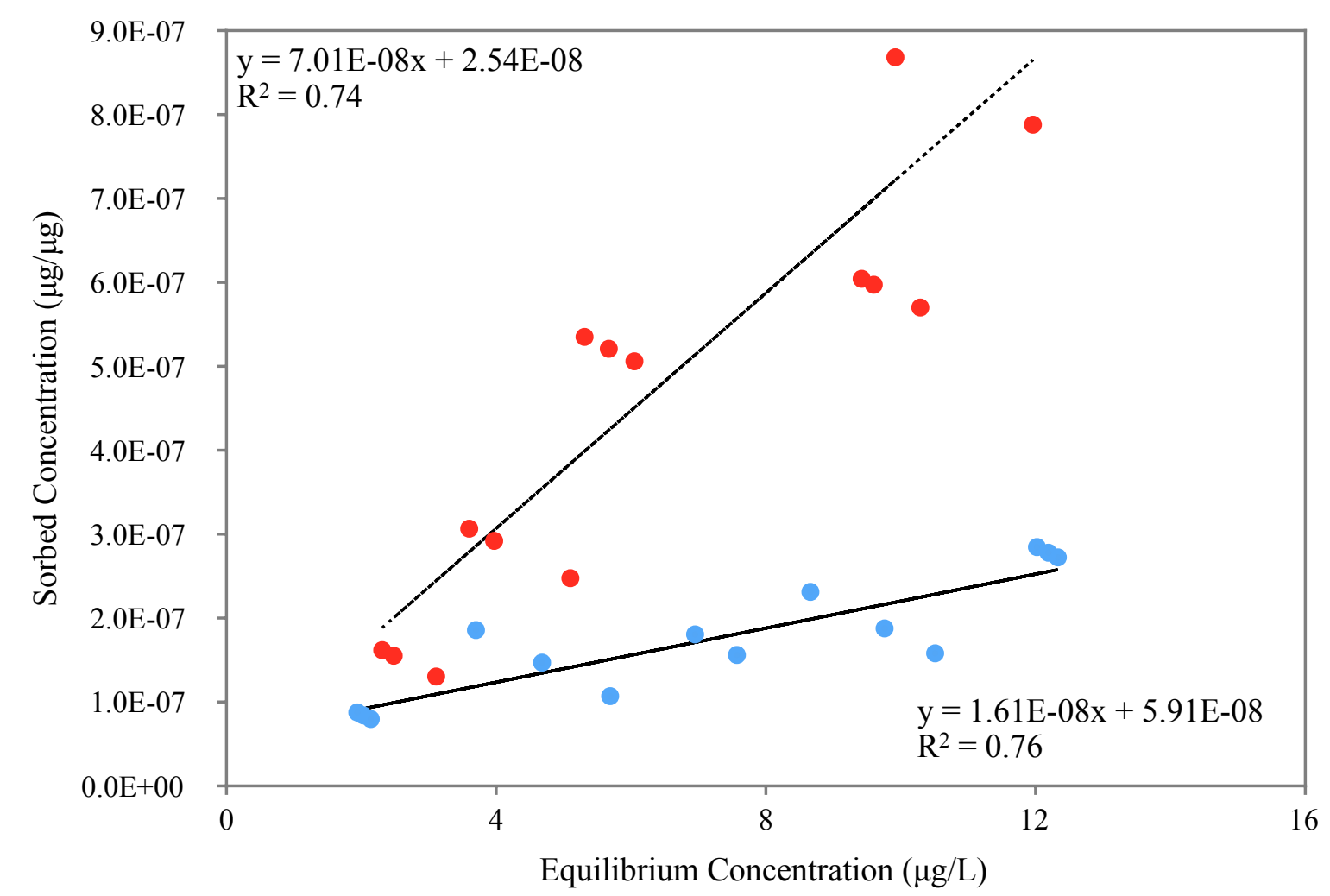

- $20^{\circ} \mathrm{C}$ Data $-20{ }^{\circ} \mathrm{C}$ Fit

- $30^{\circ} \mathrm{C}$ Data $\cdots 30^{\circ} \mathrm{C}$ Fit

Figure 4-2. Linear sorption isotherm for $\mathrm{O}-2$ at $20^{\circ} \mathrm{C}$ (blue) and $30{ }^{\circ} \mathrm{C}$ (red) 


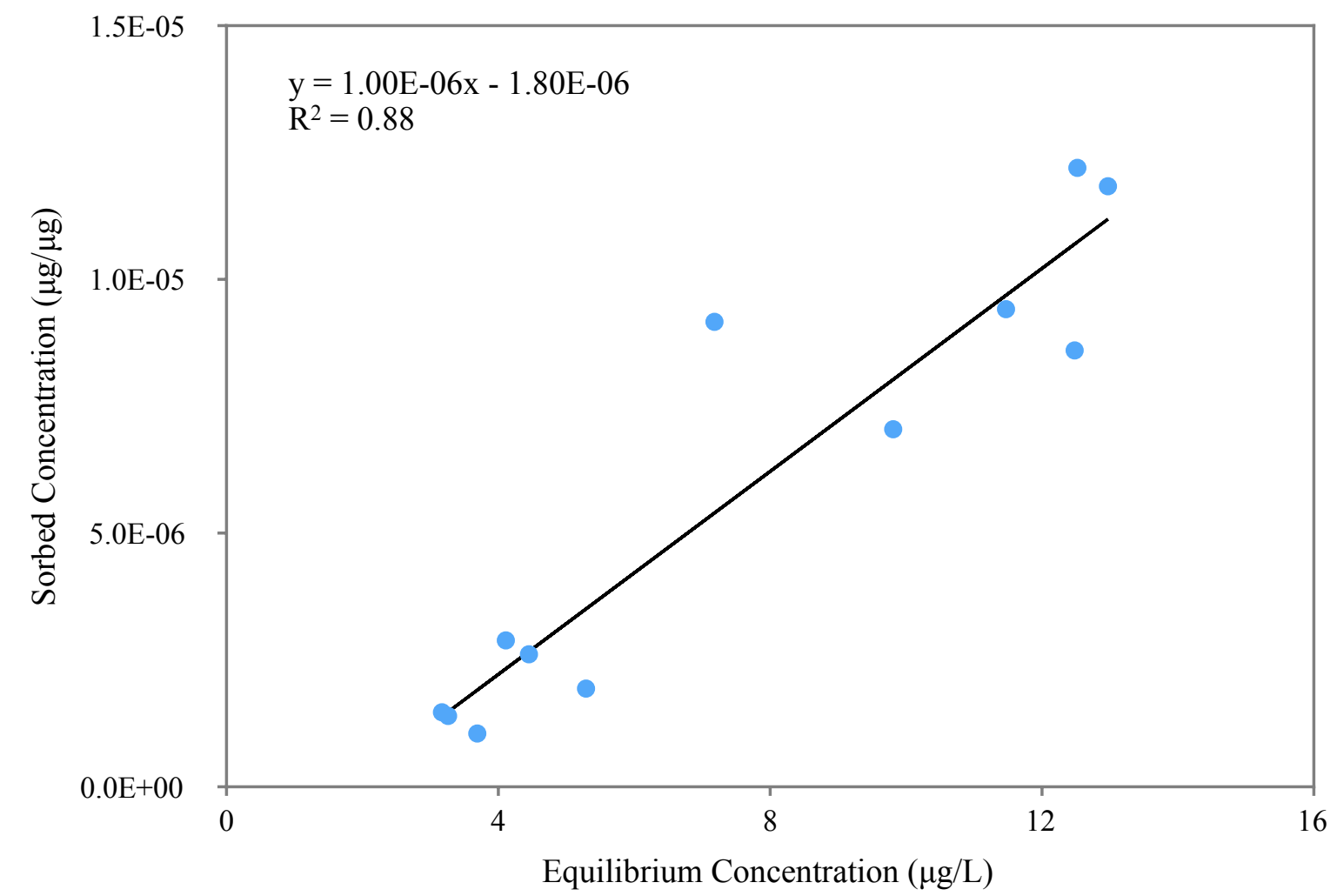

- $20^{\circ} \mathrm{C}$ Data

$-20^{\circ} \mathrm{C}$ Fit

Figure 4-3. Linear sorption isotherm for AMD-1 at $20{ }^{\circ} \mathrm{C}$. 


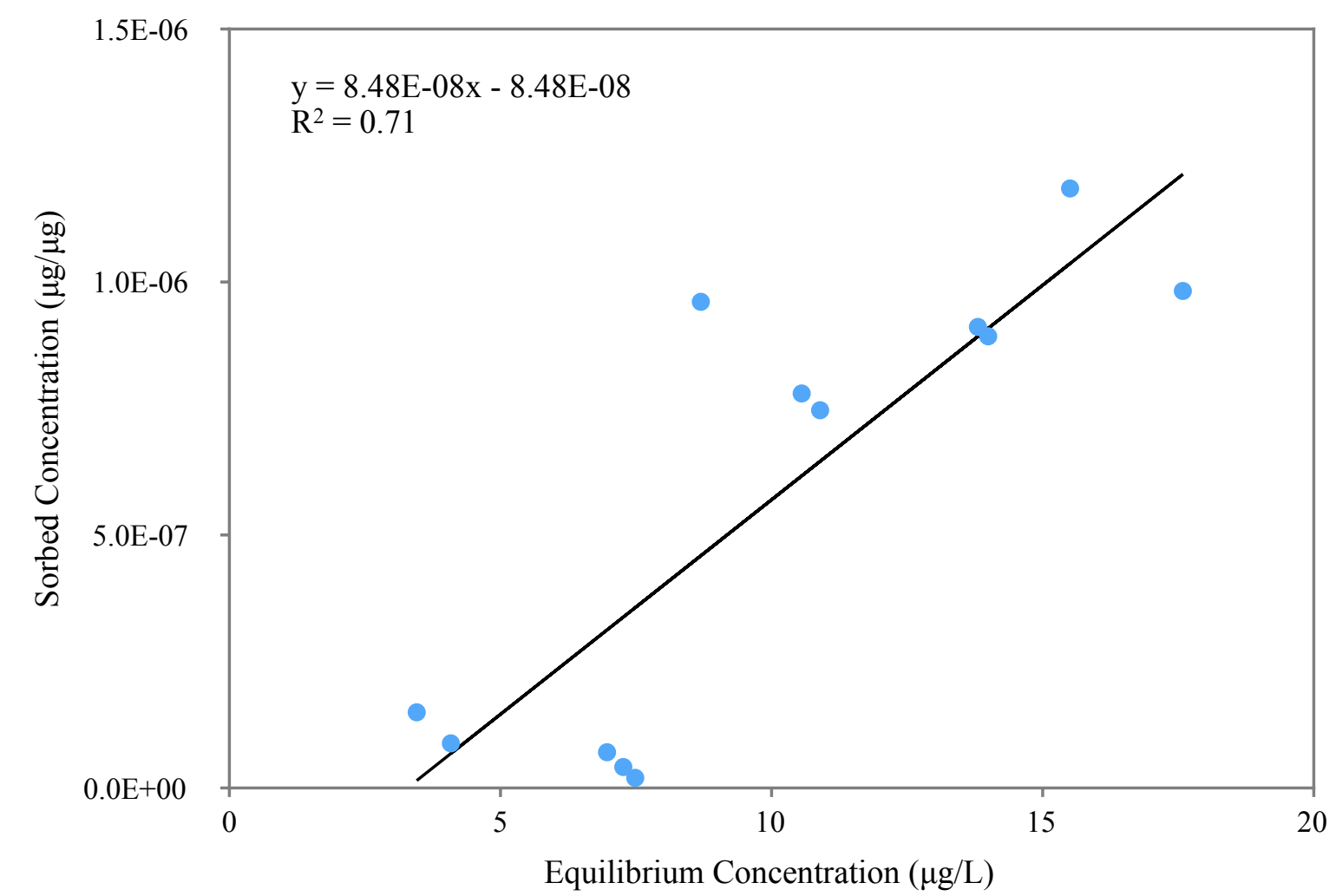

- $20^{\circ} \mathrm{C}$ Data

- $20^{\circ} \mathrm{C}$ Fit

Figure 4-4. Linear sorption isotherm for AMD-2 at $20^{\circ} \mathrm{C}$. 


\section{CHAPTER 5: SUMMARY AND CONCLUSIONS}

Selenium is the micronutrient with the smallest range between beneficial and toxic concentrations. Coal mining exposes reduced strata which contain Se; as these materials leach or undergo oxidation, Se is solubilized and can enter surface waterways. Diel cycles have been observed for Se within fringe wetlands along the GSL. This study focused on the effect of temperature on Se sorption, a possible controlling factor in Se diel cycles.

Methodology was developed for total Se quantitation using HG-AFS. Detection limits and sample stability on the autosampler with time was evaluated. In order to apply the developed methods on waterways impacted by coal mining, an interference study was also conducted for common ions present in these waterways $\left(\mathrm{Fe}^{+3}\right.$ and $\left.\mathrm{SO}_{4}^{-2}\right)$. Lastly, the suitability of four labware materials (glass, silanized glass, PTFE, and PP) was assessed for use in Se experiments.

Experimental results showed that

- HG-AFS was superior for Se quantitation with instrumental detection limits of 0.008 $\mu \mathrm{g} \mathrm{L}-1$ and $0.002 \mu \mathrm{g} \mathrm{L}-1$ for the low and high range methods respectively. The LLOQ was determined to be $0.0005 \mu \mathrm{g} \mathrm{L}^{-1}$ and $0.05 \mu \mathrm{g} \mathrm{L} \mathrm{L}^{-1}$ for each method.

- HG-AFS measured trace levels of Se in the presence of coal mine drainage ions $\left(\mathrm{Fe}^{+3}\right.$ and $\mathrm{SO}_{4}^{-2}$ ) without analytical concern.

- Silanized glass was the most suitable labware for Se work.

Additionally, the impact of temperature on Se sorption was evaluated. Increasing temperature corresponded with decreased sorption for O-1, which supports the hypothesis. However, the reverse trend was observed for O-2, which does not support the hypothesis. The trend of 
decreased sorption of Se in conjunction with increasing temperature for O-1 collaborates studies that found Se sorption was an exothermic process. The differing trends in sorption with temperature changes may be the result of mineralogical differences between the overburden materials. Overall, this work does not support the hypothesis that temperature can be a primary control on Se diel cycles.

The mass of passive and active treatment solids needed to conduct the sorption studies was much less than the mass of overburden material. This illustrates that mine drainage solids have a greater affinity for Se sorption than overburden materials. The largest observed $\mathrm{K}_{\mathrm{D}}$ value $(1.00 \times$

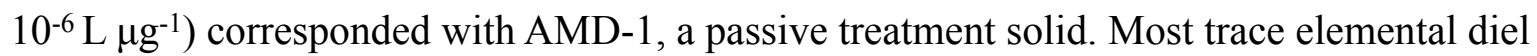
cycles are observed in surface waters which receive water from mining discharges, such as the Great Salt Lake. Selenium diel cycles are hypothesized to be the result of sorption and desorption to solids, such as those from mine discharges. The highly sorptive nature of AMD-1 supports this hypothesis.

Additional work is required for a characterization of the influence of temperature on Se sorption. Due to equipment problems, isotherms could not be constructed for both mine drainage solids at $30{ }^{\circ} \mathrm{C}$ and for all solids at $10{ }^{\circ} \mathrm{C}$. The work will be repeated to characterize the role of these temperatures on $\mathrm{Se}(\mathrm{IV})$ sorption This study did not seek to determine the kinetics of or the mechanism responsible for Se sorption, which could be topics of future work. Other factors such as light intensity and biological influence could be investigated as possible controls on $\mathrm{Se}$ (IV) sorption. 
APPENDIX A: OPERATING CONDITIONS AND METHOD DEVELOPMENT FOR PSA 10.055 MILLENNIUM EXCALIBUR HYDRIDE GENERATION-ATOMIC FLUORESCENCE SPECTROMETRY 
The 10.055 Millennium Excalibur HG-AFS unit (Figure A-1) for use in this study was purchased from PSA (Orpington, United Kingdom) and was installed in September of 2015. The combination of hydride generation (HG) and atomic fluorescence spectrometry (AFS) allow for low detection limits and a wide linear calibration range.

\section{A.1 Reagents}

Hydride generation requires a reducing agent and an acidic environment. For Se, sodium tetrahydroborate $\left(\mathrm{NaBH}_{4}\right)$ was used as the reducing agent (Equation 1). The sodium tetrahydroborate solution was prepared by dissolving a mass of $7.0 \mathrm{~g}$ of $\mathrm{NaBH}_{4}$ in $500 \mathrm{~mL}$ of distilled deionized water in a $1 \mathrm{~L}$ volumetric flask. After dissolution, a mass of $4.0 \mathrm{~g}$ of sodium hydroxide $(\mathrm{NaOH})$ was added. The solution was diluted to volume and passed through a Fisherbrand P8 filter before use. The solution must be filtered to prevent small particles from collecting in the instrument tubing and interfering with flow.

$$
\mathrm{NaBH}_{4}+3 \mathrm{H}_{2} \mathrm{O}+\mathrm{HCl} \rightarrow \mathrm{H}_{3} \mathrm{BO}_{3}+\mathrm{NaCl}+8 \mathrm{H}^{+} \rightarrow \mathrm{SeH}_{2}^{+}+\mathrm{H}_{2}
$$

Prepared sodium tetrahydroborate must be kept in an open container to prevent pressure build-up from hydrogen evolution. If the solution must be stored, it may be stored in a container with a small hole in the lid to allow for off-gassing. Sodium tetrahydroborate can be used up to 48 hours after preparation. Any sodium tetrahydroborate that was not used in this time period must be diluted with water in a fume hood before being disposed of as segregated hazardous 
waste. Sodium tetrahydroborate must be stored away from other chemicals when not in use as it reacts violently with acid.

Because hydride generation requires an acidic environment, a 40\% hydrochloric acid $(\mathrm{HCl})$ solution was used as the reagent blank. The reagent blank was prepared by diluting $400 \mathrm{~mL}$ of trace-metal grade $\mathrm{HCl}(11.65 M)$ in $400 \mathrm{~mL}$ of distilled deionized water in a $1 \mathrm{~L}$ volumetric flask and was then brought to volume with distilled deionized water. Hydrochloric acid can contain small concentrations of Se, so trace metal grade acid should be used to minimize introduced Se. All samples contain $20 \%$ hydrochloric acid by volume to allow for hydride generation.

\section{A.2 Flow of Liquid Reagents}

All solutions are pumped from the liquid manifold using peristaltic pumps and are introduced into the gas/liquid separator by the sample valve. There are two peristaltic pumps (Figure A-2). The first peristaltic pump was responsible for pumping the blank and sample to the sample mixer, and the second peristaltic pump was responsible for returning the blank from the sample mixer to its container during energized mode and for pumping the reductant to the sample mixer.

The reagents are mixed at the sample valve and are then introduced into the gas/liquid separator. The sample valve has two modes: standby and energized (Figure A-3). During standby mode, the blank and reductant are mixed together and directed to the gas/liquid separator. The sample was diverted to waste. Standby mode serves to produce a baseline measurement before sample analysis. In energized mode, the sample valve diverts the blank back to its container. The sample and reductant are mixed and sent to the gas/liquid separator. Energized mode occurs during sample analysis. 
The flow rate of these solutions was determined by the tubing used. Green-green bridged $1.854 \mathrm{~mm}$ inner diameter tubing was used for the reagent blank and sample at a flow rate of 8 $\mathrm{mL} \mathrm{min}^{-1}$. Santoprene gray-gray bridged tubing $1.854 \mathrm{~mm}$ inner diameter tubing was used for the reductant, establishing a flow rate of $4.5 \mathrm{~mL} \mathrm{~min}^{-1}$. Pressure was applied to the tubing using ratcheting cassettes at each peristaltic pump. The lever on each ratcheting cassette should be pushed back 10-12 clicks to apply the appropriate amount of pressure.

\section{A.3 Carrier/Shield and Dryer Gases}

The carrier gas was used to carry the vaporized sample to the detector. The shield gas was used to contain the sample vapor in a laminar flow through the measuring chamber. The same gas should be used as both the carrier and shield gas. Argon was the recommended carrier/shield gas. While nitrogen gas may be used, it reduces the fluorescence sensitivity by a factor of eight and results in a higher detection limit. Air should never be used as a carrier/shield gas as it will combust. The inlet gas pressure was $40 \mathrm{psi}$. Once inside the instrument, the carrier/shield gas was regulated to $30 \mathrm{psi}$ and a flow rate of $0.25 \mathrm{~L} \mathrm{~min}^{-1}$.

The dryer gas was used to dry the sample vapor before it reaches the detector. Any inert gas may be used as a dryer gas. PSA recommends compressed air or argon. Once inside the instrument, the dryer gas was regulated to $30 \mathrm{psi}$ from an inlet pressure of $40 \mathrm{psi}$ and a flow rate of $0.25 \mathrm{~L} \mathrm{~min}^{-1}$. The moist dryer gas exits the instrument via a rear port. While the gas contains no harmful products, the gas was vented through a fume hood to prevent gas buildup around the instrument. As currently configured, argon serves as both the carrier/shield and dryer gas. 
Gas tank(s) should be checked weekly. A tank should never be completely emptied before replacement; gas tanks should be replaced when the pressure was $600 \mathrm{kPa}$. Gas at the bottom of the tank may contain contaminants from inside the tank. These can impact the performance of the instrument. If the baseline was noisy and if sample concentrations are drifting downward with each analysis, the unit should be purged with gas for two hours to remove contaminants.

\section{A.4 Gas/Liquid Separator}

The sample or blank and reductant are introduced into the gas/liquid separator through the leftmost inlet. The carrier gas was introduced into the gas/liquid separator through the middle inlet arm. The carrier gas mixes with the Se hydride gas and was pulled out of the gas/liquid separator through the rightmost outlet at the top of the gas/liquid separator (Figure A-4). The gas was carried into the Perma dryer drawer where the gas was dried.

At completion of analysis, distilled deionized water must be pumped through the system to remove all acid and sodium tetrahydroborate. When there was no longer bubbling from the sodium tetrahydroborate or indication of acid in the gas/liquid separator, the liquid manifold tubes should be removed from the water container so that air may enter the lines. Once no more liquid was entering the gas-liquid separator, the unit can be turned off.

\section{A.5 Perma Dryer Drawer}

The produced hydride gas was carried into the dryer drawer where the dryer gas was used to remove any water vapor. Wet gas results in decreased sensitivity as water molecules will excite at a different energy than Se. The produced hydride gas flows from right to left, whereas the dryer 
gas flows from left to right. The differing flow pattern ensures that the hydride gas was dry before being introduced into the detector.

\section{A.6 Excitation and Detection}

After exiting the dryer drawer, the hydride gas was carried to the hydrogen diffusion flame where any hydrogen gas produced in the generation of Se hydride was combusted. The hollow cathode lamp was focused with a lens at the bottom portion of the flame. This serves to excite $\mathrm{Se}$ electrons. Se electrons are excited at a wavelength of $196.0 \mathrm{~nm}$ by the boosted discharge hollow cathode lamp. The electrons return to ground state by releasing energy; however, the energy released was different than the excitation energy — fluorescence. The Se electrons are focused through a series of lenses (Figure A-5) before reaching the detector where the signal was translated into a concentration (Figure A-6).

\section{A.7 Boosted Discharge Hollow Cathode Lamp}

Each element of interest (antimony, arsenic, bismuth, mercury, Se, and tellurium) has an individual hollow cathode lamp. The system was capable of holding a single lamp at a time, and, consequently, only a single element can be analyzed during any sequence. The Boosted Discharge Hollow Cathode Lamp (BDHCL) utilizes two discharges so that concentration broadening and line broadening are minimized, thereby improving detection limits (Figure A-7). The primary discharge $(\mathrm{P})$ occurs between the anode and cathode, which was standard in all hollow cathode lamps. This discharge excites the majority of electrons at the cylindrical cathode. The auxiliary or secondary boost (B) also occurs at the cylindrical cathode. However, this 
discharge originates at the electron emitter below the cathode and anode. The secondary discharge excites any remaining ground state electrons. When in operation, the primary discharge (P) should be set to $20.0 \pm 0.5 \mathrm{~mA}$ and the secondary boost (B) should be set to $25.0 \pm 0.5 \mathrm{~mA}$ for Se determination.

Before beginning each sequence, the system should be turned on for at least twenty minutes to ensure the lamp warms up properly. While the system undergoes a two minute warm up period before allowing a sequence to begin, a longer warm up time allows for the lamp to stabilize the primary discharge and boost. In the event that the primary and boost do not reach the proper setting, begin a sequence. If the primary and boost do not display proper currents with the initiation of a sequence, shut down the entire unit, ensuring both power switches (one on front and one in back) are off. Unplug the two fuses located on the front of the unit and reconnect. Overtime these fuses can shift and no longer provide proper contact to ensure adequate current to the lamp. If reconnecting the fuses on the front panel of the unit does not correct the lamp reading, open the top of the instrument and visually inspect the lamp. The glass of the lamp should be clear; if the lamp was cloudy, replace the lamp. Also, inspect the position of the lamp within the holder. The lamp may shift position and may no longer be aimed at the correct location of the flame.

A.8 Maintenance of the Gas/Liquid Separator, Dryer Drawer, and Peristaltic Pumps Because $\mathrm{NaCl}$ was formed during the hydride generation process, some precipitation was possible in the U-bend of the gas/liquid separator. A dilute aqua regia (1:4 by volume) should be pumped through the system periodically to remove any precipitates that could block liquid flow. 
The dryer drawer, where the generated vapor was dried with gas, should be checked every six months. When the internal filter turns orange, the drawer must be replaced to ensure proper vapor drying.

The peristaltic pumps are susceptible to surface rusting due to acid vaporization even with proper ventilation. The surface rust can be removed with WD- $40^{\mathrm{TM}}$. Each month WD- $40^{\mathrm{TM}}$ should be sprayed into the gears of the peristaltic pumps to remove any internal rust and to maintain proper lubrication. Surface rust on metal components can be removed by wiping with a paper towel and WD- $40^{\mathrm{TM}}$. Pump tubing should be replaced based on use or when switching between analyte. Tubing that has deepened in color with use must be replaced. The cassette heads which hold the tubing in contact with the peristaltic pump should be replaced when the pressure adjustment level must be moved more than ten to twelve clicks in order to maintain pressure on the tubing.

\section{A.9 Autosampler Conditions}

Before each sequence, check the supply of the the probe rinse container (5 L). PSA recommends an $\mathrm{HCl}$ solution of $35-40 \%$ be used. This solution was pumped into the wash position to ensure proper probe rinsing between samples. Before initiating a sequence, check that the wash position was adequately filled and that there are no kinks in either the inflow tubing or outflow tubing. Kinks and air bubbles within the tubing prevent adequate flow of rinse solution from entering or exiting the wash position. When flow was properly established to and from the wash position, tape the outflow tube to the counter to prevent the tube from moving and stopping proper flow. 
The autosampler was capable of holding 75 samples. However, positions 1-6 and 70-75 are too small to hold the polypropylene sample vials provided by PSA from Environmental Express (SC, USA). As a result only 63 samples can be analyzed in a single run.

The sampling probe must be raised from the wash station at the completion of analysis. Increased contact time in the wash station can cause corrosion of the sampling probe. Wipe the tip of the probe with a wet paper towel to remove residual acid. If corrosion of the sampling probe occurs, a green solid will from on the tip of the probe. The solid can be wiped off with a wet paper towel, or the sampling probe can be lowered into the wash station containing probe rinse solution. Wiping the solid from the probe was preferred so that small particulates are not drawn up into the probe, potentially blocking flow.

\section{A.10 Instrumental Operating Conditions}

The continuous flow vapor generation was composed of two peristaltic pumps used to deliver reductant, reagent blank, and sample. The analysis cycle undergoes three stages which can be adjusted based on the concentration of the samples. (1) Delay time primes the sample tubing for analysis. During delay, the sample was pumped to prime the tubing for that particular sample. The sample was diverted to waste. The reagent blank was pumped to the gas/liquid separator along with sodium tetrahydroborate to establish a baseline. (2) During analysis time, the switching valve was activated so that the sample was pumped to the gas/liquid separator with sodium tetrahydroborate. The blank was diverted back to the reagent bottle. (3) Memory time allows the system to return to baseline. The sample was diverted to waste and the blank was pumped to the gas/liquid separator with sodium tetrahydroborate. The ratio of flow rates of 
reductant line to blank/sample lines should be approximately $1: 2$. Typical flows are $4-5 \mathrm{~mL} \mathrm{~min}^{-1}$ for sodium tetrahydroborate and $8-10 \mathrm{~mL} \mathrm{~min}^{-1}$ for sample and blank solutions. Tube length between the autosampler, vapor generator, and detector should be kept to a minimum so that the cycle stages are not negatively impacted. Based on the sample concentration, the recommended times and amplification range are listed in Table A-1.

\section{A.11 Calibration Standards}

For all developed methods, a blank and four standards are used for calibration. Standards are made fresh prior to each analysis. A $10 \mu \mathrm{g} \mathrm{L}{ }^{-1}$ Se stock solution was prepared daily from a purchased $1000 \mu \mathrm{g} \mathrm{L}^{-1}$ Se standard (AccuStandard ${ }^{\circledR}$, Inc. New Haven, CT). This standard was further diluted was to prepare all standards. All standards are prepared so that the final concentration was $20 \%$ hydrochloric acid.

Each standard was analyzed five times, and the average was plotted to make a calibration curve by the Millennium Sir Galahad software. Least squares method was utilized to fit the calibration curve. A correlation coefficient less than 0.98 was not acceptable. In the case of a correlation coefficient less than 0.98 , the calibration should be repeated with new standards. 


\section{A.12 Developed Methods}

Two methods were developed: one for 0-10 $\mu \mathrm{g} \mathrm{L}^{-1} \mathrm{Se}$, and one for 0-50 $\mu \mathrm{g} \mathrm{L}^{-1} \mathrm{Se}$. Two methods were developed because samples with low concentrations could not be detected above the baseline of the instrument with a single method. The parameters outlined in Table A-2 were used to establish the two methods currently in use based on PSA Recommended Operating Conditions. 
Table A-1. Instrumental settings by concentration range (PSA Customer Technical Information File).

\begin{tabular}{ccccc}
\hline Concentration Range & Amplification Range & Delay Time & Analysis Time & Memory Time \\
\hline $0-200 \mu \mathrm{g} \mathrm{L}^{-1}$ & 1 & $\ldots \ldots \ldots \ldots \ldots$ & 5 & 40 \\
$0-20 \mu \mathrm{g} \mathrm{L}^{-1}$ & 10 & 10 & 15 & 40 \\
$0-2 \mu \mathrm{g} \mathrm{L}^{-1}$ & 100 & 10 & 30 & 40 \\
$0-100 \mathrm{ng} \mathrm{L}^{-1}$ & 1000 & 10 & 30 & 40 \\
\hline
\end{tabular}

Table A-2. Settings for developed methods.

\begin{tabular}{ccccc}
\hline Method & Amplification Range & Delay Time & Analysis Time & Memory Time \\
\hline & & $-\ldots \ldots \ldots$ & 5 & 40 \\
High Range $\left(0-50 \mu \mathrm{g} \mathrm{L}^{-1}\right)$ & 1 & 10 & 15 & 40 \\
Low Range $\left(0-10 \mu \mathrm{g} \mathrm{L}^{-1}\right)$ & 10 & 10 & & \\
\hline
\end{tabular}




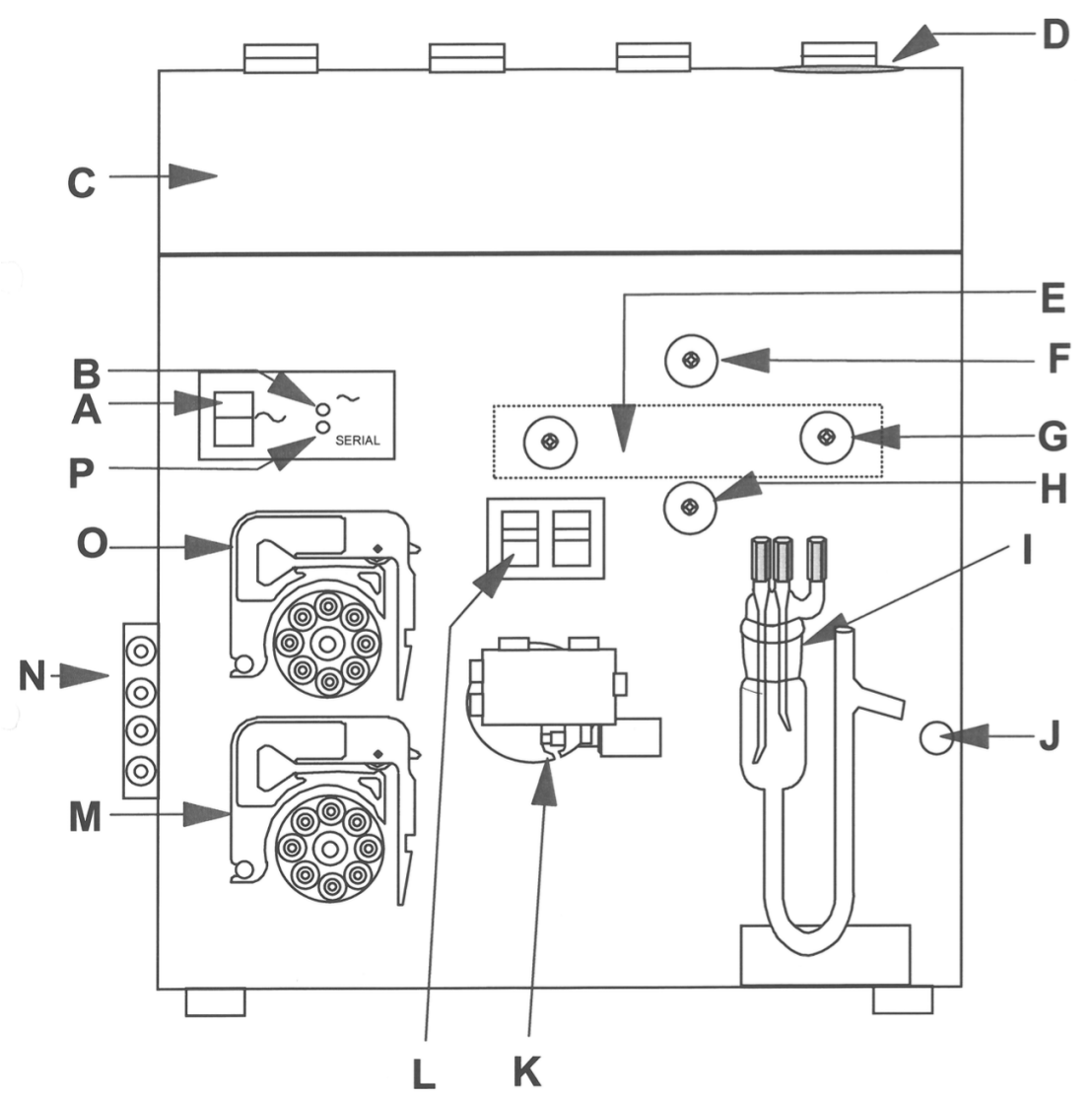

Figure A-1. Schematic diagram of HG-AFS (PSA Customer Technical Information File).

A: power switch for unit

$\mathrm{B}$ : power LED, green indicates unit is on

C: top cover which provides access to hollow cathode lam

D: vent for waste sample vapor

E: Perma Pure Dryer Drawer

F: sample input port to detector

G: sample input to dryer drawer

$\mathrm{H}$ : carrier gas output to gas/liquid separator

I: gas/liquid separator

$\mathrm{J}$ : waste tubing channel

$\mathrm{K}$ : sample valve used to switch between sample and blank solution

L: electrical connections for sample valve

M: peristaltic pump 2 responsible for pumping reductant and wash station fluid

$\mathrm{N}$ : liquid manifold

O: peristaltic pump 1 responsible for pumping sample and blank

P: serial LED which is green when USB connections are achieved 


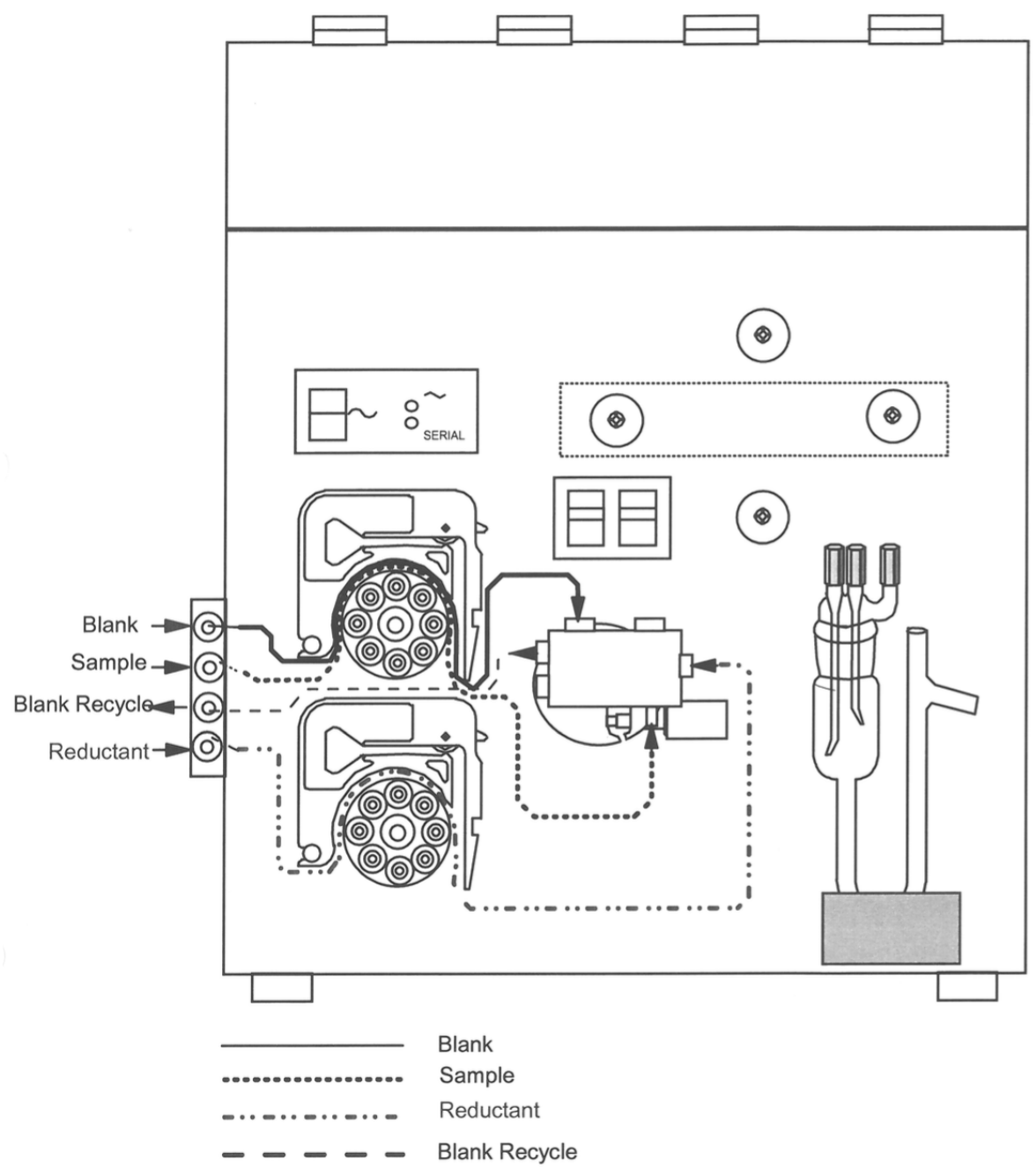

Figure A-2. Schematic diagram of liquid reagent flows (PSA Customer Technical Information File). 

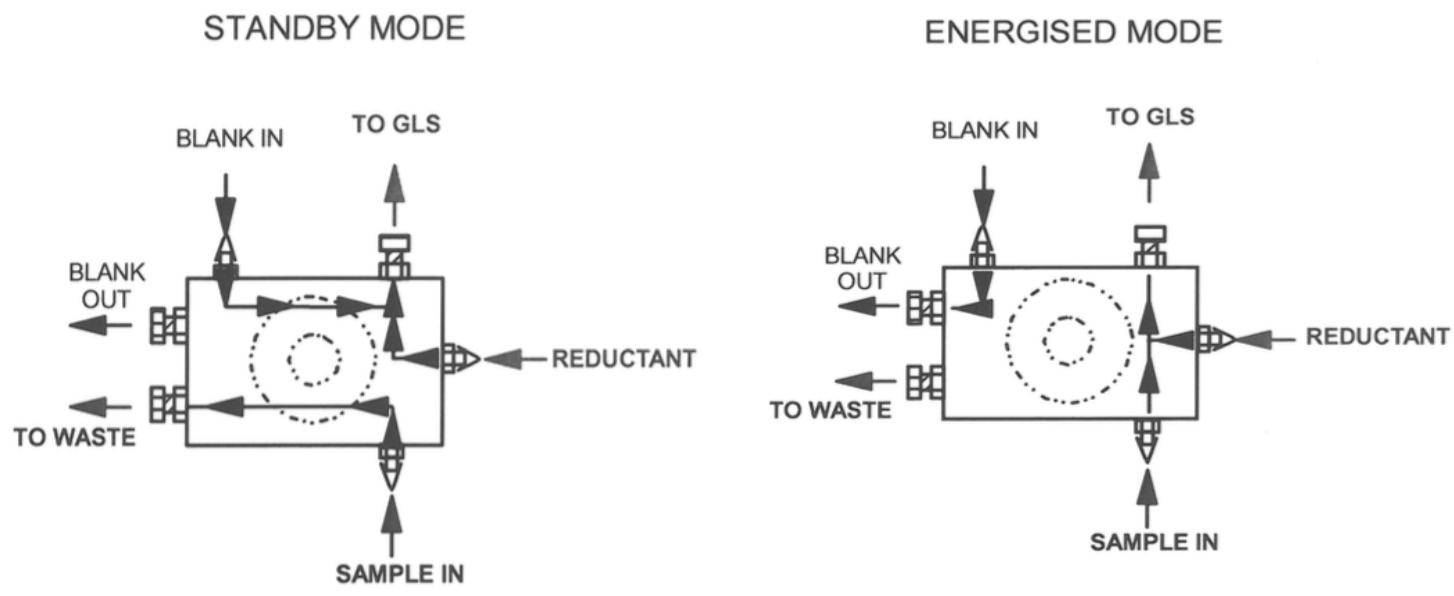

Figure A-3. Schematic diagram of the sample valve for standby and energized mode (PSA Customer Technical Information File). 


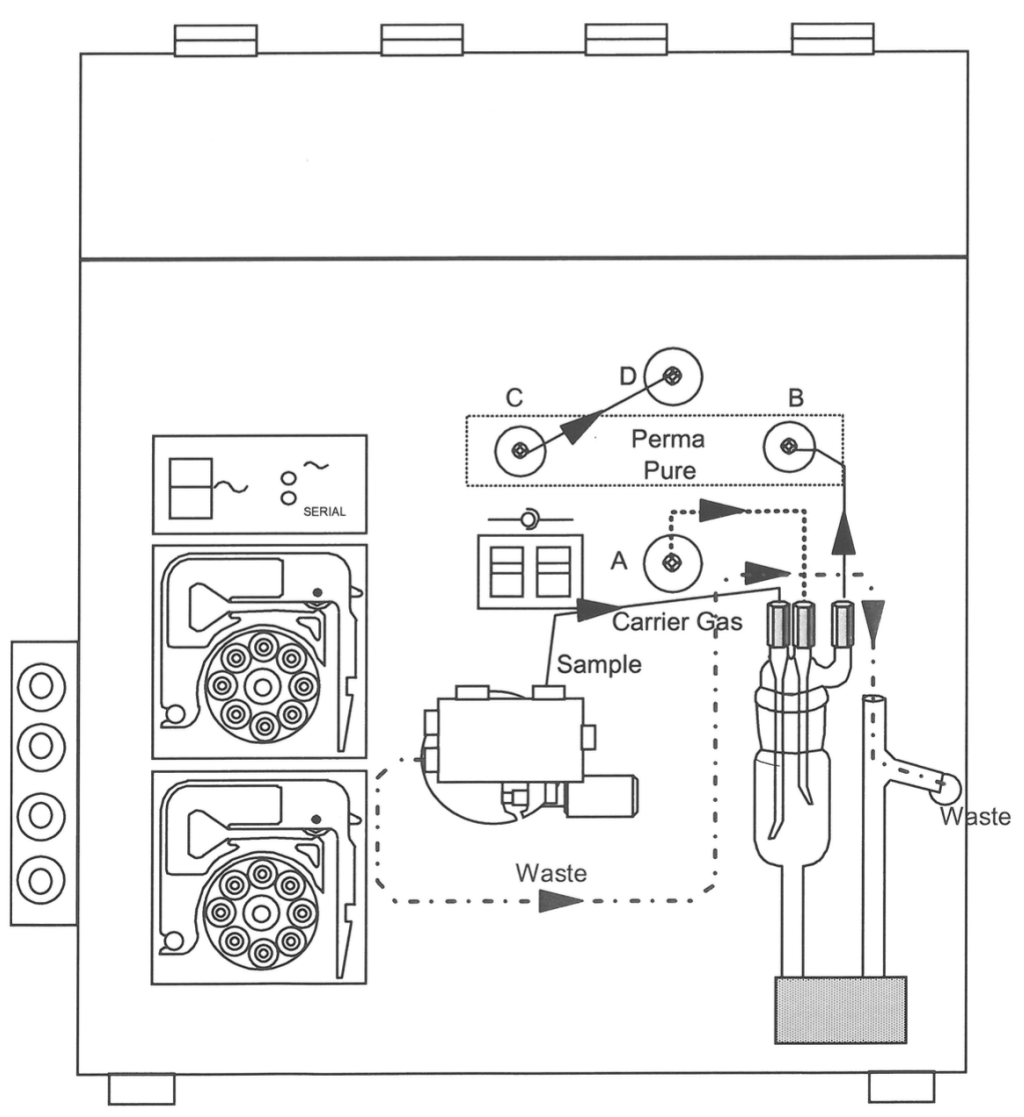

Figure A-4. Schematic diagram of reagent and gas flow from the sample valve to the gas/liquid separator and dryer drawer (PSA Customer Technical Information File) 


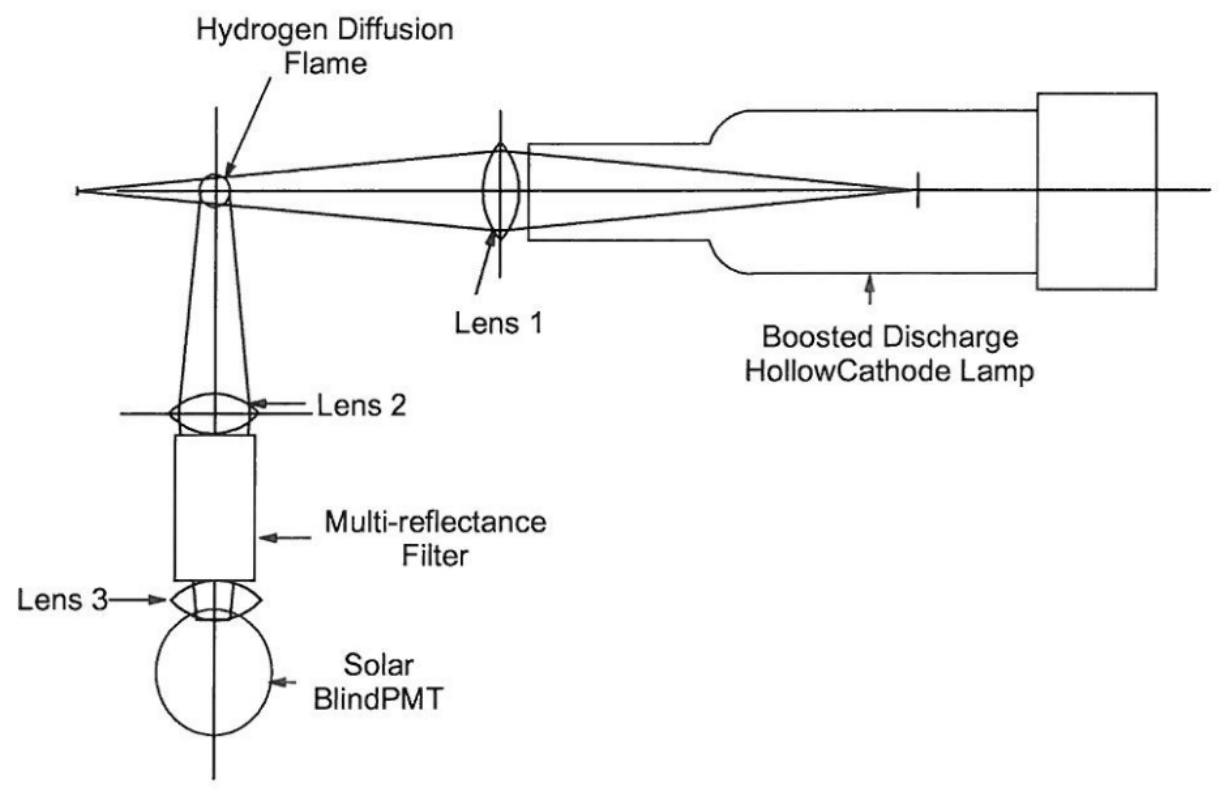

Figure A-5. Optical diagram of the Millennium Excalibur (PSA Customer Technical Information File). 


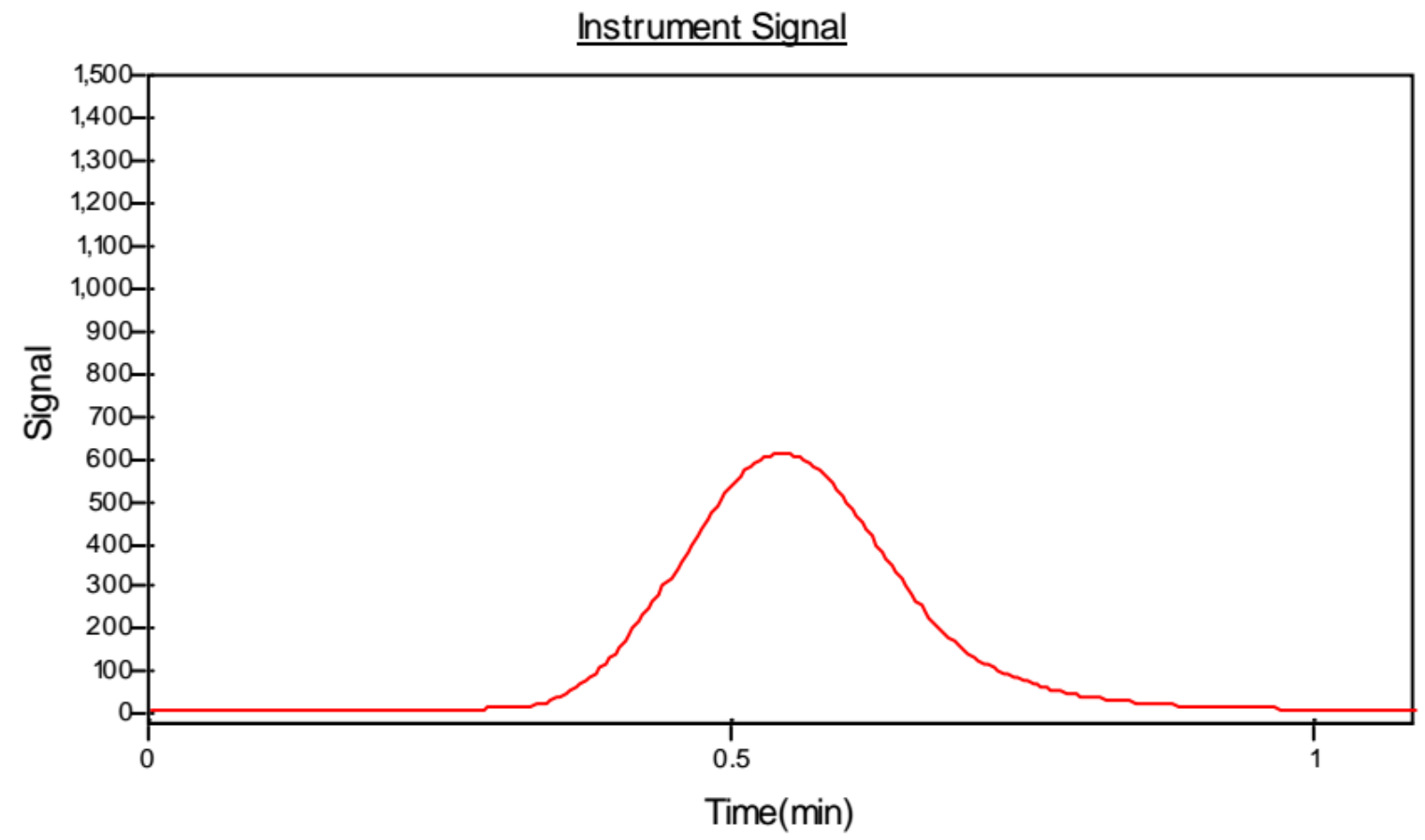

Figure A-6. Example of signal generated. Signal height was converted to concentration based on the calibration curve. 


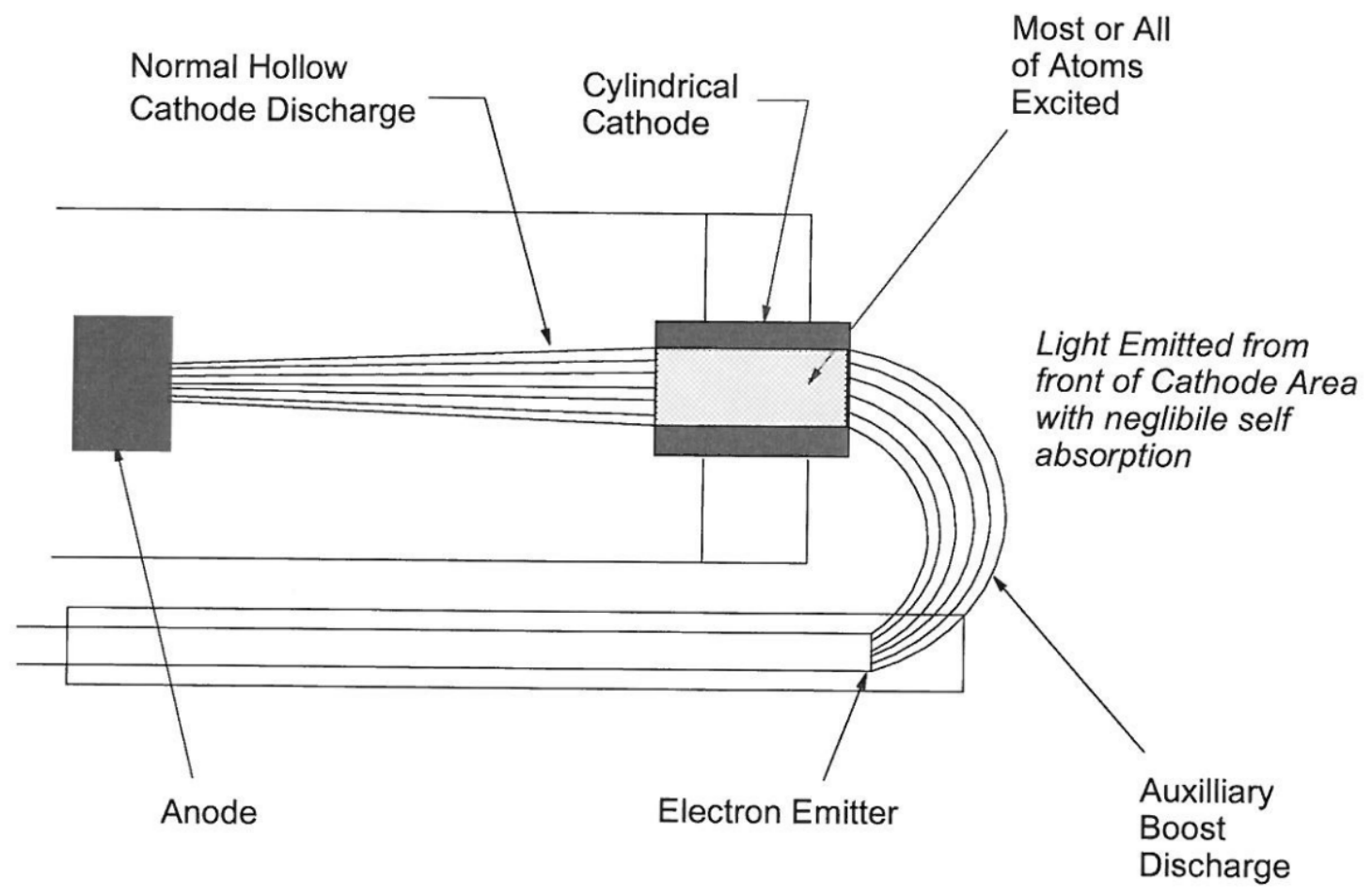

Figure A-7. Schematic diagram of boosted discharge hollow cathode lamp (PSA Customer Technical Information File). Curved lines indicate the flow of electrons. The first discharge of energy occurs between the anode and cathode. Most electrons are excited at the cathode. Any remaining electrons are excited by the auxiliary boost discharge at the electron emitter. 